Recuperação de objetos tridimensionais utilizando características de séries temporais

\author{
Rafael Umino Nakanishi
}



Data de Depósito:

Assinatura:

Rafael Umino Nakanishi

\section{Recuperação de objetos tridimensionais utilizando características de séries temporais}

\footnotetext{
Dissertação apresentada ao Instituto de Ciências Matemáticas e de Computação - ICMC-USP, como parte dos requisitos para obtenção do título de Mestre em Ciências - Ciências de Computação e Matemática Computacional. VERSÃO REVISADA

Área de Concentração: Ciências de Computação e Matemática Computacional

Orientador: Prof. Dr. Afonso Paiva Neto
} 
Ficha catalográ ela elaborada pela Biblioteca Prof. Achille Bassi e Seção Técnica de Informática, ICMC/ USP,

com os dados fornecidos pelo(a) autor(a)

Nakanishi, Rafael Umino
Recuperação de objetos tridimensionais utilizando
caracteristicas de séries temporais / Rafael
Umino Nakanishi; orientador Afonso Paiva Neto. -
São Carlos - SP, 2016.
88 p.
Dissertação (Mestrado - Programa de Pós-Graduação
em Ciências de Computação e Matemática Computacional)
- Instituto de Ciências Matemáticas e de Computação,
Universidade de São Paulo, 2016.
1. Recuperação de objetos. 2. recuperação
parcial de objetos. 3. processamento geométrico.
4. processamento de dados. 5. objetos
tridimensionais. I. Neto, Afonso Paiva, orient. II.
Título.


Rafael Umino Nakanishi

\section{D shape retrieval using temporal series features}

Master dissertation submitted to the Instituto de Ciências Matemáticas e de Computação - ICMCUSP, in partial fulfillment of the requirements for the degree of the Master Program in Computer Science and Computational Mathematics. FINAL VERSION

Concentration Area: Computer Science and Computational Mathematics

Advisor: Prof. Dr. Afonso Paiva Neto

USP - São Carlos

July 2016 

À minha família e amigos. 

Agradeço a Deus em primeiro lugar eà minha família por toda força e apoio ao longo dos anos. À minha mãe, meu pai, minha irmã e meus avós por estarem sempre presentes e me ajudarem e apoiarem a continuar sempre em frente. Também gostaria de agradecer aos meus amigos por estarem sempre comigo, fisica ou mental mente, pelo apoio oferecido, pelos tardes do café e pel as horas de descontração.

Agradeço ao meu orientador Afonso Paiva Neto pelo auxílio e orientação durante os anos de mestrado e ao professor doutor Luis Gustavo Nonato por ter me orientado nas fases iniciais desse proj eto e durante a trilha de graduação-mestrado. Agradeço também a todos os professores que contribuíram pelo meu desenvol vimento pessoal e profissional, direta e indiretamente.

Agradeço ao ICMC e toda a equipe técnica pel a infra-estrutura e apoio fornecido para o desenvol vimento dessa dissertação.

E agradeço ao CNPq pelo apoio financeiro oferecido. 

" Os acertos não serão muitos nessa vida,

mas é bom que treinemos com eles para nos aperfeiçoar."

(Ton Adalclê) 



\section{RESUMO}

NAKANISHI, R. U.. Recuper ação de obj etos tr idimensionais utilizando car acter ísticas de sér ies tempor ais. 2016. 88 f. Dissertação (Mestrado em Ciências - Ciências de Computação e Matemática Computacional ) - Instituto de Ciências Matemáticas e de Computação (ICMC/USP), São Carlos-SP.

Com o aumento da capacidade de armazenamento de informação em bancos de dados e em computadores pessoais, surge a necessi dade de al goritmos computacionais capazes de real izar o processamento automático para recuperação desses dados. Esse fato não é diferente para objetos tridimensionais armazenados em formato de arquivos. Nesta Dissertação de Mestrado foram estudadas novas técnicas para processamento desses objetos utilizando uma abordagem não comum à área: técnicas para análise de séries temporais, tais como scattering wavel ets e gráficos de recorrência. No caso de recuperação total de objetos, ou seja, dado uma mal ha tridimensional encontrar outras mal has que são visual mente semel hantes, uma única característica é extraídacurvatura gaussiana e variação de superfície, por exemplo - e ordenada como uma série com a informação provida pelo vetor de Fiedler. Então processa-se essa série utilizando a técnica scattering wavelets, que são capazes de analisar o comportamento temporal de conjunto de dados seriais. Para esse problema, os resultados obtidos são comparáveis com outras abordagens apresentadas na literatura que utilizam várias características para se chegar ao resul tado. Já no caso de recuperação parcial de objetos, em que apenas uma parte do objeto é dado como parâmetro de busca, é necessário real izar uma segmentação das mal has para se encontrar outras partes que são visual mente semel hantes. Ao utilizarmos um gráfico de recorrência para anali sar os objetos, é possível encontrar não apenas a região mais semel hante dentro da mesma (ou de outra) mal ha, mas também se obtém todas as regiões que são si milares ao parâmetro de busca.

Palavr as-chave: Recuperação de objetos, recuperação parcial de objetos, processamento geométrico, processamento de dados, objetos tridimensionais. 



\section{ABSTRACT}

NAKANISHI, R. U.. Recuper ação de obj etos tr idimensionais utilizando car acter ísticas de sér ies tempor ais. 2016. 88 f. Dissertação (Mestrado em Ciências - Ciências de Computação e Matemática Computacional ) - Instituto de Ciências Matemáticas e de Computação (ICMC/USP), São Carlos-SP.

With the increasing data storage capacity of databases and personal computers, arises the necessity of computer algorithms capable of performing processing for automatic recovery of data and information. This fact is no different for three-dimensional objects stored in files. In this Master's Thesis we studied new techniques for processing such data objects using an unusual approach to the geometric processing area: techniques for analyzing time series, such as scattering wavelets and recurrence plots. For shape retrieval problem, i.e., given a tridimensional mesh try finding other meshes that are visually similar, our method extract only one feature - Gaussian curvature and surface variation, for example - and organize it as a series using information given by Fiedler vector. Then, the next step is to process the resulting series using a technique called scattering wavel ets, that is capable of analyzing the temporal behavior of a set of serial data. For this problem, the results are comparable with other approaches reported in the literature that use multiple characteristics to find a matching mesh. In the case of partial retrieval of objects, in which only a part of the object is given as search parameter, it is necessary to perform a segmentation of the meshes in order to find other parts that are visually similar to the query. By using Recurrence Plot to analyze the objects, our method can find not only the most similar region within the same (or other) object, but also get all the regions that are similar to the search parameter.

Key-words: shape retrieval, partial shape retrieval, geometric processing, data processing, tridimensional objects. 



\section{LISTA DE ILUSTRAÇÕES}

Figura 1 - Uma mão sob vários graus de deformação isométrica. . . . . . . . . . . . 26

Figura 2 - Diferença entre uma recuperação de objetos global e parcial. . . . . . . . 28

Figura 3 - Exemplo de recuperação parcial. À esquerda estão as mal has de consulta. Ao centro, o banco de dados utilizado. À di reita esstão os resultados, sendo que:

(a) é o resultado para uma consulta de parte no completo; e (b), completo no completo. . . . . . . . . . . . . . . . . . . . . . . . . 29

Figura 4 - Pipeline empregado para a recuperação de objetos tridimensionais. . . . . 30

Figura 5 - Exemplo dos objetos contidos na base SHREC 2011. . . . . . . . . . . . 39

Figura 6 - Região B utilizada para cál culo das curvaturas princi pais. . . . . . . . . . 43

Figura 7 - Variação de superfície variando o número de vizinhos. À esquerda está o modelo origi nal; variação de superfície com 10 vizinhos ao centro; evariação com 50 vizinhos à direita. A cor azul representa menores val ores. . . . . . . .

Figura 8 - Ângul os utilizados para cál culo dos pesos cotangentes na matriz Laplaciana. Em cinza é a área de Voronoi do vértice i. . . . . . . . . . . . . . . 45

Figura 9 - Exemplo de ordenação dos vértices. À esquerda está uma ordenação arbitrária, possivel mente como é dada no arquivo da mal ha; à direita os vértices estão ordenados pelo vetor de Fiedler. . . . . . . . . . . . . . . . . . 46

Figura 10 - Banco de filtros utilizado para dois níveis do Scattering Wavel ets. No eixo das abscissas, afrequencia. . . . . . . . . . . . . . . . . 48

Figura 11 - Imagem ilustrativa do funcionamento da técnica Scattering Wavelets . . . . 49

Figura 12 - Exemplo de coeficientes obtidos através da técnica Scattering wavel ets. Cada linha representa uma frequencia; e cada col una, umajanela da série. A figura a representa o resultado após a aplicação dos filtros, enquanto que a figura $b$ é a aplicação dos filtros no resíduo produzido por a. . . . . . . . . . . . 50

Figura 13 - Esquema de al inhamento e mapeamento de deformação utilizando DTW. . . 52

Figura 14 - Na imagem da esquerda está a órbita gerada pelo sistema de Lorenz, em que regiões com os pontos escuros estão próximos e são considerados recorrentes, enquanto que o ponto branco não. À direita, a matriz CRP resultante da auto-recorrência, em que as regiões escuras representam pontos semelhantes no sistema original. . . . . . . . . . . . . . . . . . . . . 54

Figura 15 - Exemplo de um gráfico de preci são-revocação . . . . . . . . . . . . 56

Figura 16 - Exemplo de uma matriz de distância. . . . . . . . . . . . . . . . . 57 
Figura 17 - Exemplo de uma imagem camada. Os pixels pretos representam os vizinhos mais próximos; em vermel ho, a primeira camada; e em azul, a segunda camada 57

Figura 18 - Pipeline empregado para a recuperação de objetos tridimensionais. . . . . . 60

Figura 19 - Comparação entre as ordenações dos vértices da mal ha. À esquerda, a ordenação presente no arquivo; à direita, ordenação obtida pel o vetor Fiedler. Cores mais claras representam os vértices iniciais da ordenação e cores mais escuras, os vértices finais. . . . . . . . . . . . . . . . . . . .

Figura 20 - Ilustração das características utilizadas: variação de superfície (à esquerda), com cores azuis representando regiões de baixa curvatura; e curvatura gaussiana (à di reita), com cores azui s representando curvaturas côncavas, e vermeIhas, curvaturas convexas . . . . . . . . . . . . . . . . . . . .

Figura 21 - Sinal obtido ao se combinar o vetor de Fiedler com as características extraídas. Nesse caso, a característica é a curvatura gaussiana. . . . . . . . . . . 63

Figura 22 - Exemplo de consulta real izada para o model o de um cavalo. O elemento mais à esquerda é o model o de consul ta. Cada linha representa uma tamanho de janela utilizado. . . . . . . . . . . . . . .

Figura 23 - Exemplo de consul ta real izada para o modelo de um formiga. O el emento mais à esquerda é o model o de consulta. Cada linha representa uma tamanho de janela utilizado. . . . . . . . . . . . . . . . . . . .

Figura 24 - Exemplo de consulta realizada para o modelo de um humano. O elemento mais à esquerda é o model o de consulta. Cada linha representa uma tamanho de janela utilizado. . . . . . . . . . . . . . . . .

Figura 25 - Gráfico obtido na competição SHREC 2015. O mel hor resul tado obtido com o nosso método foi utilizando a janela de $1024 . \quad \ldots \ldots \ldots$. . . . . 68

Figura 26 - Pipeline empregado para a recuperação parcial de objetos. . . . . . . . . . 72

Figura 27 - Subdivisões de um objeto tridimensional. Comparação entre o resul tado gerado pelo al goritmo de Rodola, Bulò e Cremers (2014) (à esquerda) e a modificação implementada para se adequar ao problema (à direita). . . . . . 73

Figura 28 - Il ustração exemplificando as diferenças de frequências em diferentes regiões de um mesmo objeto. As janel as das frequência estão igual mente escaladas para fins de comparação. No eixo das abscissas estão os vértices ordenados de cada região; e nas ordenadas estão os val ores do HKS no tempo $t=t_{\text {min }}$.

Figura 29 - Dado um dos braços do centauro como entrada (em verde), a matriz do CRP resul tante mostra os candi datos semel hantes. As mel hores partes estão destacadas em azul escuro e correspondem à região azul destacada no centauro da direita . . . . . . . . . . . . . . . . . . . . . . . . . . . 
Figura 30 - Dado um dos braços do humano como entrada (em verde), a matriz do CRP resultante mostra os candidatos semel hantes. A região mais semel hante encontrada pelo $S_{\max }$ está destacada em azul e corresponde à região em azul do centauro. . . . . . . . . . . . . . . . . . . . . . . . . . . 77

Figura 31 - Utilizando uma das pernas da formiga como entrada (em verde), é possível encontrar as demais pernas e as antenas (em azul). . . . . . . . . . . 77

Figura 32 - Resultado gerado pra uma busca completa no banco de dados utilizando uma das pernas do Armadillo como entrada (em verde). Resultados destacados em azul. Foram exigi dos duas partes mais semel hantes em cada modelo, para essa consulta . . . . . . . . . . . . . . . . . . 78

Figura 33 - Resultado gerado pra uma busca completa no banco de dados utilizando um do braços do model o masculino como entrada (em verde). Resultados destacados em azul. . . . . . . . . . . . . . . . . . . . . . . . 78

Figura 34 - Resultado gerado pra uma busca completa no banco de dados utilizando um do braços do modelo masculino como entrada (em verde). Resultados destacados em azul. . . . . . . . . . . . . . . . . . . . . . . . . . . . . . 79 



\section{LISTA DE TABELAS}

Tabela 1 - Tabela com resul tados quantitativos utilizando variação de superfície como característica na base SHREC 2011. O método de comparação é a correlação cruzada. . . . . . . . . . . . . . . . . . . . . . . . 64

Tabela 2 - Tabela com resul tados quantitativos utilizando curvatura como característica na base SHREC 2011. O método de comparação é a correlação cruzada. . . 64

Tabela 3 - Tabela com resul tados quanti tativos utilizando variação de superfície como característica na base SHREC 2011. O método de comparação é o DTW. . . . 68

Tabela 4 - Tabela com resul tados quantitativos utilizando curvatura como característica na base SHREC 2011. O método de comparação éo DTW. . . . . . . . . . . . 68

Tabela 5 - Resul tado obtido na competição SHREC 2015 para diferentes tamanhos de janela e utilizando variação de superfície como característica. . . . . . . . . . 69 



\section{LISTA DE ABREVIATURAS E SIGLAS}

BoF ...... Bag of Features

CRP ...... Cross Recurrence Plot

DCG ..... Ganho Cumulativo Descontado

DTW ..... Dynamic Time Warping

HKS ..... Heat Kernel Signature

ICP ...... Iterative Closest Point

MDS ..... Multidimensional Scaling

MLA ..... Minimum Linear Arrangement

NIST .... National Institute of Standards and Techonology Shape Benchmark

PCA ..... Análise de Componentes Principais

PSB ...... Princeton Shape Benchmark

RP ...... Recurrence Plot

RQA ..... Análise Quantitativa de Recorrência

SHREC .. Shape Retrieval Contest

SIFT ..... Salient Local Features 

INTRODUÇÃO . . . . . . . . . . . . . . . . . . . . . . . 25

$1.1 \quad$ Características e similaridades em objet os tridimensionais . . . . . . 26

1.2 Recuperação de objetos . . . . . . . . . . . . . . . . 27

1.2.1 Recuperação total . . . . . . . . . . . . . . . . . . . . 27

1.2 .2 Recuperação parcial . . . . . . . . . . . . . . . . . 28

1.2.2.1 Parte no completo . . . . . . . . . . . . . . . . . . . . 28

1.2.2.2 Completo no completo . . . . . . . . . . . . . . . . . . . . . . 29

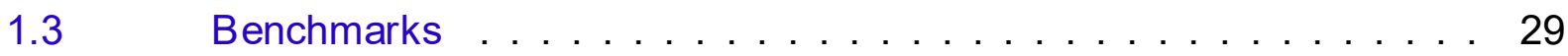

$1.4 \quad$ Objetivos e cont ribuições . . . . . . . . . . . . . . 30

$1.5 \quad$ Organização da monogra䑐 . . . . . . . . . . . . . . . 31

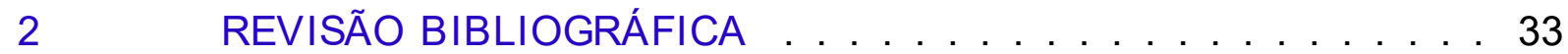

2.1 Classi Eclação dos métodos de recuperação de objetos . . . . . . . 33

2.1.1 Características locais . . . . . . . . . . . . . . 33

$2.1 .2 \quad$ Estruturas topológicas . . . . . . . . . . . . . . . 34

2.1.3 Propriedades geomét ricas globais . . . . . . . . . . . . . . . . . 34

$2.1 .4 \quad$ Correspondência direta . . . . . . . . . . . . . . . 35

$2.1 .5 \quad$ Formas canônicas . . . . . . . . . . . . . . . . . 35

2.2 Classi Eckação dos métodos de recuperação parcial . . . . . . . . . . 36

2.2.1 Características locais . . . . . . . . . . . . . . . 36

2.2 .2 Segmentação . . . . . . . . . . . . . . . . . . . . 37

$2.2 .3 \quad$ Visão . . . . . . . . . . . . . . . . . . . . . . . . . . 37

$2.3 \quad$ Benchmarks e bases de dados . . . . . . . . . . . . . . 37

3 CONCEITOS BÁSICOS . . . . . . . . . . . . . . 41

$3.1 \quad$ Descritores de objetos tridimensionais . . . . . . . . . . . . . 41

$3.1 .1 \quad$ Curvaturas . . . . . . . . . . . . . . . . . 42

$3.1 .2 \quad$ Variação de superfície . . . . . . . . . . . . . . . 43

3.1.3 Vetor de Fiedler . . . . . . . . . . . . . . . . . . . 44

$3.1 .4 \quad$ Heat Kernel Signature . . . . . . . . . . . . . . . . . . 46

$3.2 \quad$ Descritores de séries temporais . . . . . . . . . . . . . . . 47

3.2.1 Scattering Wavelets . . . . . . . . . . . . . . . . 48

$3.3 \quad$ Medidas de dissimilaridade . . . . . . . . . . . . . . . 50 
3.3.1 Correlação cruzada . . . . . . . . . . . . . . . . . . 51

3.3.2 Dynamic Time Warping . . . . . . . . . . . . . . 51

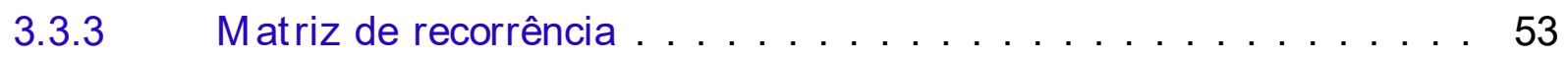

$3.4 \quad$ Métodos de avaliação . . . . . . . . . . . . . . . . . . 55

4 MÉTODO PARA RECUPERAÇÃO OBJETOS . . . . . . . . . 59

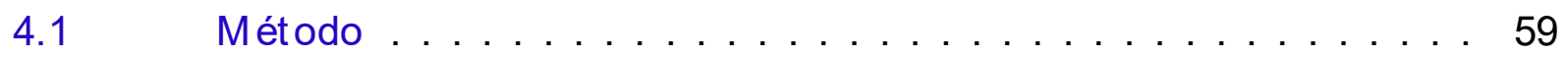

$4.1 .1 \quad$ Ordenação dos vértices . . . . . . . . . . . . . . . . . . . . . 61

4.1 .2 Extração das caract erísticas . . . . . . . . . . . . . . . 61

$4.1 .3 \quad$ Comparação com a base . . . . . . . . . . . . . . 62

$4.2 \quad$ Resultados . . . . . . . . . . . . . . . . 63

$4.3 \quad$ Discussão . . . . . . . . . . . . . . . . . . . . . . . . . . . . . 69

5 MÉTODO PARA RECUPERAÇÃO PARCIAL DE OBJETOS . . . 71

$5.1 \quad$ Método . . . . . . . . . . . . . . . . . . . 71

$5.1 .1 \quad$ Segmentação dos objetos . . . . . . . . . . . . . . 71

5.1 .2 Extração das características . . . . . . . . . . . . . . . 74

5.1.3 Comparação com a base . . . . . . . . . . . . . . . . 74

$5.2 \quad$ Resultados . . . . . . . . . . . . . . . . . . 76

$5.3 \quad$ Discussão . . . . . . . . . . . . . . . . . . . . . . . . 79

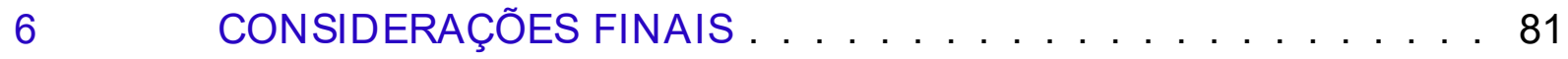

6.1 Trabalhos futuros . . . . . . . . . . . . . . . . . . . 81

$6.1 .1 \quad$ Recuperação total . . . . . . . . . . . . . . . . . . . 82

6.1 .2 Recuperação parcial . . . . . . . . . . . . . . . . . . 82

$6.2 \quad$ Publicações . . . . . . . . . . . . . . . . 83

Referências . . . . . . . . . . . . . . . . . . . . . . 85 
CAPÍTULO
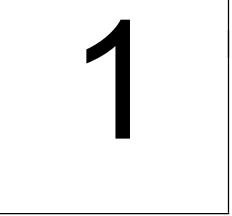

INTRODUÇÃO

A capacidade do cérebro humano em perceber formas e objetos à nossa vol ta é surpreendentemente grande e muitas vezes acaba passando despercebido por ser real izado de forma subconsciente. Ao entrarmos em contato com al gum objeto, nós o compreendemos e analisamos o formato com informações anteriores, adqui ridas no decorrer dos anos de nossas vidas, para criarmos novos conceitos e então essa experiência poderá ser repetir futuramente. Observando um cenário de um filme, por exemplo, rapidamente identificamos as formas básicas que compõem cada objeto pelo fato de já termos tido al gum contato prévio com al gum outro objeto semel hante. Entretanto, se descrevermos tal cenário de forma semântica por meio de pal avras é muito provável que cada indivíduo sintetize uma imagem diferente.

Com o advento da computação, novas tecnol ogias e al goritmos para reconhecimento de padrões vêm sendo desenvolvidos, na tentativa de imitar o reconhecimento humano. Entretanto ensi nar uma máqui na a identificar um objeto tridimensional, semanticamente, não é uma tarefa simples. O desafio começa na necessidade de modelar computacional mente os dados - processo de discretização - para então real izar uma anál ise sobre o objeto. Em geral, procura-se representá los por meio de nuvem de pontos, mal has triangulares, superfícies paramétricas ou superfícies implícitas.

O interesse dessa Dissertação não está na discretização do objeto - o que já é muito conhecido na literatura -, mas sim em caracterizálo e ser capaz de encontrar outros objetos que sejam parecidos aos ol hos humanos. Nesse processo é necessário levar em consideração as mudanças na forma do objeto, que chamaremos de deformações. Tais deformações possuem duas naturezas: rígidas e não-rígi das. As de natureza rígi da não alteram o formato do objeto e são compostas de transl ações e rotações no espaço. Um exemplo de transformação rígida é escrever seu nome em uma fol ha de papel e movêla pela mesa: as letras mantem o formato, mas estão em outro local, diferente do ori ginal . Em contrapartida, uma deformação não-rígi da seria pedir aos amigos para escreverem o mesmo nome em outras fol has de papel: são o mesmo 
objeto (seu nome), mas estão sob diferentes deformações (escrita pessoal de cada amigo). O que é de maior interesse da comunidade científica são as transformações não rígidas, pois são deformações que al teram o formato do objeto e, consequentemente, acabam dificultando seu reconhecimento por al goritmos.

\subsection{Características e similaridades em objetos tridimensi- onais}

Em termos computacionais, para que um al goritmo seja capaz de identificar objetos tridimensionais, é necessário que haja comparações entre outros objetos conheci dos que sejam similares ao objeto alvo, gerando uma medida de similaridade. Entretanto, para se definir uma medida de similaridade entre dois objetos, é necessário escol her quais propriedades, ou características, se estará comparando. Em particular, é de interesse encontrar propriedades que possam ser atribuídos de maneira equival ente entre as deformações. Em caso de objetos não rígidos, esse é um problema mais complexo, pois os modelos podem assumir diversas configuraçães possíveis devido à deformação. Tendo em mente as inúmeras possi bilidades de deformações, considera-se apenas as def ormações articul adas, que são chamadas de deformações isométricas, ou seja, transformações que deformam o obj eto, mas preservam as distâncias entre pontos próximos. Na Figura 1 é possivel ver um modelo tridimensional e suas deformações isométricas. Observe que esse ti po de deformação ocorre natural mente na vida real, em que, por exemplo, a flexão de braços e joel hos são parte de uma deformação isométrica.

Figura 1 - Uma mão sob vários graus de deformação isométrica.
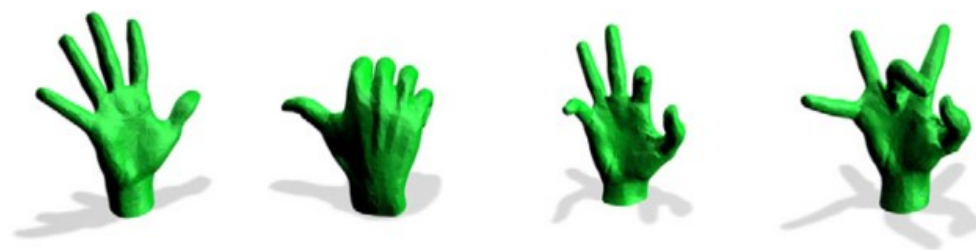

Fonte: Lian et al. (2013).

Uma vez considerando-se apenas objetos com deformações isométricas, é necessário sel ecionar características que são invariantes à isometria e preservam a geometria intrínseca do objeto. Ou seja, características que não se al teram, ou que tenham pouca al teração, de um objeto para outro isométrico, tais como curvatura gaussiana, distância geodésica e o operador de núcleo de calor (do inglês, heat kernel signature. No exemplo da Figura 1 procuraríamos por uma propriedade que caracteriza igual mente a mão aberta e a mão fechada.

Ao tratarmos esse problema de similaridade tridimensional, estamos querendo encontrar uma medida quantitativa capaz de descrever uma "distância" entre as características de dois objetos: se o val or for baixo, dizemos que os dois são similares. E novamente a medi da a ser 
escolhida é importante, pois di ferentes manei ras de se medir a similaridade levam a diferentes conclusões.

\subsection{Recuperação de objetos}

Recuperação de objetos (do inglês, shape retrieval) é uma das áreas de pesquisa em Ciências da Computação responsável por processar e assimilar um grau de similaridade entre dois objetos diferentes e apontar, para o usuário, quais são os objetos mais semel hantes. No caso dessa Dissertação de Mestrado estaremos sempre nos referindo a objetos tridimensionais.

Podemos dividir a recuperação de obj etos tridimensionais em duas princi pais categorias:

- Total: considerando as similaridades dos objetos como um todo;

- Parcial: considerando similaridades parciais entre objetos, ou pedaços que são similares.

Cada categoria se di ferencia da outra na manei ra em que trata um obj eto. Entretanto os métodos desenvol vidos compartilham características que são desejáveis para esse tipo de resolução de problema:

1. Alta capaci dade de adaptação aos tipos de modelos, ruídos, pequenas al terações locais e topol ogia degenerada;

2. Invariância às deformações rígi das - rotação, transl ação, escal a - e não-rígidas;

3. Extração de características com al to grau discriminativo.

Val e ressal tar que al guns tópi cos podem ser adicionados para o caso de recuperação parcial de objetos. Com relação ao Item 2, espera-se que os métodos de recuperação parcial sejam capazes de encontrar semel hança entre objetos que foram local mente deformados. Além disso, a extração de estruturas capazes de identificar bem as regiões também é desejável.

A Figura 3 ilustra bem a diferença entre as duas categorias citadas. Enquanto que a recuperação total procura encontrar objetos que são isometricamente idênti cos, a recuperação parcial busca por isometrias em partes dos objetos.

\subsubsection{Recuperação total}

O termo recuperação total de objetos busca por objetos que são si milares visual mente, mas que no ambiente computacional estão sob al gum tipo de deformação. Em termos matemá ticos, sejam M um objeto e K uma deformação de $M$. Queremos que o método desenvolvido seja capaz de encontrar uma medida de dissimilaridade $\mathrm{d}(\mathrm{M} ; \mathrm{K})$ próxima de zero para essa 
Figura 2 - Diferença entre uma recuperação de objetos gl obal e parcial.

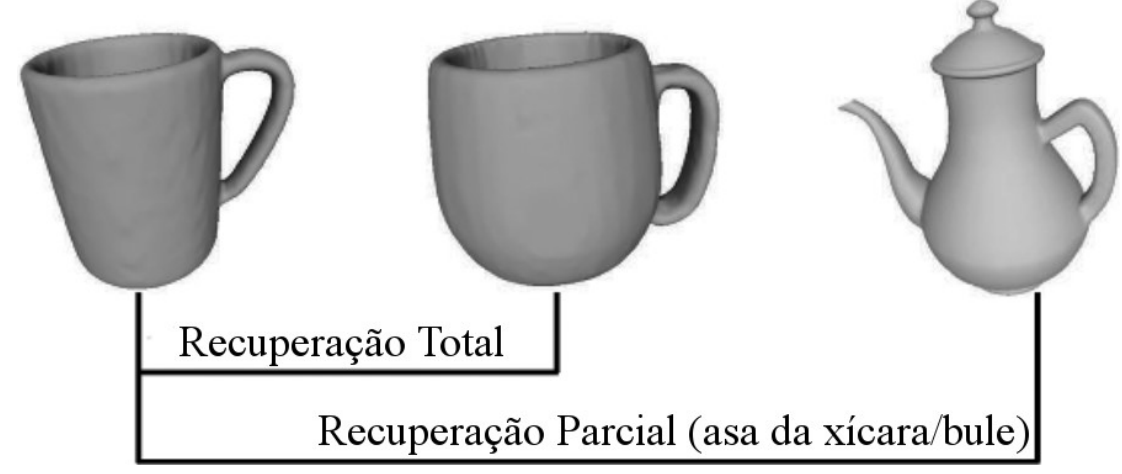

Fonte: Liu et al. (2013).

deformação. Esse tipo de problema é anál ogo ao probl ema de recuperação de imagens: encontrar duas imagens que representam a mesma cena, ou objeto.

Nessa dissertação, a não ser que citado, sempre trataremos recuperação total como recuperação de objetos

\subsubsection{Recuperação parcial}

O termo parcial remete à ideia de que algo é dividido em vários pedaços com significados próprios. Modelos tridimensionais, em especial, o objeto possui vários conjuntos de pedaços individuais, que juntos compõem o objeto final. Por exemplo, o corpo humano pode ser consi derado um conjunto de partes individuais, como os braços e pernas.

A dificul dade em se trabal har com recuperação parcial de objetos está na interpretação das partes de cada objeto. Diferentes níveis de parcial idade podem ser levados em consi deração. Voltando ao exemplo do ser humano e do braço, se consi derarmos cada braço como um obj eto completo, podemos separálo novamente em vários subconj untos que, mesmo sendo subconjuntos do braço, ainda são partes do corpo humano. Isso nos leva a ter que considerar o objetivo da aplicação para a qual se está querendo realizar a busca pel os objetos. Podemos dividir, então, os problemas de recuperação parcial em duas vertentes diferentes (LIU et al., 2013): busca por parte-no-compl eto; e busca por completo-no-completo.

\subsubsection{Parte no completo}

Seja $\mathrm{M}$ um objeto tridimensional compl eto formado por $k$ conjuntos $m_{i}, i=1 ; 2 ; \cdots ; k$, pertencentes a M. Dado um subconjunto $m^{\prime}$, presente ou não em $M$, queremos encontrar $m_{i}$ tal que $\mathrm{d}\left(\mathrm{m}^{\prime} ; \mathrm{m}_{\mathrm{i}}\right)$ seja o menor possível, em que $\mathrm{d}(\cdot ; \cdot)$ é uma medida de dissi milaridade. É possível observar que será necessário real izar a medida de di ssi mi laridade em todos os subconjuntos de $\mathrm{M}$, o que acaba se tornando um problema de busca por um subconjunto ótimo.

Um exemplo desse tipo de recuperação parcial é procurar por uma roda em uma bicicleta. 
Nesse caso estamos consi derando $\mathrm{m}^{\prime}$ como sendo nossa roda e o conjunto compl eto M sendo a bicicleta.

\subsubsection{Completo no completo}

Diferentemente da busca de partes em um objeto completo, a busca de completo no completo procura encontrar similaridades parciais entre dois objetos inteiros. Observe que é diferente da recuperação total, uma vez que não requer que os dois objetos sejam total mente similares. Sejam $M$ e $N$ dois objetos tridimensionais. $M$ possui $k_{m}$ partes definidas como $m_{i}$, $i=0 ; 1 ; 2 ; \cdots ; k_{s}$. E N, analogamente, possui $k_{n}$ partes $n_{j}, j=0 ; 1 ; 2 ; \cdots ; k_{t}$. Busca-se então encontrar as partes que são similares da seguinte forma: encontrando uma ou mais pares de partes $m_{i}$ e $n_{j}$; ou definindo uma medida de di stância $d\left(m_{i} ; n_{j}\right)$ por recuperação total entre $m_{i} e$ $n_{\mathrm{j}}$. Note que as partes de $\mathrm{M}$ e $\mathrm{N}$ podem não estar bem defini das, o que resul ta em um problema de encontrar a intersecção ótima entre $\mathrm{M}$ e N.

Tome como exemplo um centauro e um ser humano. Mesmo que, como objetos completos, os dois objetos não são similares, é possível notar a similaridade parcial do busto dos dois modelos.

Figura 3 - Exemplo de recuperação parcial. À esquerda estão as mal has de consulta. Ao centro, o banco de dados utilizado. À direita esstão os resultados, sendo que: (a) é o resultado para uma consulta de parte no completo; e (b), completo no completo.

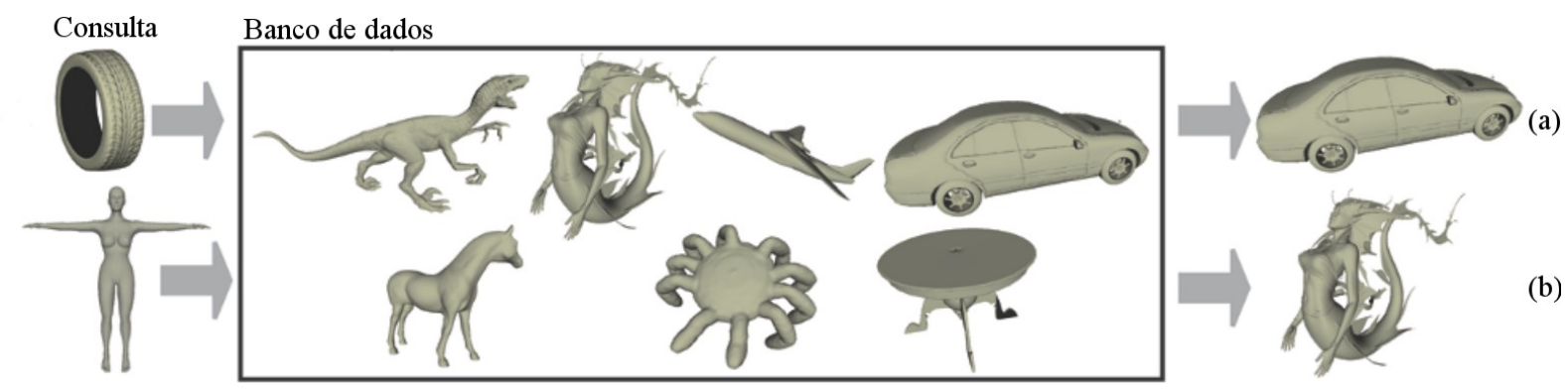

Fonte: Liu et al. (2013).

\subsection{Benchmarks}

Com o grande crescimento da área de pesqui sa e o interesse de vários grupos em atacar o problema, houve um grande aumento na quantidade de métodos que buscam os melhores resultados. Tais resultados eram muitas vezes gerados em bases de dados com objetos de uso particular, dificultando a comparação entre duas técnicas sob o mesmo conjunto de modelos. Além disso, os resultados gerados são subjetivos para humanos, principal mente por se tratar de uma medida de qual idade entre técnicas. Isso acaba levando, ainda, a outro problema: a aval iação ser viesada. 
Tentando dimi nuir a subj etividade e mel horar aval iação dos resultados de cada técnica desenvolvida, foram criados métodos e conjuntos de dados padronizados, chamados benchmarks. Os benchmarks apresentam um conjunto de modelos 3D que são abertos para a comunidade científica, além de um conjunto de métricas de avaliação que podem ser executados após a obtenção dos resul tados. Por avaliarem sob uma mesma base com várias classes de objetos é possível realizar várias outras análises, tais como a efetividade do método desenvolvido sobre a base inteira e sobre classes isoladas.

\subsection{Objetivos e cont ribuições}

Com a visão geral do problema a ser estudado - recuperação de obj etos e recuperação parcial de objetos -, objetivamos estudar as técnicas já presentes na literatura que abordam esse tema de diferentes manei ras. Além disso, muitos tipos de características intrínsecas podem ser encontradas. Para o desenvol vimento do nosso método buscaremos encontrar uma del as que seja simples e ao mesmo tempo al tamente descritiva. Além disso, visamos estudar caracterizadores de séries temporai s para serem utilizados nessa Dissertação de Mestrado. I sso é justificado pelo fato de se poder obter uma ordenação uniforme para classes de obj etos. E, ainda nessa di ssertação, buscaremos implementar o método proposto e aval iálo conforme os benchmarks utilizados por vários grupos de pesquisa dessa área.

Em resumo, a partir de um objeto tridimensional, dado como entrada para o método de recuperação, tentaremos buscar na base de objetos os correspondentes mais próximos do objeto dado. Umailustração do método para recuperação de objetos pode ser visto na Figura 4. Para a recuperação parcial de objetos, o pi peline geral é praticamente idêntico, diferenciando apenas em um pré processamento das mal has em que são feitas segmentações das mesmas para se obter regiões de semânticas diferentes - braço separado do tronco e pernas, por exemplo.

Figura 4 - Pipeline empregado para a recuperação de objetos tridimensionais.

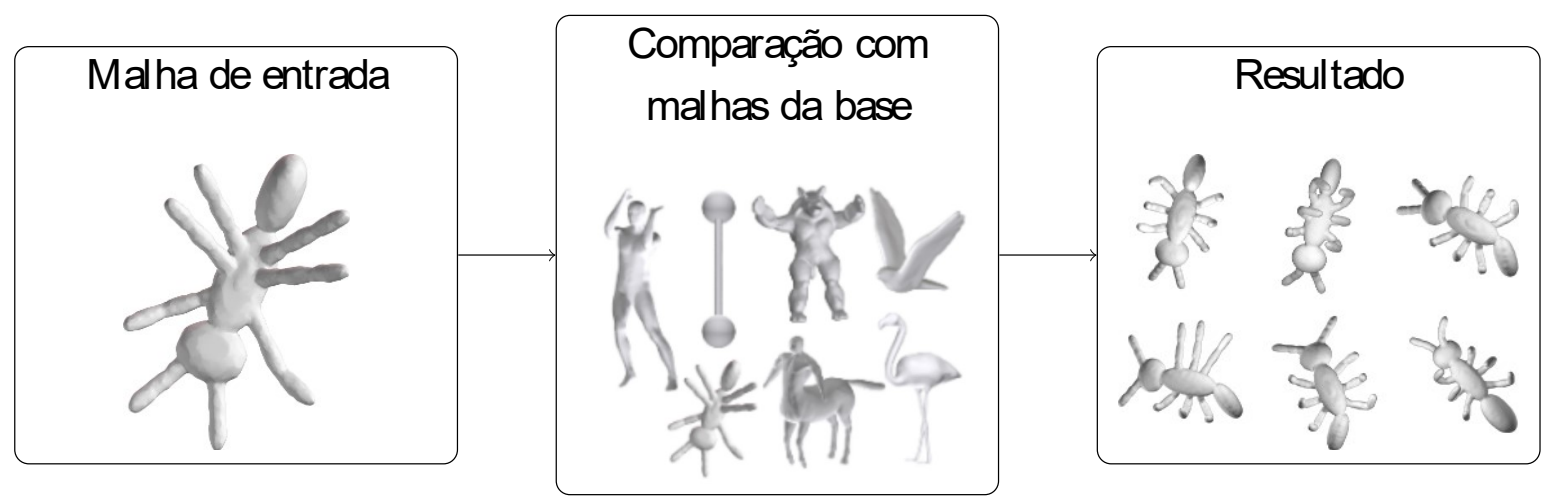

Fonte: Elaborada pelo autor. 
Como princi pais contribuições dessa Dissertação de Mestrado, podemos citar:

- Descrição de uma nova abordagem para recuperação gl obal e parcial de objetos utilizando descritores de séries temporais através da ordenação de suas características.

Utilização de apenas uma característica para descrição dos objetos.

Além disso, com o desenvolvimento dessa dissertação foi possível obter duas publicações: a primeira envolvendo recuperação de objetos, no Workshop of 3D Object Retrieval, realizado em Zurich em 2015 (LIAN et al., 2015); e a segunda sobre recuperação parcial de objetos, no Conference on Graphics, Patterns and Images, em 2016 (NAKANISHI et al ., 2016).

\subsection{Organização da monogra昫}

No capítulo que se segue apresentaremos al guns trabal hos que foram desenvolvidos visando a recuperação de objetos não rígidos, tanto na área de recuperação de objetos como recuperação parcial. Nesses ramos de pesquisa várias abordagens diferentes foram utilizadas e várias técni cas desenvol vidas. Além disso discutiremos al gumas medi das estatísticas que foram propostas em benchmarks, bem como um padrão para comparação das técnicas e apresentaremos al gumas bases de dados utilizados pel a comuni dade científica.

No Capítul o 3, abordaremos al guns conceitos necessários para mel hor entendi mento da abordagem a ser desenvol vida nessa Di ssertação. Apresentaremos al gumas características utilizadas em objetos tridimensi onais e al guns extratores de características utilizadas em séries temporais.

A seguir, no Capítulo 4 e no Capítul o 5, apresentamos a metodologia dessa Dissertação de Mestrado, utilizando os conceitos apresentados no capítulo anterior. Além disso, apresentaremos os resultados obti dos para cada tipo de problema atacado, uma breve discussão dos mesmos em questões quantitativas e qualitativas, e as principais dificuldades encontradas na técnica.

Por fim, no Capítulo 6, apresentaremos nossas considerações finais sobre a Dissertação de Mestrado. Apresentaremos, também, a publicação obtida com o desenvolvimento da técnica e trabal hos futuros que podem ser derivados a partir das metodol ogias apresentadas. 



\section{2}

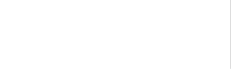

REVISÃO BIBLIOGRÁFICA

Com o crescimento da capacidade de produção de obj etos tridimensionais e o aumento da capaci dade de armazenamento desses dados surgiu a necessi dade de criação de ferramentas de buscas apropriadas. Diferentemente da busca por textos, não é possivel realizar uma comparação tão precisa em objetos tridimensionais. Em sua mai oria ocorre a extração e comparação de características intrínsecas de cada objeto para se encontrar outros que são semel hantes - não necessariamente apenas obj etos isométricos. Na literatura é possível encontrar uma variedade de métodos desenvolvidos para recuperação de objetos. Inicial mente surgi ram vários al goritmos que buscam por similaridades em objetos rígidos. A busca por semelhança em objetos não-rígidos é consi derado, ai nda, um ramo de interesse na pesquisa.

\subsection{Classi ⿷匚⿱⺊口冋lação dos mét odos de recuperação de objetos}

Dentre os métodos apresentados até então, é possível classificálos em al gumas categorias (LIAN et al., 2013): métodos que utilizam características locais, estruturas topológicas, propriedades geométricas invariantes à isometria, comparação di reta ou formas canônicas.

\subsubsection{Características locais}

Técnicas de recuperação de objetos baseados em características locais medem a dissimilaridade através de val ores que são extraídos de vários conjuntos de pontos que estão próximos, em cada objeto. Esses val ores são armazenados em al gum tipo de estrutura a fim de se extrair a métrica de dissimilaridade. Vale ressal tar que tais características devem ser invariantes às transformações isométricas.

Operadores de difusão são um exemplo de características locais bem utilizadas na literatura. Ovsjanikov et al. (2010) utiliza o núcleo de calor (do inglês, Heat Kernel) para encontrar correspondências entre dois objetos. Essa característica utiliza noção de que o cal or 
se difunde mais rapidamente em regiões mais planas, e em regiões com mais detal hes ocorre uma difusão menor. Dessa forma val ores ao longo do tempo são obti dos e uma análise com esses vários estados - análi se multivariada - da característica pode ser real izado. Uma derivação do núcleo de cal or proposto por Sun, Ovsjanikov e Guibas (2009) é o Heat Kernel Signature (HKS), que será descrito com mais detal hes na subseção 3.1.4.

Outro tipo de característica considerada local é o Salient Local Features (SIFT) (Características locais sal ientes, em tradução livre), proposto por Ohbuchi et al. (2008). Nessa abordagem, é criado um vetor de características a partir do histograma das características extraídas do obj eto. São real izadas capturas da forma do objeto em imagens sob vários ângulos do objeto e então as características extraídas são transformadas em hi stogramas para medi da de dissimilaridade.

\subsubsection{Estruturas topológicas}

Recuperação de objetos tridi mensionais baseados em estruturas topológi cas real izam comparações entre as topologias dos objetos. Em geral, as topol ogias são representadas por meio de uma estrutura de grafos, fazendo com que o problema se torne encontrar a dissimilaridade de dois grafos.

Um grafo topol ógico que pode ser extraído de um objeto tri dimensional éo grafo de Reeb, introduzido por Reeb (1946). Esses grafos são definidos através de uma relação de equival encia entre os pontos. Se dois pontos estão em um mesmo componente conexo, então eles fazem parte da mesma região no grafo. Hilaga et al . (2001), baseiam-se nos grafos de Reeb para encontrar objetos que são similares.

Um outro tipo de estrutura topológica extraída é o esqueleto tridimensional, como o apresentado por Sundar et al. (2003). Segundo os autores, o esqueleto de dois modelos isométricos não se al tera durante a articulação do objeto. Dessa forma é possível encontrar objetos similares utilizando os seus esqueletos. Para comparação entre os modelos, novamente são utilizadas técnicas de comparação de grafos.

\subsubsection{Propriedades geomét ricas globais}

Ao contrário das características locais, propriedades gl obais levam em consi deração o objeto como um todo para se construir o descritor que será utilizado na recuperação não rígida. Um exemplo de característica geométrica consi derada gl obal é a distância geodésica entre os pontos, pois seu cál culo envolve todo o objeto. Jai n e Zhang (2007) propuseram utilizar o espectro de uma matriz de distâncias geodésicas para comparação de objetos tridimensionais, dizendo que os autoval ores obtidos são invariantes à i sometria.

Seguindo a mesma linha pensamento, a utilização do espectro da matriz de LaplaceBeltrami foi apresentado por Reuter, Wolter e Peinecke (2005). Como tal operador pode ser 
cal cul ado para qual quer representação da superfície (explícita e implícita), essa técni ca se torna mais genérica para cal cular as características dos objetos.

Uma outra abordagem para cal cular características gl obais é utilizado por Mahmoudi e Sapi ro (2009), real izando comparações entre a di stribui ções de distâncias intrínsecas (di stância geodési ca, distância de difusão, etc). As distri buições geradas são armazenadas em histogramas, e as comparações entre essas assi naturas são feitas através de model os estatísticos. Essa abordagem é semelhante à que será apresentada nessa dissertação de mestrado, em que as mal has são descritas por uma determinada distribuição e sua comparação é feita util izando ferramentas estatísticas.

\subsubsection{Correspondência direta}

A correspondência direta entre objetos é baseada na comparação de dois espaços métricos, que nesse caso representam cada obj eto tri dimensional. Mémoli e Sapiro (2005) introduziram a teoria baseada na distância de Gromov-Hausdorff entre espaços métricos aplicado em conjunto de pontos, que representavam um objeto tridimensional. Utilizando desse arcabouço teórico, Memoli (2007) estendeu o seu uso para superfícies, sendo possível a utilização da distância de Gromov-Hausdorff para recuperação de objetos.

Várias outras variantes do uso da distância de Gromov-Hausdorff foram desenvolvidas, por ser uma métrica que demanda muito tempo de processamento. Bronstein, Bronstein e Kimmel (2006) formulou esse problema como um problema de otimização contínua, utilizando Multidimensional Scaling.

A pesar da comparação di reta entre os objetos apresentar bons resul tados, seu al to custo computacional (LIAN et al ., 2013) desencoraja o uso para aplicações que necessitam de respostas próximas do imediato. Além disso, com o aumento da quantidade de objetos em um banco de dados, seu uso vem se tornando cada vez mais inviável.

\subsubsection{Formas canônicas}

Formas canônicas são uma forma de representação tal que todos os objetos possuem uma forma de descrição única. Dessa forma, se dois obj etos são semel hantes, então sua forma canônica devem ser a mesma, ou com um valor de dissimilaridade muito baixo.

Elad e Kimmel (2003) introduziram a ideia de utilizar as formas canônicas em objetos tridimensionais, extraindo as distâncias geodésicas dos pontos e então aplicando o Multidimensional Scaling (MDS), um método de projeção que procura preservar as di stâncias entre os pontos da melhor maneira possível. Com isso, os autores conseguiram aproximar a distância geodésica cal cul ada na superfície do obj eto para uma distância euclidiana. Mais recentemente, Lian et al . (2010b) apresentaram uma abordagem utilizando a projeção MDS juntamente com descritores locais. 
Uma outra abordagem semel hante, porém sem utilização das distâncias geodésicas foi apresentada por Rustamov (2007). Nesse trabal ho, o autor apresenta uma forma de caracterizar os objetos tridimensi onais utilizando uma assi natura, obtida através do espectro do operador de Laplace-Beltrami. Essa assinatura funciona como um espaço n-dimensional, e ao se projetar um objeto no espaço visual, é possível visual izar a dissi milaridade entre dois modelos.

\subsection{Classi 䶌ação dos métodos de recuperação parcial}

Os métodos para recuperação parcial , diferentemente da recuperação de objetos, devem ser capazes de reconhecer semel hanças em cada parte dos model os, e não apenas discriminálos como semel hantes. Na literatura são apresentadas al gumas categorias para classi ficação dos al goritmos (LIU et al., 2013), similar à classificação de recuperação de objetos baseados em: características locais, segmentação, e visão.

\subsubsection{Caract erísticas locais}

Semel hante aos métodos baseados em características locais descritos na subseção 2.1.1, a recuperação parcial busca extrair informações através de uma vizinhança de pontos para cál culo da dissi milaridade. Esse tipo de metodol ogia utilizada apresenta a vantagem de não precisar de uma segmentação avançada do modelo, ou seja, não é necessário dividir o objeto tridimensi onal em partes semânticas menores (por exemplo, dividir um modelo de um cão em cabeça, corpo, patas e rabo). A principal diferença com os métodos para recuperação total de objetos está no modo de comparar as características. Em geral, os métodos de recuperação parcial estão interessados em pontos chaves da mal ha - regiões de um objeto que contem mai s informação, por exemplo, regiões de alta ou baixa curvatura - e realizam as comparações de regiões ou pequenos conjuntos. Por exemplo, Zou et al. (2008) utiliza um detector de pontos-chave no espaço de escal a geodésica e então real iza a comparação das características nesses pontos para encontrar regiões similares.

Outra abordagem utilizada é a proposta por Haar e Vel tkamp (2007), em que é utilizado o al goritmo Iterative Closest Point (ICP) para encontrar o mel hor al inhamento possível entre duas nuvens de pontos provenientes de escaneamentos 3D. Por outro lado, a utilização de Bag of Features (BoF) tem se tornado popular, devido aos bons resultados apresentados em processamento de textos e imagens. Lavoué (2011) constrói um dicionário de características visuais utilizando o operador de Laplace-Beltrami cal cul ado sobre pontos uniformemente amostrados na superfície. Enquanto que Ovsjanikov et al. (2009) utiliza heat kernels para construir o seu dicionário. É possível observar pel os trabal hos da literatura, que apesar das diferentes características utilizadas, todas conseguem discriminar bem um objeto de sua isometria e as técnicas diferem no método em que processam tais informações 3D. 


\subsubsection{Segmentação}

No caso de recuperação parcial de obj etos baseando-se em segmentação, a definição expl ícita das partes se faz necessária. Cada parte deve conter informações que são rel evantes para a caracterização do objeto e da sua parte. Em geral, utilizam-se estruturas do tipo grafo para armazenamento das informações topológicas, em conjunto com os atributos geométricos extraídos. Agathos et al. (2010), por exemplo, segmenta os objetos tridimensionais em grafos para comparálos entre si utilizando técnicas específicas para isso.

Uma outra abordagem explorada é a de Berger et al. (2010), que utiliza do vetor de Fiedler para anal isar os objetos tridimensionais. Apesar de não ser uma técnica vol tada para segmentação, essa ferramenta pode ser usada para tal finalidade, apresentando bons resultados. O trabal ho de Rodola, Bulò e Cremers (2014), por sua vez, busca segmentar o objeto através de segmentação consensual de várias outras segmentações. Tal método analisa um conjunto de possíveis segmentações do model o e então busca por uma segmentação após a anál ise dos candidatos.

\subsubsection{Visão}

Recuperação parcial baseado em visão é uma metodologia di ferente a ser apresentada, pois resume-se em extrair visões, ou imagens, a partir de uma esfera que cobre o objeto por completo. Logo, a comparação entre dois objetos se torna a comparação de suas imagens geradas utilizando técni cas de processamento de imagens. Uma das mai ores dificuldades dessa metodologia está na capaci dade de processar várias consul tas rápi das sobre imagens 2D extraídas de inúmeros objetos. A vantagem desses métodos está na quanti dade de processamento sobre imagens ao invés de processar um objeto tridimensional.

Os métodos presentes na literatura propõem capturar imagens dos objetos a partir dos eixos principais (LIU et al., 2008) e ao redor de uma esfera (CHEN et al., 2003). Ao se capturar as imagens, comparações são real izadas para se chegar a uma métrica de simi laridade. Seguindo uma abordagem semel hante, Shao et al . (2011) propõe uma busca por modelos tridimensi onais baseados em rascunhos de imagens. Ao contrário de real izar uma busca através de um objeto tridimensional, a proposta oferece a possibilidade de um usuário leigo encontrar modelos realizando comparações com imagens.

\subsection{Benchmarks e bases de dados}

Um benchmark é um conjunto de testes real izados sobre diferentes tecnol ogias com a final idade de comparar o desempenho dos mesmos. Com o crescente interesse por se encontrar objetos tridimensionais que são si milares, e com o crescente aumento de algoritmos desenvolvidos, viu-se a necessidade de um padrão para comparação das técnicas. Esse padrão foi, 
inicialmente, introduzido por Shilane et al. (2004) com Princeton Shape Benchmark (PSB) ${ }^{1}$, utilizando-se de métricas e outros benchmarks que já eram muito utilizados em outras áreas de processamento de dados, tais como textos e imagens. Além disso, o PSB apresentou um conjunto de mal has que devem ser processadas para aval iar o desempenho do al goritmo.

Um dos probl emas que pode ser apontado para a base de mal has apresentado por Shilane et al. (2004) é a quantidade desi gual de instâncias em cada classe, o que torna a classificação do método mais parcial. Para resolver esse problema, Fang et al. (2008) apresentaram uma base com classes balanceadas: o National Institute of Standards and Techonol ogy Shape Benchmark (NIST).

Com essa introdução de métrica para se aval iar o desempenho dos al goritmos, vários outros bancos de dados foram surgindo com diferentes propósitos. Entre eles, podemos destacar o concurso anual de recuperação de objetos, Shape Retrieval Contest (SHREC). A cada ano, desde de 2006, são propostos diversos problemas envolvendo recuperação de objetos, que vão desde recuperação de objetos isométricos, ou seja, que sofreram al gum tipo de deformação não-rígida; até recuperação de objetos parciais, que podem ser partes de objetos completos, ou mesmo objetos com fal has, tais como buracos. Os principais problemas de interesse para esse trabal ho de mestrado são os de recuperação de obj etos não-rígi dos e podemos destacar as bases SHREC 2010 (LIAN et al., 2010a), SHREC 2011² (LIAN et al., 2011) e SHREC 2015³ (LIAN et al., 2015). Essas bases utilizadas apresentam um conjunto de classes bem diversificado e bal anceado, fazendo com que os métodos sejam submetidos a diversos tipos de objetos. Além disso, el as util lizam as métricas propostas pel o PSB, garantindo uma padronização na comparação dos algoritmos. Na Figura 5 apresentamos um exemplo dos objetos contidos na base SHREC 2011 retirado da página da competição.

Nessa Dissertação de Mestrado utilizamos a base SHREC 2011 para análise do método desenvol vido. Essa base apresenta uma boa diversidade de objetos e classes (30 classes com 20 objetos cada) e é utilizado para recuperação de objetos. Para a recuperação parcial de objetos utilizamos essa mesma base, devido à dificuldade de encontrar um banco de objetos que se fosse adequado para o método desenvolvido para recuperação parcial. Em 2015, surgiu mais uma competição de recuperação de obj etos não rígi dos, proposto por Lian et al. (2015). Como consequência da submissão do nosso método para a competição, tivemos acesso à base de dados. Utilizamos seus objetos apenas para processamento e submi ssão da matriz de distâncias. Entretanto, por possuir mais mal has (20 objetos distribuídos em 60 classes), uma maior variedade de resultados poderia ser obtido. Além disso, segundo os próprios organizadores da competição, essa base contém deformações que al teram a topologia dos objetos, ou seja, regiões antes separadas podem aparecer juntas - duas pernas abertas que se fecharam, por exemplo.

\footnotetext{
<http://shape.cs.princeton.edu/benchmark/>, último acesso em 26/04/2016.

<http://www.itl.nist.gov/iad/vug/sharp/contest/2011/NonRigid/>, último acesso em 01/05/2016.

<http://www.icst.pku.edu.cn/zlian/shrec15-non-rigid/>, último acesso em 01/05/2016.
} 
Figura 5 - Exemplo dos objetos contidos na base SHREC 2011.

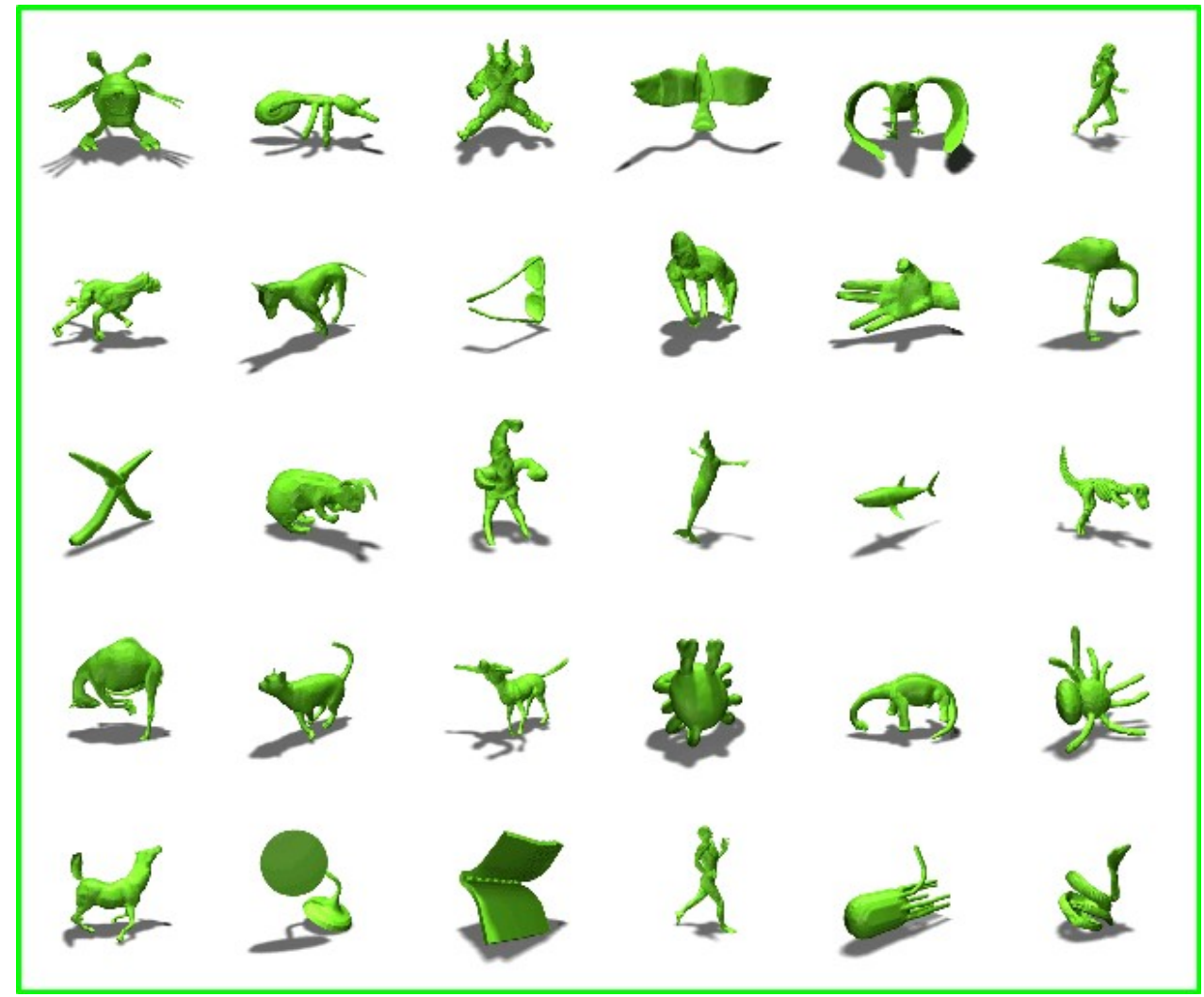

Fonte: Lian et al. (2011). 



\section{CONCEITOS BÁSICOS}

Neste capítulo apresentaremos al guns conceitos básicos para melhor entendimento dessa dissertação de Mestrado. Entre tais conceitos estão as características estudadas e as medidas utilizadas. Cada característica a ser apresentada é invariante à isometria e possuem diferentes vantagens a serem exploradas na área de recuperação de informação. Uma anal ogia pode ser feita com as feições humanas que permitem diferenciar pessoas uma das outras: apesar das feições serem diferentes, ainda é possível identificá-lo.

Além do conjunto de características a serem apresentadas, as medi das escol hi das também formam a base desse trabal ho. Em nosso contexto, apresentaremos diferentes medidas utilizadas em modelos estatísticos para mensurar a si milaridade entre duas séries temporais di stintas. Para melhor anál ise da efetividade dessas medi das, apresentaremos ainda meios de aval iação que servem como referência para comparação de trabal hos na área de recuperação de informação.

\subsection{Descritores de objetos tridimensionais}

Um dos grandes desafios na área de recuperação de informação é a escol ha de bons descritores e assinaturas. Espera-se que sejam capturados propriedades capazes de distinguir objetos pertencentes a diferentes classes. Em geral espera-se que os descritores possuam as seguintes propriedades (ABDELRAHMAN; EL-MELEGY; FARAG, 2012):

1. Invariância à isometria: objetos isométricos devem possuir o mesmo descritor, independente de sua posi ção no espaço;

2. Invariância à escal a: diferentes tamanhos não devem al terar o descritor;

3. Similaridade: objetos similares devem possuir descritores similares;

4. Eficiência: a complexidade computacional deve ser razoável; 
5. Completude: um descritor deve ser capaz de descrever um objeto por completo.

Para cál culo de características de objetos tridimensionais, é necessário que sua representação computacional esteja na sua forma discretizada. Um objeto tridimensional discretizado pode assumir várias formas, tais como mal ha de triângul os (ou quadriláteros) para superfícies, mal ha de tetraedros (ou hexaedros) para volumes, nuvem de pontos, superfícies paramétricas ou superfícies implícitas. Consideraremos apenas mal has triangul ares para o desenvol vimento dessa Dissertação de Mestrado. Denominamos, então, uma mal ha de triângul os $M=(V ; E ; F)$ em que $V$ representa o conjunto vértices; $E$, o conjunto de arestas; e $F$, o conjunto de faces. Cada vértice $v_{i} \in V$ é representado por suas coordenadas cartesianas no espaço, $v_{i}=\left(x_{i} ; y_{i} ; z_{i}\right)$. As arestas representam uma ligação entre dois pontos, $e_{\mathrm{i}}=\left(v_{\mathrm{j}} ; v_{\mathrm{k}}\right)$, com $v_{j} ; v_{k} \in V$. E as faces podem ser represetadas pelas arestas que as compõem, $f_{i}=\left(e_{j} ; e_{k} ; \Theta\right)$, com $e_{j} ; e_{k} ; \theta \in E$.

\subsubsection{Curvaturas}

O tensor de curvatura é bem conhecido da geometria diferencial para cál cul o de curvaturas em variedades. Entretanto, pode possuir várias interpretações, por ser linear por partes. $O$ que Alliez et al. (2003) propõem é construir um campo tensorial de curvatura que é linear por partes, estimando o val or da curvatura em cada vértice. Para isso se cal cula a curvatura em cada aresta do objeto e em segui da é possível definir os val ores em cada ponto. Dada uma região $B$ arbitrária, podemos real izar a soma de cada parte de B afim de obter o tensor $\mathrm{T}(\mathrm{v})$ :

$$
T(v)=\frac{1}{|B(v)|} \underset{e \in B(v)}{\hat{A}} b(e) w(B(v) ; e) \tilde{e} \otimes \tilde{e} ;
$$

em que temos $v$ representando um vértice arbitrário; $B(v)$ uma região definida por $v$; e uma aresta em $B(v) ;|B(v)|$ sendo a área de $B(v) ; b(e)$ sendo o ângulo com sinal formado pelas normais dos triângul os incidentes à aresta $\mathrm{e}$ (como mostrado na Figura 6$)$; $w(B ; \mathrm{e})$ é uma ponderação feita entre e e $B(v)$ para al iviar o ef eito das aresta que não estão total mente contidas em $B(v)$; ẽ é o vetor unitário com mesma direção de e; e o operador $\otimes$ é o produto tensorial entre dois vetores.

As curvaturas principais podem ser obti das através do espectro do tensor $\mathrm{T}(\mathrm{v})$. A normal no vértice corresponde ao autovetor associado ao autoval or de menor magnitude, enquanto que os demais autovalores são correspondem às curvaturas mínima e máxima, denominados $\mathrm{k}_{\text {min }}$ e $k_{\max }$, respectivamente. Val e ressal tar que a magnitude dos autoval ores é invertida: o menor autoval or corresponde à direção da curvatura máxima, e o maior autoval or está associado à direção da curvatura míni ma. As curvaturas gaussianas e médias são obtidas multiplicando e somando-se as curvaturas máximas e mínimas, respectivamente. A implementação foi feita em MATLAB e está presente no pacote Graph Tool box 1 . 
Figura 6 - Região B utilizada para cál culo das curvaturas principais.
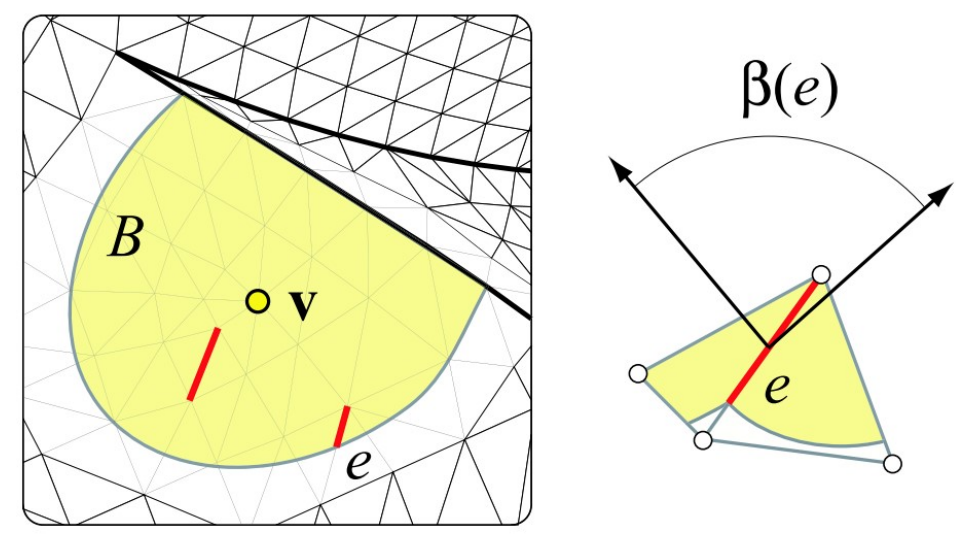

Fonte: Alliez et al. (2003).

\subsubsection{Variação de superfície}

Variação de superfície (do inglês, surface variation) é uma ferramenta utilizada para estimação da curvatura média em nuvem de pontos. Nesses casos não há informação de vizinhança e muitas vezes o ruído presente no objeto impede a medição precisa da curvatura. Pauly, Gross e Kobbelt (2002) e Pauly, Keiser e Gross (2003) foram os introdutores desse conceito. Estenderemos o conceito apresentado pel os autores originais do trabal ho para mal has de triângulos por ser um estrutura com menos vértices e ainda contém a informação de conectividade.

Nessa técni ca é utilizada Anál ise de Componentes Principais (PCA) da vizinhança de um determinado ponto para determinar as características da superfície. Dado um conjunto de pontos $V$ pertencentes a uma mal ha $M$, define-se uma vizinhança $N_{p}$ do ponto $p \in V$ utilizando as informações de vizinhanças inerentes de $M$. Seja $\bar{p}$ o centroide e calcula-se a matriz de covariância $\mathrm{C}$ de $\mathrm{N}_{\mathrm{p}}$ :

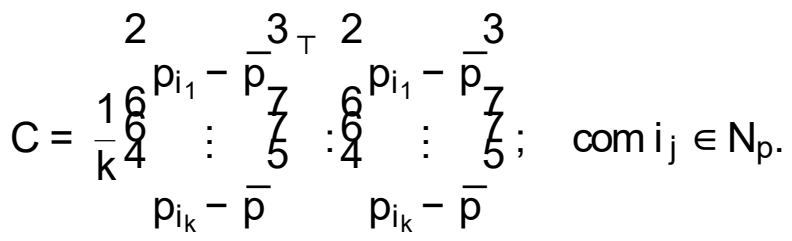

Segundo Pauly, Keiser e Gross (2003), a aproximação para curvatura média no ponto $p, s(p)$ corresponde ao quociente do menor autoval or de $C$ dividido pela soma de todos os autovalores:

$$
s_{n}(p)=\frac{I_{0}}{I_{0}+I_{1}+I_{2}} ;
$$

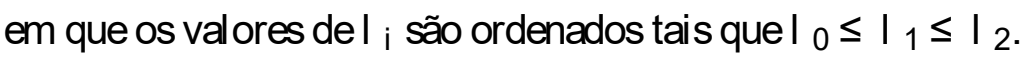

Observe que a variação de superfície é dependente do número de vizinhos escol hidos. Dessa forma, quanto mais vizinhos, menor vai ser a interferência de ruídos. A Figura 7 ilustra a variação dos val ores para diferentes val ores de vizinhança. 
Figura 7 - Variação de superfície variando o número de vizinhos. À esquerda está o modelo original; variação de superfície com 10 vizinhos ao centro; e variação com 50 vizinhos à direita. A cor azul representa menores valores.
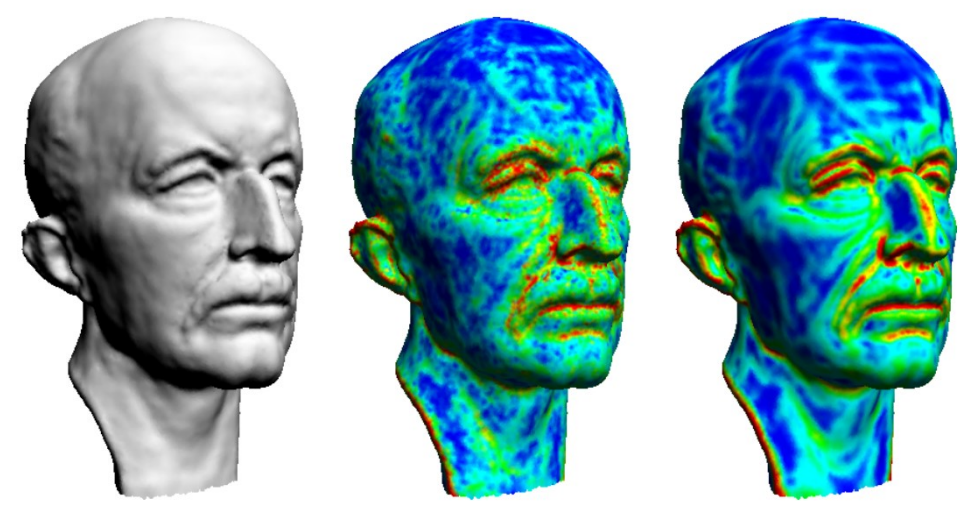

Fonte: Pauly, Keiser e Gross (2003).

\subsubsection{Vetor de Fiedler}

O vetor de Fiedler é uma característica que define a conectividade da mal ha, ou seja, como os vértices estão conectados entre si. É possível utilizar essa informação como uma forma de ordenação dos vértices, organizando os dados como uma série. Além de ser invariante à isometria, ele aplica uma transformação na ordem das características, permitindo assim a utilização de medi das semel hantes às utilizadas em métricas temporais.

Dada uma variedade $M$ com métrica Ri emanniana e seja uma função de val ores reai s e classe $C^{2}$ definida sobre M . O operador de Laplace-Beltrami D é definido como:

$$
\operatorname{Df}=\operatorname{div}(\operatorname{grad}(f)) \text { : }
$$

E o problema de autofunções do Laplaciano se torna Df $=-I f$ :

Para cal cul armos os autoval ores, defini remos uma matriz Laplaciana discreta. Dado uma mal ha M como definido no começo deste capítulo, considere $\mathrm{N}(\mathrm{i})$ o conjunto de vizinhos do vértice i. Defini remos uma matriz de adjacência ponderada A como sendo:

$$
W_{i j}=\stackrel{8}{<} w_{i j} \quad(i ; j) \in E
$$

ea matriz diagonal $V$ tal que $V_{i i}=v_{i}$, com $v_{i}=\hat{A}_{j \in N(i)} W_{i j}$. Define-se então uma matriz de rigidez $A=V-W$ e uma matriz diagonal de massas $D=\operatorname{diag}\left(d_{1} ; \cdots ; d_{n}\right)$, com cada $d_{i}$ representando uma massa associada ao vértice $i$. $A$ matriz $L$ aplaciana, então, é definida como sendo $L=D^{-1} A$.

Uma escol ha simples para os pesos $w_{i j}$ e para as massas $d_{i}$ são val ores unitários: $w_{i j}=1$ se existe ligação de i para j e 0 caso contrário; e $d_{i}=1$. Nesse caso, a matriz $L$ se torna a matriz Laplaciana topológica e provê informações de conectividade, mas não de geometria da mal ha. Essa matriz é muito estudada em teoria dos grafos (CHUNG, 1997) por apresentar propriedades 
Figura 8 - Ângulos utilizados para cál culo dos pesos cotangentes na matriz Laplaciana. Em cinza é a área de Voronoi do vértice i.

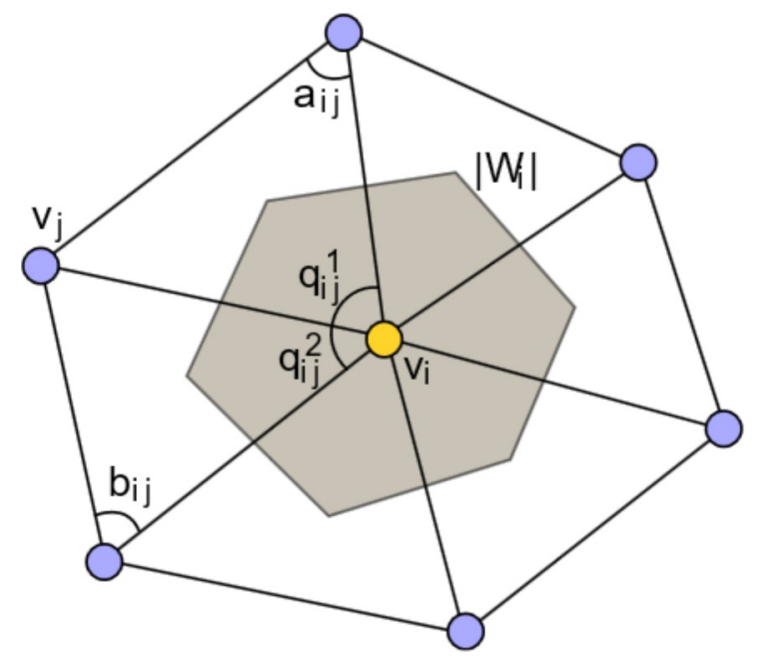

Fonte: Adaptada de Sorkine (2006).

al gébricas rel acionadas às propriedades combinatoriais do grafo. Uma abordagem para inserir a informação de geometria ao operador é utilizando pesos cotangentes (PINKALL; POLTHIER, 1993):

$$
w_{i j}=\frac{\cot \left(a_{i j}\right)+\cot \left(b_{i j}\right)}{2} ;
$$

em que $a_{i j}$ e $b_{i j}$ são os ângul os opostos da aresta $\left(v_{i} ; v_{j}\right)$, como mostra a Figura 8. Desbrun et al . (1999) refinaram essa definição modificando, também, a matriz de massas:

$$
\mathrm{d}_{\mathrm{i}}=\left|\mathrm{W}_{\mathrm{i}}\right|
$$

em que $\left|W_{i}\right|$ representa a área de Voronoi do vértice $i$, aproximada como sendo um terço da soma das áreas dos triângul os adjacentes $a v_{i}$.

Com a extração do espectro das matrizes Laplacianas é possível encontrar as informações de conectividade da mal ha. Uma vez que a matriz $L$ é si métrica, positiva e semi-definida, ela possui uma base ortonormal. Sejam os autoval ores denotados por I tal que

$$
0=\mathrm{I}_{0} \leq \mathrm{I}_{1} \leq \cdots \leq \mathrm{I} \mathrm{n}:
$$

Nota-se então que os primeiros autovetores, associados aos menores autovalores, são suaves. Dessa forma, dizemos que o autovetor associado ao primei ro autoval or não nulo l 1 é o vetor de Fiedler. Esse vetor é dito ser solução para um problema NP-difícil de Arranjo Linear Mínimo (do inglês, Minimum Linear Arrangement (MLA)), proposto por (HARPER, 1964), em queo obj etivo é procurar por permutações $p: V \rightarrow\{1 ; 2 ; \cdots ; n\}$ dos vértices de $M$ tal que $\hat{A}_{(i ; j) \in E}|p(i)-p(j)|$ seja mínimo.

Tal vetor apresenta a menor variação possível na mal ha - depois do vetor nulo - e consequentemente podemos associálo a uma ordenação possível dos vértices $V$. Observe na 
Figura 9 - Exemplo de ordenação dos vértices. À esquerda está uma ordenação arbitrária, possivel mente como é dada no arquivo da mal ha; à direita os vértices estão ordenados pelo vetor de Fiedler.
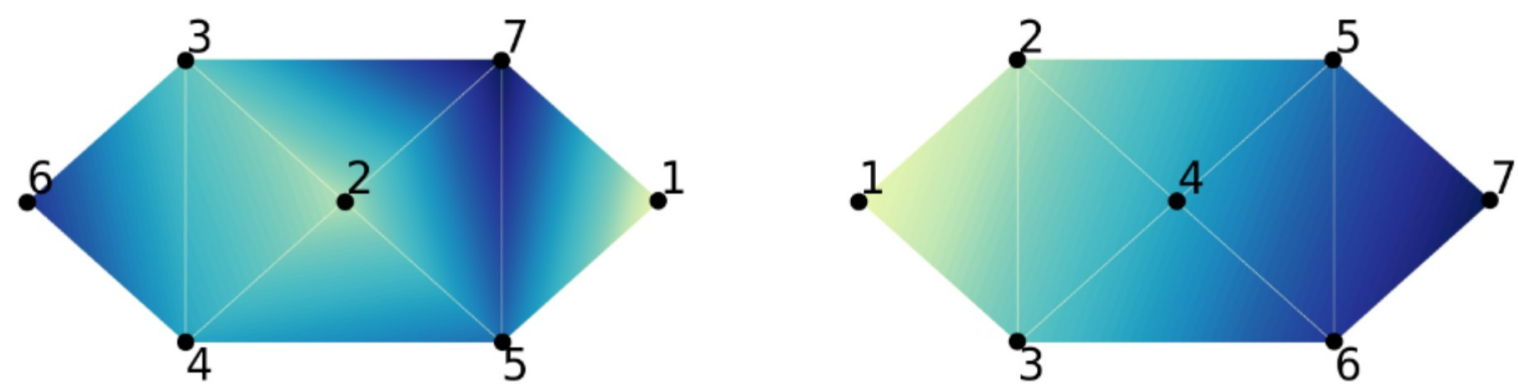

Fonte: Elaborada pelo autor.

Figura 9 um exemplo simples dessa ordenação: inicial mente a mal ha é lida e apresentada conforme os vértices são lidos do arquivo; em segui da, aplicam-se o a ordenação de Fiedler.

Essa informação provida pel o vetor de Fiedl er, extraído da matriz Laplaciana geométrica, permite simular uma ordenação dos vértices e, assim, apl icar medidas de séries em obj etos que natural mente não apresentam essas características. Um ponto a ser destacado que a ordenação em mal has isométricas pode aparecer com o sentido invertido.

\subsubsection{Heat Kernel Signature}

Para definirmos o HKS, é necessário introduzir noções bási cas de difusão de cal or em superfícies tridimensionais. O núcleo de cal or (do inglês, heat kernel) cal cula o fluxo de cal or ao longo da superfície M e é definido para cada ponto sobre M :

$$
D_{\mathrm{M}} u(x ; t)=-\frac{\partial}{\partial t} u(x ; t):
$$

Observe que $\mathrm{D}_{\mathrm{M}}$ denota o operador de Laplace-Beltrami . A função $\mathrm{u}(\mathrm{x} ; \mathrm{t})$ representa a solução da equação de cal or com condições iniciais $u(x ; 0)=u_{0}(x)$. Sendo $x$ e y dois pontos da superfície, $\operatorname{para~}_{0}(x)=d(x-y)$ em que

$$
\mathrm{d}(\mathrm{x}-\mathrm{y})=\begin{array}{ll}
<^{<} 0 & \text { se } \mathrm{x} / \mathrm{y} \\
: & \text { caso contrário }
\end{array}
$$

é a função del ta de Dirac, que satisfaz

$$
\stackrel{Z_{+}}{Z_{-}} d(x-y) \quad d x=1
$$

dizemos que a solução da Equação 3.7 é chamada núcleo de calor e é denotado por $k_{t}(x ; y)$. Para uma superfície $\mathrm{M}$, definimos:

$$
k_{t}(x ; y)=\hat{A}_{i=0}^{n} e^{-l_{i} t} f_{i}(x) f_{i}(y)
$$


em que $\mathrm{I}_{\mathrm{i}}$ e $\mathrm{f}_{\mathrm{i}}$ correspondem ao i-ésimo autovalor correspondente ao i-ésimo autovetor do operador de Laplace-Bel trami que satisfazem $D_{M} l_{i}=f_{i} l_{i}$.

Com a definição de núcleo de calor, passamos a definir um assinatura do núcleo de calor (Heat Kernel Signature). Dado um ponto x na malha tridimensional $M$, definimos o HKS: $\mathrm{R}^{+} \rightarrow \mathrm{R}$ como sendo uma função do domínio temporal:

$$
\operatorname{HKS}(x ; t)=k_{t}(x ; x)
$$

Dessa forma, o HKS passa a ser uma função apenas do tempo e do ponto de interesse. Com isso é possível eliminar problemas de redundância provenientes do núcleo de calor e evitar comparações desnecessárias entre assi naturas de mal has e pontos. Além disso, Sun, Ovsjanikov e Gui bas (2009) apresentaram uma prova de que essa característica é tão informativa quanto o núcleo de cal or, apesar de ser bem menos complexa. E por se tratar de uma derivação deste, o HKS é capaz de herdar as propriedades do heat kernel, tais como ser intrínseco, robusto e de multi-escala.

O cál cul o numérico do núcl eo de cal or é feito através do operador di screto geométrico de Laplace-Bel trami apresentado anteriormente. Cada objeto tridimensiona é avaliado no interval o logarítmico de tempo $t=\left[t_{\min } ; t_{\max }\right]$.

\subsection{Descritores de séries temporais}

Uma descrição para séries temporais pode ser dada como: observações capturadas em sequência ao longo do tempo, geralmente ocorrendo em interval os regulares. Vale ressaltar que, para essas observações, a ordem é essencial, ao contrário do que acontece com dados de regressões lineares, por exemplo. O principal interesse nesse tipo de observação temporal éa anál ise da dependência dos dados e como isso influencia a série como um todo.

Ao se observar dados ao longo do tempo, muitas vezes não é visível a relação que está agregada. Devido a essa dificul dade tem se utilizado de ferramental estatístico para se descrever o comportamento da séries temporais. Várias medidas são si mples, tais como média, mediana e frequência. Entretanto, para séries mais compl exas, tais como séries financeiras e áudio, a utilização de ferramentas mai s sofi sticadas se faz necessário.

Nessa seção apresentaremos a princi pal ferramenta utilizada nesse trabal ho de mestrado, denominada Scattering wavel ets. Por se tratar de uma ferramenta nova e seu uso ser inédito na área de processamento geométrico, sua escol ha pode não parecer intuitivo a princípio, mas ao se simular a ordenação das características dos objetos tridimensionais, é possível encontrar bons resultados. A principal vantagem apresentada por essa técnica é manter a relação temporal das amostras, ao contrário do que acontece com a transformada de Fourier, por exemplo. 


\subsubsection{Scattering Wavelets}

Como principais extratores de características de séries temporais pretendemos analisar e utilizar a técnica de scattering wavelets (ANDÉN; MALLAT, 2011; ANDÉN; MALLAT, 2012; CHEN; RAMADGE, 2013). Tal técnica é bem recente e possui propriedades importantes, tais como análise de al tas frequências sem muita perda de informação e a capacidade de manter a informação temporal. Dessa forma será possível anali sar a sequência ordenada obtida anteriormente de uma maneira mais precisa.

Essa técni ca consegue caracterizar o sinal através de várias frequências defini das por um banco de filtros wavel et (como apresentado na Figura 10), através de repeti das aplicações do filtro. Na Figura 11 é possível se ter uma ideia de como a técnica funciona: o sinal x é submetido ao banco de filtros e gera um resultado. O sinal que seria descartado é então processado novamente para que se obtenha um segundo conjunto fil trado e assi m sucessivamente. O resul tado é capaz de recuperar informações de al tas frequências ao mesmo tempo que é estável a deformações do sinal. Em termos matemáticos, dado um banco de filtros wavel ets definidos por $\left\{y_{\mid}\right\}_{\mid} \in L$, em quel é o centro do filtro, a transformada wavelet é definida convoluindo $x \operatorname{com}$ os filtros $W_{x}(t)$, definidos na Equação 3.10, em que f representa o fil tro passa baixa cobrindo interval os de baixa frequência não coberto pelas demais wavel ets.
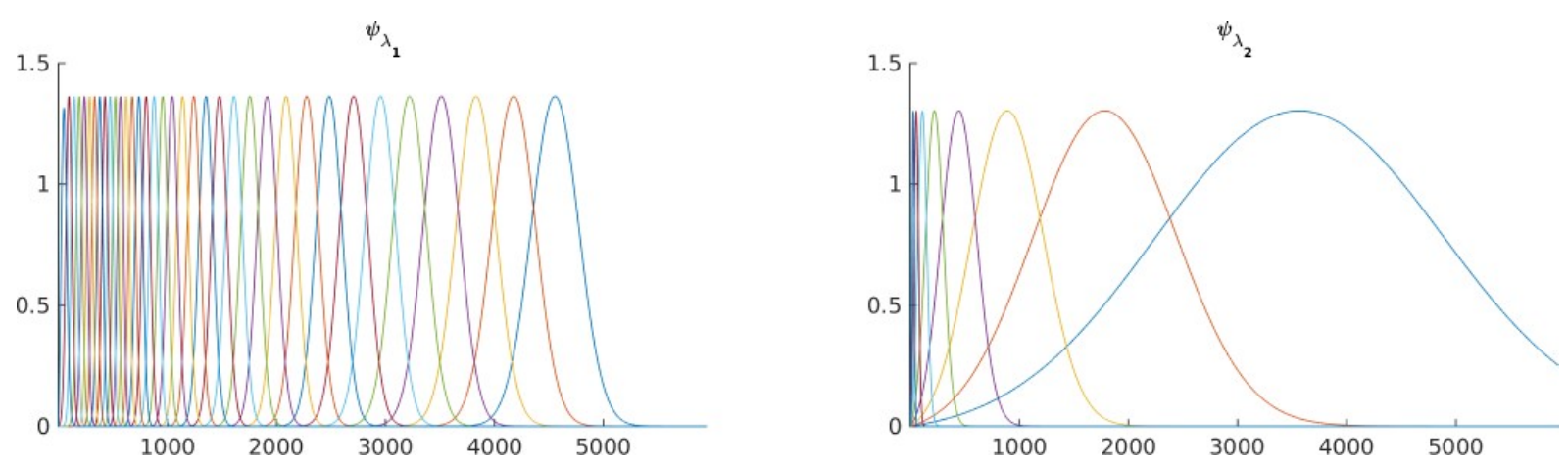

Figura 10 - Banco de filtros utilizado para dois níveis do Scattering Wavelets. No eixo das abscissas, a frequencia.

$$
W_{x}(t)=\begin{aligned}
& x ? f(t) ! \\
& x ? y_{I}(t) \quad \mid \in L
\end{aligned}
$$

Então cal cula-se o módulo e toma-se a média no tempo, como na Equação 3.11

$$
\left|x ? y_{1}\right| ? f(t)
$$

Entretanto, com essa representação, ocorre perda de informações espectrais não estacionárias, tais como transientes, ou seja, picos na frequência. Para recuperar a parte da informação 
Figura 11 - Imagem ilustrativa do funcionamento da técnica Scattering Wavelets

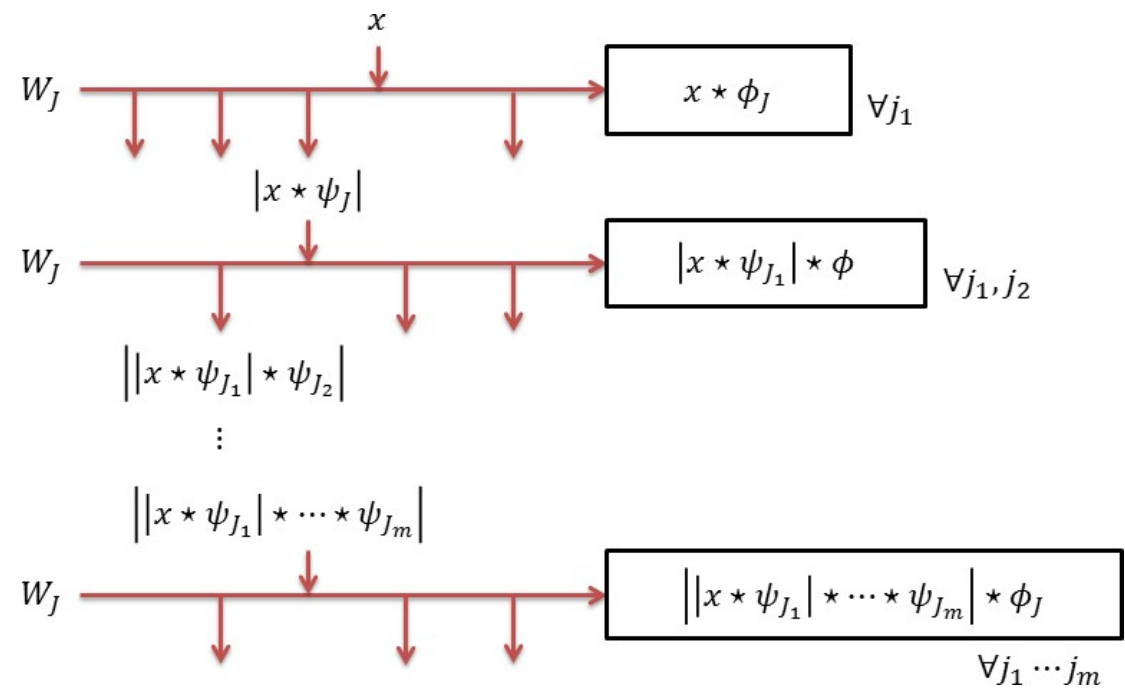

Fonte: Elaborada pelo autor.

perdida, real iza-se decomposi ções adicionai s cascateando o mesmo operador, ou seja, aplicandose o fil tro novamente, como mostrado na Equação 3.12 .

$$
W_{\left|x ? y_{I_{1} \mid}\right|}(t)=\underbrace{}_{\left|x ? y_{I_{1}}\right| ? f(t)} !
$$

Dessa forma, a informação perdida na convolução de x com $f$ etá contida nos coeficientes ||$x ? y_{\mathrm{I}_{1}} \mid$ ? $\mathrm{y}_{\mathrm{I}_{2}}(\mathrm{t}) \mid \mathrm{ff}(\mathrm{t})$. Anal ogamente, é possível aplicar recorrentemente o operador nos demais coeficientes, obtendo um cascateamento de wavelets.

Além disso, pela técnica oferecer o resul tado por meio de coeficientes obtidos através de janelas temporais, é possível criar grupos de vértices para serem analisados, diminuindo assim, o processamento de grande quantidade de dados. Na Figura 12 são apresentados os coeficientes de primeira e segunda ordem obtidos, em forma de imagem. Observe que no eixo vertical encontram-se os coeficientes e o eixo horizontal éo eixo do tempo. Cada cél ula na figura corresponde a uma janel a temporal .

Como medida entre os coeficientes obtidos pretendemos utilizar o técnica de correl ação cruzada, vinda da estatística. Essa medida permite mensurar a si milaridade entre duas séries temporais. Utilizaremos os coeficientes obtidos com a técnica scattering wavel ets como uma série temporal . É possível observar que a correlação cruzadaindepende do tamanho das séries, podendo ambas serem de tamanhos diferentes. Então será possível anali isar mal has que possuam números de vértices também distintos. Dessa forma será possível obter uma medida de dissimilaridade entre duas mal has triangulares distintas. 
Figura 12 - Exemplo de coeficientes obtidos através da técnica Scattering wavelets. Cada linha representa uma frequencia; e cada coluna, uma janela da série. A figura a representa o resultado após a aplicação dos filtros, enquanto que a figura b é a aplicação dos filtros no resíduo produzido por a.

(a)

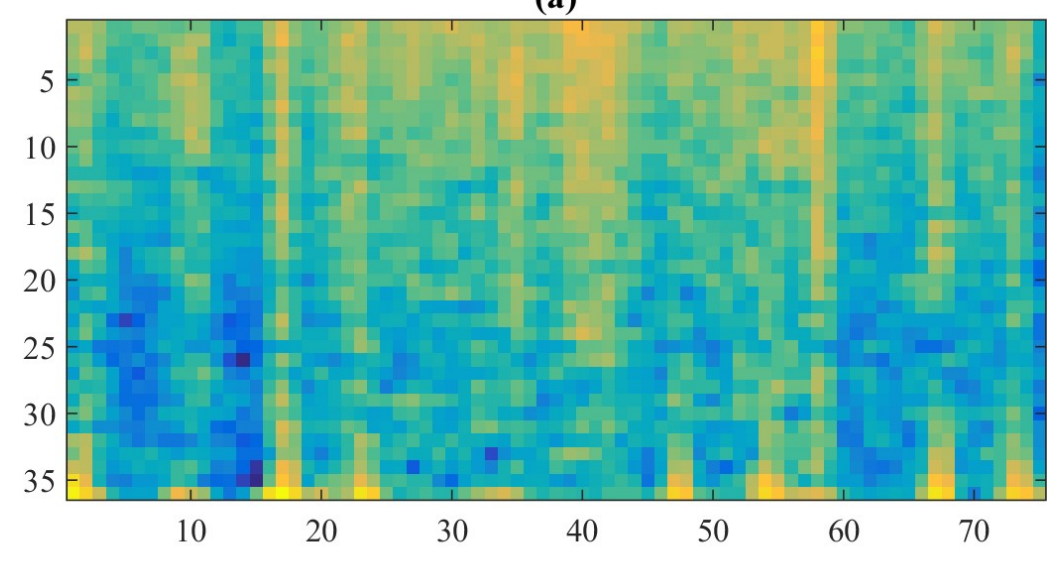

(b)

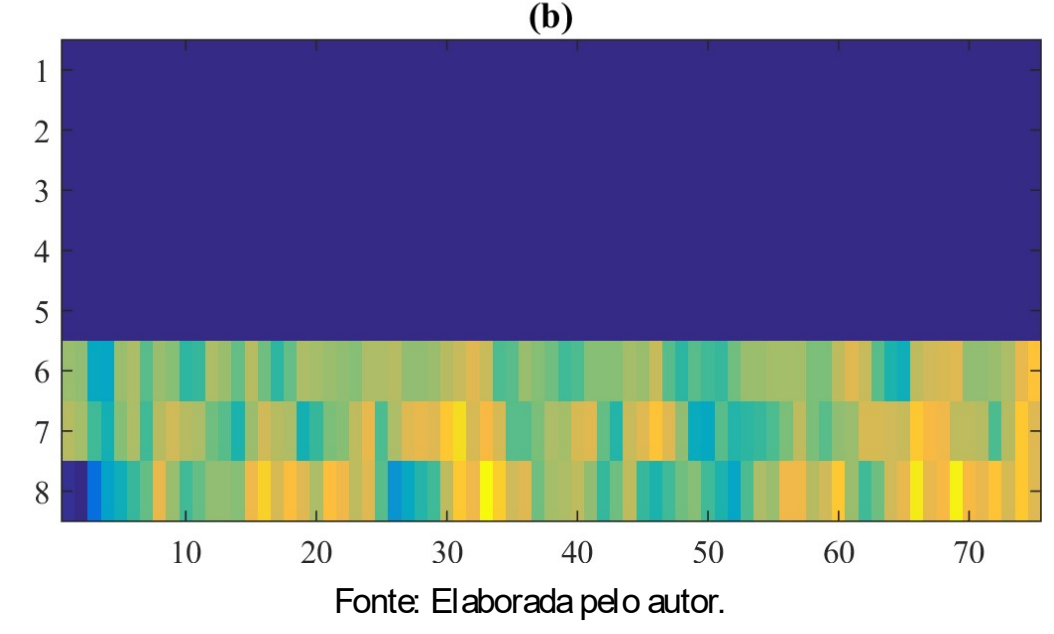

\subsection{Medidas de dissimilaridade}

A comparação de dois objetos - tridimensionais, imagens, sinais temporais - é um passo importante para recuperação de informação. Na maioria dos casos, uma comparação direta não é possível. Na perspectiva de objetos tridimensionais, isso ocorre por vários motivos: pelo tamanho dos dados; fal ta de correspondência entre os pontos; semânticas diferentes, entre outros. Para amenizar e facilitar os passos de comparação, são extraídos características (como as apresentadas anteriormente nesse capítulo) capazes de descrever uni camente o objeto. Como foi apresentado, as características dos objetos tridimensi onais são transformadas com o intuito de simular uma dependência temporal nos dados. Ao longo dessa seção apresentaremos al gumas medidas utilizadas em anál ise estatística de séries temporais para se comparar esses vetores ordenados. 


\subsubsection{Correlação cruzada}

Correlação cruzada é uma ferramenta estatística utilizada para medir a similaridade entre duas séries temporais distintas em função de um atraso apl icado a uma das séries (CHATFIELD, 2003, Capítulo 8). Ou seja, uma das séries é deslocada para que se faça as comparações dos val ores. Para caracterizarmos a correlação cruzada é necessário definirmos al guns conceitos.

Suponha $N$ observações sob um mesmo período, ditas $\left(x_{1} ; y_{1}\right) ;:: ;\left(x_{N} ; y_{N}\right)$, de um processo estocástico bivariado $\left(X_{t} ; Y_{t}\right)$. O primei ro e segundo momento desse processo - média e função de auto-covariância, respectivamente - são apresentados como

Média: $E\left(X_{t}\right)=m_{k} e E\left(Y_{t}\right)=m_{y}$;

Auto-covariância: $\operatorname{cov}\left(X_{t} ; X_{t+k}\right)=g_{x}(k) e \operatorname{cov}\left(Y_{t} ; Y_{t+k}\right)=g_{y}(k)$;

Covariância cruzada: $\operatorname{cov}\left(X_{t} ; Y_{t}\right)=E\left[\left(X_{t}-m_{k}\right)\left(Y_{t+k}-m_{y}\right)\right]=g_{x y}(k)$.

Em geral , a dimensão dos coeficientes é af etada pelas grandezas dos processos $X_{t} e$ $Y_{t}$. Então para questões de interpretação do resultado é apropriado normalizar a função de covariância cruzada, gerando desse modo a função de correlação cruzada:

$$
r_{x y}(k)=p \frac{g_{x y}(k)}{g_{x}(0) g_{y}(0)}=\frac{g_{x y}(k)}{s_{x} s_{y}}
$$

em que $s_{x}$ é corresponde ao desvio padrão do processo $X$.

Uma propriedade importante da correl ação cruzada é o fato de seu módulo ser sempre menor ou igual a 1. Nesse caso, correlacionando uma função com ela mesma gerará o val or unitário e quanto mais si milares as séries temporais, mais próximos desse val or a correlação cruzada será apresentada. É importante observar que essa medida não é de distância, porém é facilmente convertível:

$$
d_{r}(x ; y)=1-r_{x y}(k):
$$

\subsubsection{Dynamic Time Warping}

Para comparação da séries temporais e seus respectivos coeficientes, uma das possíveis técnicas a ser utilizada Dynamic Time Warping (DTW) (KEOGH; RATANAMAHATANA, 2005). Tal técnica é baseada em programação di nâmica e possi bilita encontrar similaridades em dados variantes no tempo que possuem deslocamentos temporais. No contexto dos coeficientes de um modelo tridimensional e suas propriedades, é possível encontrar o melhor casamento dos coeficientes. 
Suponha duas séries temporais $\mathrm{Q}$ e $\mathrm{C}$, de comprimentos n e m respectivamente, amostradas arbitrariamente sobre interval os de tempo, possivelmente distintos, em que:

$$
\begin{aligned}
& Q=q_{1} ; q_{2} ;:: ; q_{i} ;:: ; q_{n} \\
& C=c_{1} ; c_{2} ;:: ; c_{j} ;:: ; ; c_{m}
\end{aligned}
$$

O al inhamento das sequências usando o DTW é real izado construindo-se a matriz $\mathrm{n} \times \mathrm{m}$ em que o $(i ; j)$-ésimo elemento da matriz contém a distância $d\left(q_{i} ; c_{j}\right)$ entre dois pontos $q_{i}$ e $c_{j}$. Cada el emento da matriz corresponde ao al inhamento entre os pontos. Observe na Figura 13 um esquema da técnica.

Figura 13 - Esquema de al inhamento e mapeamento de deformação utilizando DTW.

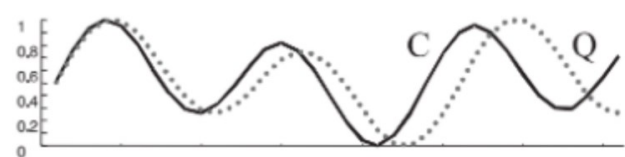

(a) Duas sequências si milares com fases distintas.
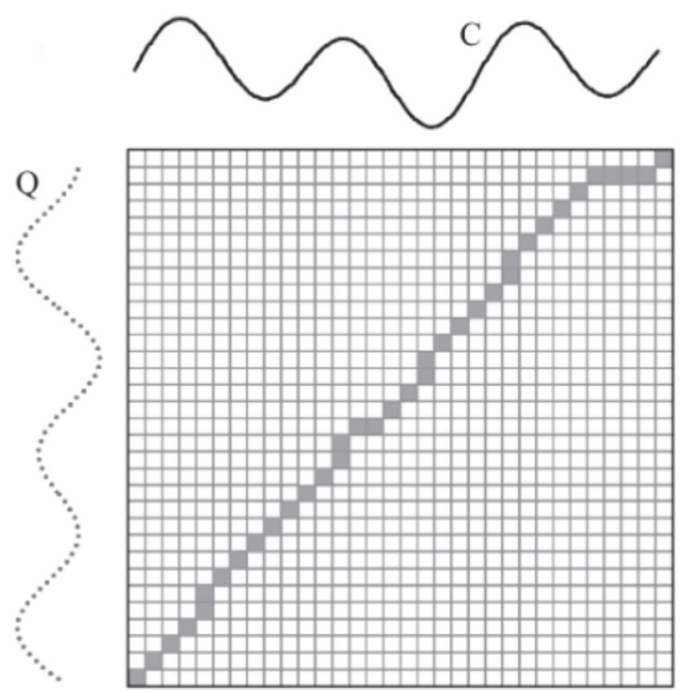

(b) Para o alinhamento, constrói-se uma matriz de deformação e procura-se pelo caminho ótimo, mostrado em mais escuro.

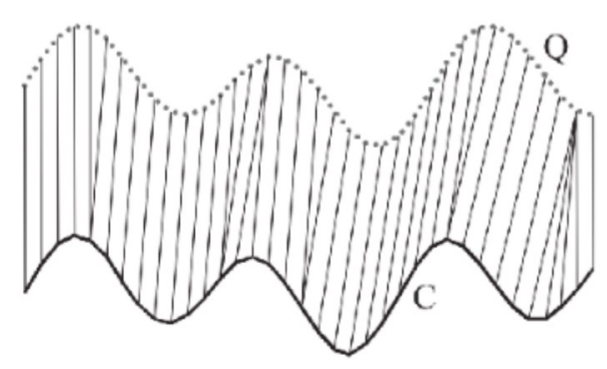

(c) Resultado do alinhamento.

Fonte: Keogh e Ratanamahatana (2005).

O caminho da matriz que corresponde ao mapeamento de $Q$ para $C$ é dito cami nho de deformação $W$, em que o k-ésimo elemento de $W$ é defini do como $w_{k}=(i ; j)_{k}$. Além disso,

$$
W=w_{1} ; w_{2} ;:: ; w_{k} ;:: ; w_{K} ; \quad \text { com } \max (m ; n) \leq K<m+n-1:
$$


O caminho de deformação ainda possui al gumas restrições:

- Condições de bor do: O caminho inicia em $w_{1}=\left(q_{1} ; c_{1}\right)$ e termina em $w_{K}=\left(q_{m} ; c_{n}\right)$, que são as pontas da matriz de distância.

- Continuidade: O caminho deve percorrer células adjacentes, inclusive as diagonais. Dado $w_{k}=(a ; b)$, então $w_{k-1}=\left(a^{\prime} ; b^{\prime}\right)$, em que $a-a^{\prime} \leq 1^{\prime}$ e $b-b^{\prime} \leq 1$.

- Monotonicidade: Isso faz com que os pontos de W sejam igual mente espaçados. Dado $w_{k}=(a ; b)$, então $w_{k-1}=\left(a^{\prime} ; b^{\prime}\right)$, em que $a-a^{\prime} \geq 0^{\prime}$ e $b-b^{\prime} \geq 0$.

Observe que vários cami nhos satisfazem as condi ções acima, entretanto se está interessado apenas no caminho cujo custo de deformação seja mínimo:

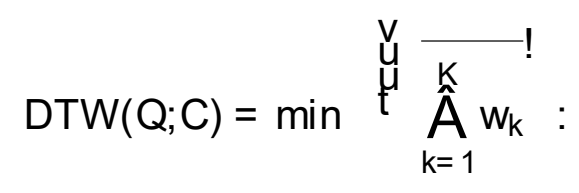

Tal caminho é obtido através de programação dinâmica, aval iando-se a recorrência defini da pela distância cumulativa $g(i ; j)$ :

$$
g(i ; j)=\min (g(i-1 ; j-1) ; g(i-1 ; j) ; g(i ; j-1)):
$$

\subsubsection{Matriz de recorrência}

As medi das de di ssi milari dade apresentadas anteri ormente são boas para um série temporal contínua e que não apresenta quebras. Entretanto, em nosso trabal ho para encontrar similari dades parciais entre dois model os tridimensionais, são real izadas várias segmentações do model o e consequentemente segmentação da série temporal . Isso acarreta em vários problemas para medição da dissi milaridade através do DTW, ou da correl ação cruzada. A técnica apresentada nessa seção, no entanto, é capaz de superar essas dificuldades, por encontrar regiões de equivalência entre duas séries.

O Recurrence Plot (RP) é uma técnica que possi bilita a anál ise de dados não lineares e não estacionários em um sistema dinâmico, ou no nosso caso séries temporais. A extensão para Cross Recurrence Plot (CRP) (MARWAN; KURTHS, 2004) foi feita com a finalidade de comparar estruturas, tais como similaridades, al inhamentos, entre dois sistemas dinâmicos diferentes. Em outras palavras, o CRP cal cula um matriz capaz de mostrar todos os estados equival entes de duas séries temporais diferentes.

Consi dere um sistema dinâmico modelado por d variáveis no instante de tempo t. Se o conj unto de variáveis for suficiente para descrever uma configuração futura do sistema, então 
elas são chamadas variáveis de estado. O vetor formado através do pareamento dessas variáveis pertence a um espaço d-dimensional chamado espaço de fase, que contém todas os possíveis estados do sistema. A evolução das variáveis de estado no tempo forma uma órbita no espaço de fase que caracteriza o sistema e pode ser apresentado para anál ise. A Figura 14 mostra um exemplo da órbita gerado no espaço e sua respectiva matriz de recorrência. Note que as regiões que possuem o mesmo estado estão bem representados na matriz pelas linhas diagonais.

Figura 14 - Na imagem da esquerda está a órbita gerada pelo sistema de Lorenz, em que regiões com os pontos escuros estão próximos e são considerados recorrentes, enquanto que o ponto branco não. À direita, a matriz CRP resul tante da auto-recorrência, em que as regiões escuras representam pontos semelhantes no sistema original.

A

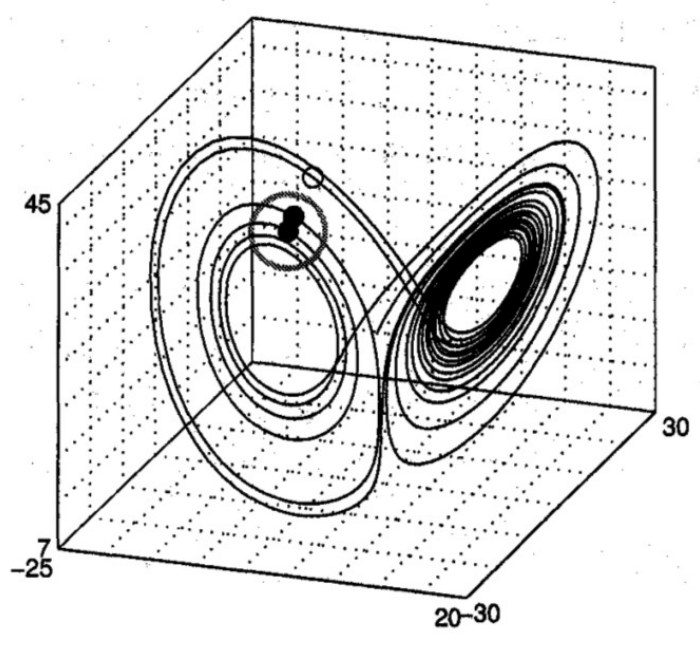

B

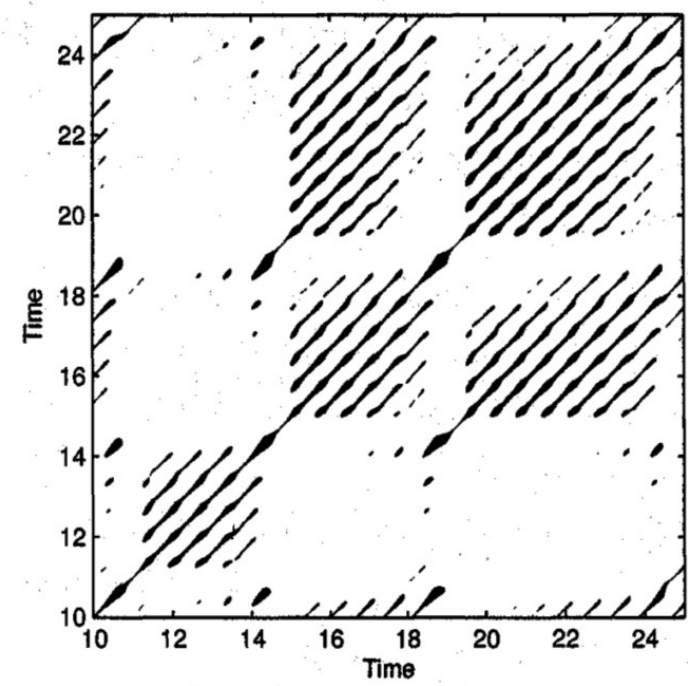

Fonte: Marwan e Kurths (2004).

Em aplicações reais, nem todas as variáveis de estado são conhecidas ou não podem ser mensuradas. Portanto, de acordo com os estudos real izados na área, o espaço de fase de uma série temporal multidimensional $x=\left\{x_{h ; i}\right\}$ pode ser reconstruído utilizando a dimensão de projeção m e um atraso temporal $t$ :

$$
x=\left\{x_{i}\right\} ; \quad \text { com } \quad i=1 ; 2 ; \cdots ; W-(m-1) t ;
$$

em queW representa o número de amostras e

$$
\begin{aligned}
& x_{i}=\left(x_{1 ; i} ; x_{1 ; i+t} ;::: ; x_{1 ; i+(m-1) t} ;::: ;\right. \\
& \mathrm{x}_{2 ; \mathrm{i}} ; \mathrm{x}_{2 ; \mathrm{i}+\mathrm{t}} ;:: ; \mathrm{x}_{2 ; \mathrm{i}+(\mathrm{m}-1) \mathrm{t}}, \ldots: ; \text {; }
\end{aligned}
$$

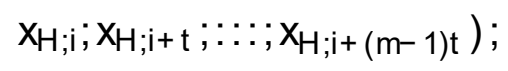

com $\mathrm{H}$ sendo o número de dimensões da série temporal multidimensional.

Mais ainda, o espaço de fases reconstruído a partir de um espaço de fase desconhecido, projetado no $R^{d}$ preserva estruturas topológicas do espaço de fases original se $m \geq 2 d+1$. 
A escol ha dos parâmetros $m$ e t são feitos utilizando estimadores tais como Fal se Nearest Neighbors, e Mutual Information (KANTZ; SCHREIBER, 2004). Nesse trabal ho, os parâmetros utilizados foram $m=5$ et $=1$.

Um espaço de fase reconstruído, em geral, possui uma dimensão maior que três, não sendo possível a visual ização dos estados e trechos em que a série é recorrente. O CRP, no entanto, resolve esse problema cruzando uma matriz bi narizada R a partir do espaço de fase m-dimensional . Cada entrada $r_{i j}$ possui val or 1 se o estado i está próximo do estado j. A Equação 3.19 apresenta em termos matemáticos a intuição apresentada anteriormente. Na equação, q representa uma função degrau (função Heaviside), $e_{i}^{x}$ e e são limiares e a é uma medi da de dissimilaridade.

$$
r_{i j}=q\left(e^{x}-\left\|x_{i}-y_{i}\right\|_{a}\right) q\left(e_{j}^{y}-\left\|x_{j}-y_{j}\right\|_{a}\right)
$$

Para aval iar a qual idade das matrizes geradas pelo CRP, várias técni cas foram desenvolvidas na literatura para avaliação automática, chamadas Análise Quantitativa de Recorrência (RQA) (do inglês, Recurrence Quantitative Anal ysis). Essas técnicas cal culam o comprimento das diagonais que são formadas nas matrizes. Nesse trabal ho utilizamos a medida $S_{\max }$, que mede o comprimento máximo do CRP, levando em consideração possíveis variações temporais. O $S_{\max }$ pode ser cal culado como maior valor da matriz $S$, definida como $S_{1 ; j}=S_{2 ; j}=S_{; ; 1}=S_{2}=1$ e mostrado na Equação 3.20.

$$
s_{i j}=\begin{array}{ll}
<_{\max }^{8}\left\{s_{i-1 ; j-1} ; s_{-2}-j-1 ; s_{i}-1 ; j-2\right\}+1 & R_{i j}=1 \\
0 & R_{i j}=0
\end{array}
$$

\subsection{Métodos de avaliação}

A pesar da grande variedade de técni cas propostas e bases de objetos disponi bilizados, poucos métodos de avali iação são apresentados na literatura. Um meio de aval iação que recebeu muita atenção dos pesqui sadores é o Benchmark de Princeton (SHILANE et al., 2004). Além de disponibilizar uma base de objetos com cerca de 1800 model os representados por mal has de triângul os, ainda apresenta uma série de ferramentas estatísticas para efetuar a val idação e avaliação das técni cas propostas.

A anál ise real izada pel o benchmark é padronizada em relação aos resul tados dos experimentos, gerando medidas de aval iação qual itativas e quantitativas para cada base em que o método a ser avaliado foi executado. Esse método de avaliação leva em consideração que a base possui $\mathrm{N}$ classes distintas. Denotamos por $\mathrm{C}_{n}$ cada classe, com $n=1 ; 2 ; \ldots ; \mathrm{N}$, e $\left|\mathrm{C}_{n}\right|$ corresponde ao número de el ementos em cada uma.

Dentre as medidas qual itativas são apresentados as seguintes: 
- Gráficos de precisão-revocação: um gráfico apresentando a relação entre a precisão e a revocação. Para cada model o de pesqui sa na classe $\mathrm{C}_{n}$, revocação (eixo das abscissas) corresponde à razão dos modelos da classe $C_{n}$ que foram recuperados nas primeiras $\mathrm{K}$ correspondências; e precisão (eixo das ordenadas) indica a razão das primeiras $\mathrm{K}$ correspondências que são da classe $C_{n}$. Exemplo de um gráfico de precisão-revocação na Figura 15.

Figura 15 - Exemplo de um gráfico de precisão-revocação

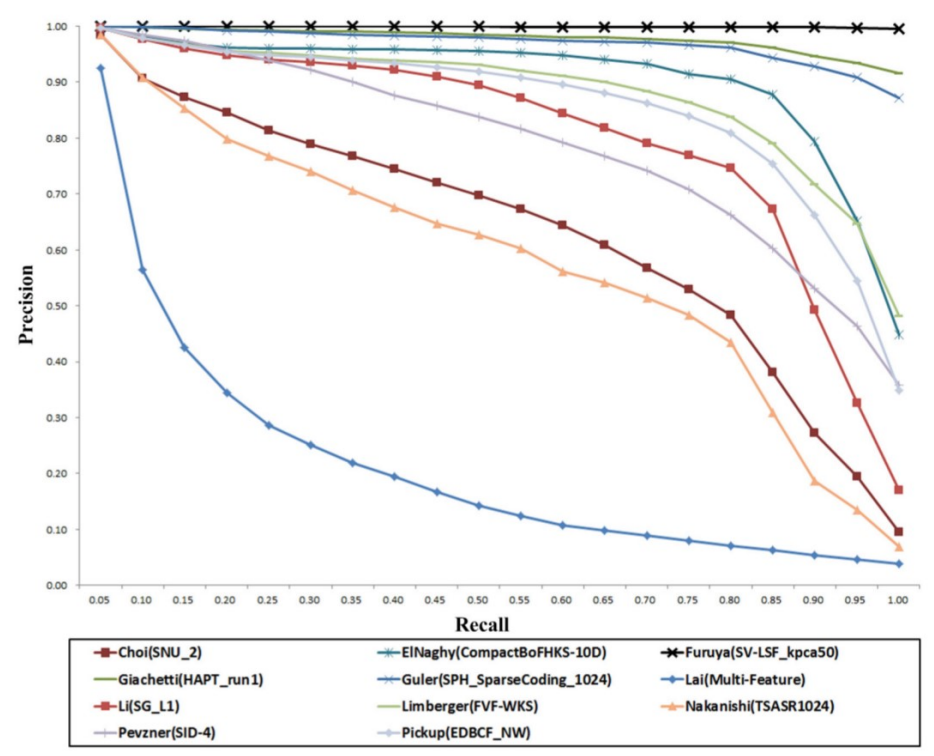

Fonte: Lian et al. (2015).

- Imagens-distância: representado como uma imagem em forma de matriz, em que a magnitude da distância de dois objetos corresponde à intensidade do brilho do pixel. Exemplo de uma imagem distância na Figura 16, onde blocos de classes são facil mente distinguíveis pixels mais claros representam instâncias mais semel hantes.

- Imagem-camada: representa uma imagem visualizando os vizinhos mais próximos, primeira e segunda camadas de cada objeto. Cada camada contém $|\mathrm{C}|$ correspondências, sendo $|C|$ o tamanho da classe em questão. Exemplo de uma imagem-camada pode ser visto na Figura 17, onde os pixels pretos da diagonal são os vizinhos mais próximos; os vermelhos representam a primeira camada e o azuis, a segunda camada.

Observe que tais medidas são apresentados como forma de imagem e sua visual ização é capaz de auxiliar na aval iação das técnicas. Outras medi das capazes de confirmar a intuição obtida nas medidas qual itativas são as medidas quantitativas. Em geral os val ores apresentados são uma média de todos os model os testados, média por classe e uma média de todos os modelos avaliados. 
Figura 16 - Exemplo de uma matriz de distância.

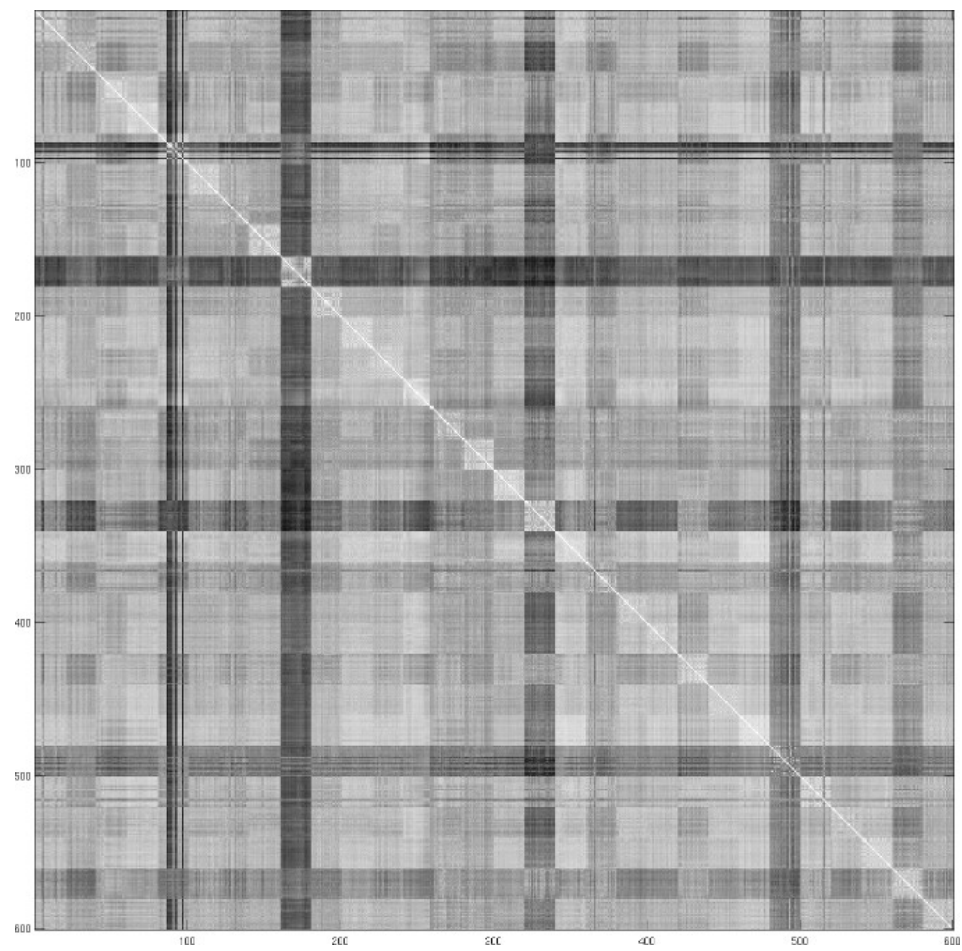

Fonte: Elaborada pelo autor.

Figura 17 - Exemplo de uma imagem camada. Os pixels pretos representam os vizinhos mais próximos; em vermelho, a primeira camada; e em azul, a segunda camada

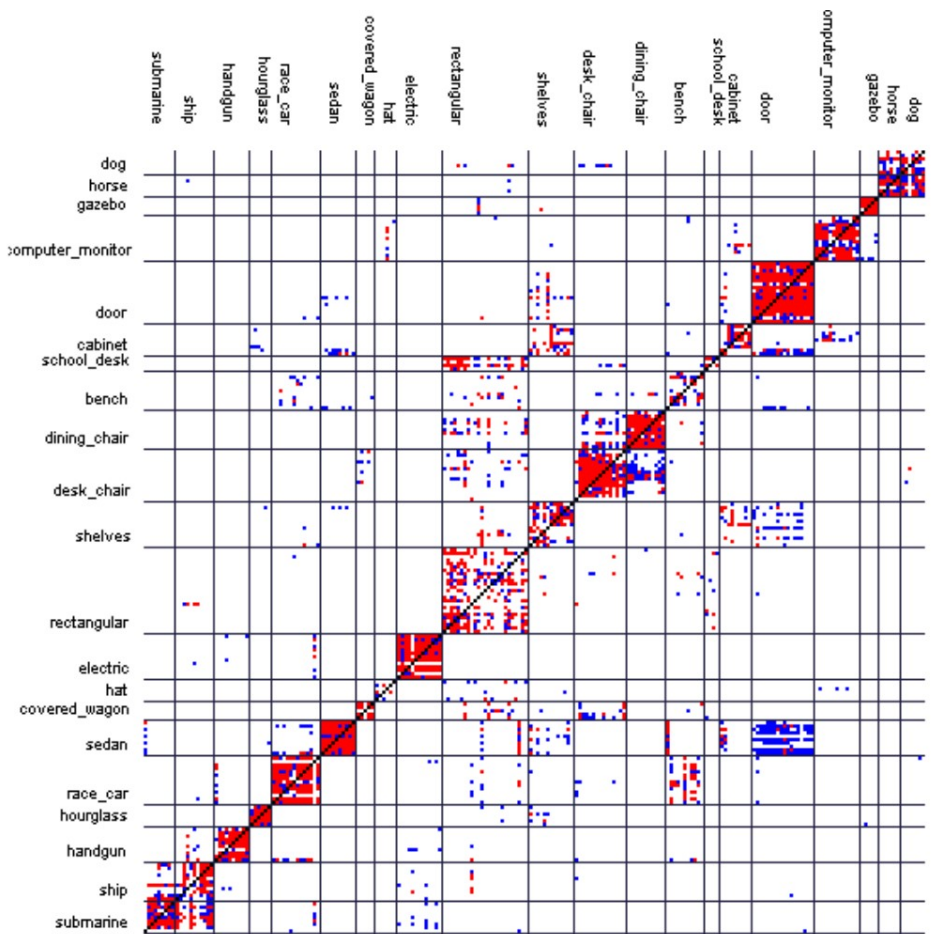

Fonte: Shilane et al. (2004). 
- Vizinho mais próximo: porcentagem do modelo mais similar recuperado que pertence à mesma classe do model o de entrada.

- Primeira e segunda camada: corresponde à porcentagem dos modelos da classe de consul ta que aparecem nas primei ras $\mathrm{K}$ correspondências e esse val or varia de acordo com o tamanho da cl asse. Para uma classe com $|\mathrm{C}|$ objetos, $\mathrm{K}=|\mathrm{C}|-1$ para a primeira camada eK $=2 *(|C|-1)$ para a segunda camada.

- Medida E: apresenta uma medida composta de preci são $P$ e revocação R para um número fixo de resul tados recuperados, levando em consi deração que os resultados mais relevantes são os que são mais semel hantes. Essa medi da é defini da como apresentado por Rijsbergen (1975), Leifman et al. (2003):

$$
E=\frac{2}{\frac{1}{P}+\frac{1}{R}}:
$$

- Ganho Cumulativo Descontado (DCG): os resul tados corretos mais próximos do modelo de entrada recebem pesos mai ores do que os que são retornados como menos similares. Para cada model o de entrada é criado uma lista ordenada R que é converti da para umalista G. Cada elemento i da lista $G, G_{i}$, possui val or 1 se o el emento $R_{i}$ está na classe correta e 0 caso contrário. ODCG é definido como

$$
D C G_{i}=G_{1}+\underset{j=2}{\hat{A}} \frac{G_{i}}{\log _{2}(j)}:
$$

O fator $\log _{2}(i)$ serve para atribuir mai or pesos aos el ementos mais si milares. Esse resultado, então, é dividido pelo val or que seria al cançado caso todos os primeiros $|\mathrm{C}|$ el ementos estivessem na classe correta - resul tado ideal. O val or final obtido com essa medida é portanto dado por

$$
D C G=\frac{D C G_{k}}{1+\hat{A}_{j=2}^{|C|} \frac{1}{\lg _{2} j}} ;
$$

em que k é o número de model os no banco de dados.

Dessa forma é possível analisar a técnica desenvolvida através de várias medidas de aval iação. Além disso, por ser consi derado um modelo de referência, essas medidas são utilizadas em vários outros trabal hos, facilitando a comparação de técnicas diferentes. Entretanto, vale ressal tar que por serem medidas queaval iam apenas através da medida de di ssi milaridade, ou seja, o resul tado final da técnica, não é possível, por exemplo, efetuar comparações de performance. A compl exidade e tempo de execução das técnicas não é levado em consideração nas medi das apresentadas. 
CAPÍTULO
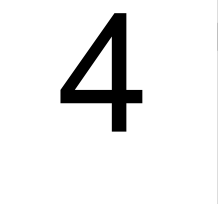

\section{MÉTODO PARA RECUPERAÇÃO OBJETOS}

A recuperação de objetos visa encontrar objetos que são visual mente semel hantes. Para isso busca-se por características que são invariantes a diversas transformações, sejam elas rígidas ou não-rígidas.

Nesse capítul o apresentaremos a metodol ogia utilizada nessa dissertação de mestrado para a comparação e recuperação de objetos si milares. Também serão apresentados a forma como são ordenados os vértices e suas características. Também apresentamos as diferenças obtidas por diferentes características e como isso afeta o método desenvol vido nesse projeto.

\subsection{M étodo}

O desenvolvimento do método utiliza de quase todo o ferramental apresentado no Capítulo 3. Na Figura 18 apresentamos uma ilustração dos passos a serem seguidos para a recuperação de objetos: escol ha de um objeto de entrada; ordenação dos vértices; extração das características; e comparação com toda a base. A seguir estão apresentados os detal hes de cada passo do método.

A partir de um objeto chamado de busca - ou, do inglês, query - procura-se por objetos que sejam visual mente semelhantes na base que foi escol hida. No caso desse trabal ho, utilizaremos a base SHREC $2011^{1}$ de objetos não rígidos. Esse banco de objetos foi escol hido por possuir várias classes (30 classes) com uma quantidade suficiente de model os em cada classe (20 model os por classe). Além disso as cl asses apresentadas são bem distintas entre si . Para o nosso problema, um elemento da base foi escol hido para que fosse tomado com query, entretanto, 0 processamento poderia ter si do real izado com um objeto externo à base. 
Figura 18 - Pipeline empregado para a recuperação de objetos tridimensionais.

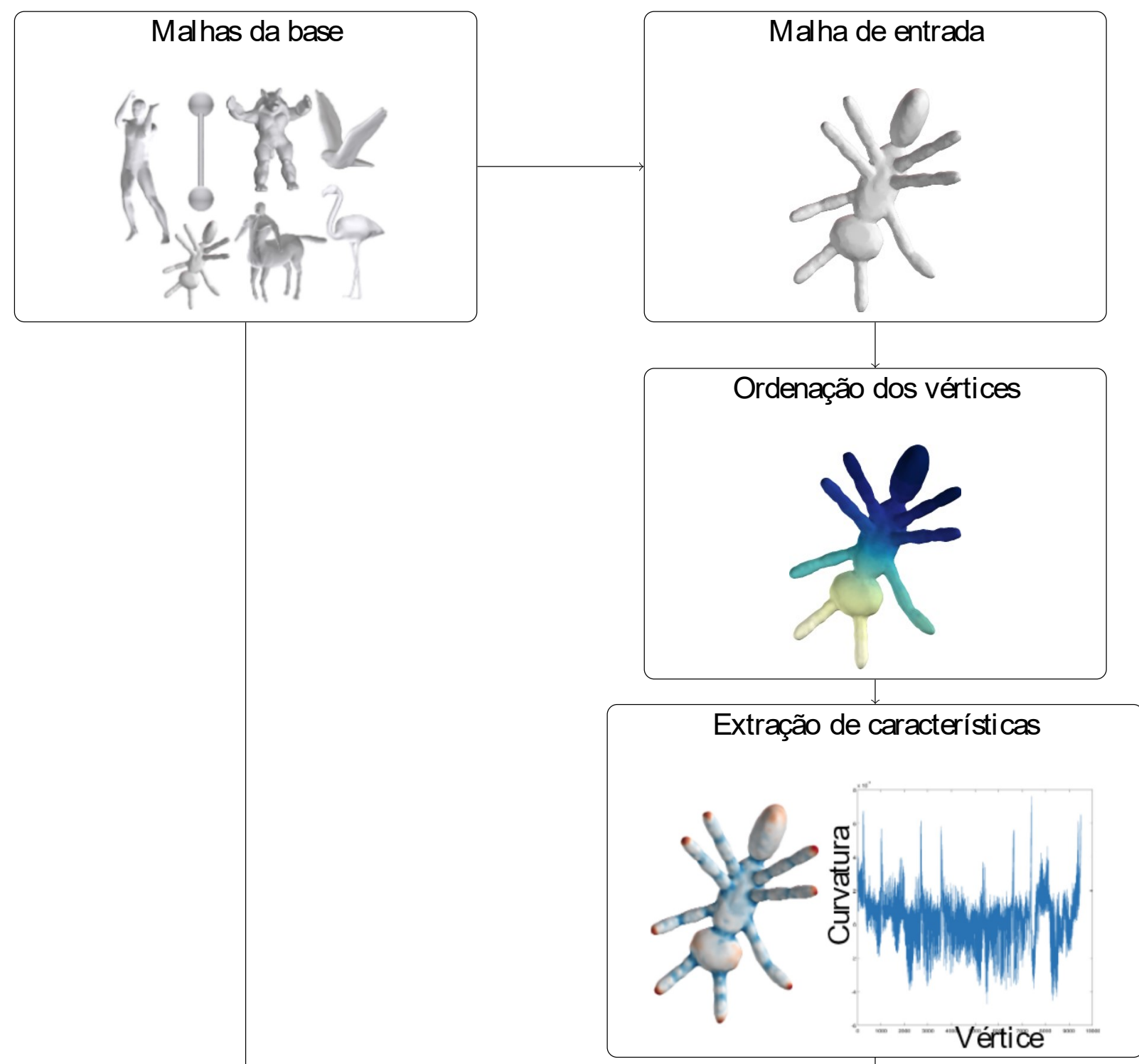

\section{Filtro de Wavel ets}

Filtro de wavelets: Janela 256

Comparação com a base

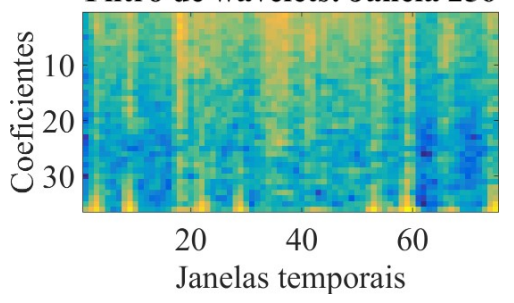

Resultado

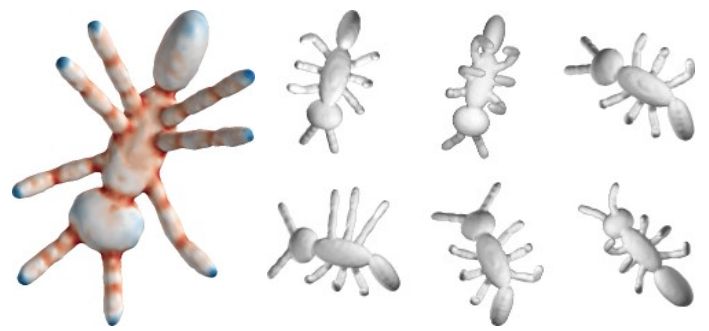


Figura 19 - Comparação entre as ordenações dos vértices da mal ha. À esquerda, a ordenação presente no arquivo; à direita, ordenação obtida pelo vetor Fiedler. Cores mais claras representam os vértices iniciais da ordenação e cores mais escuras, os vértices finais.
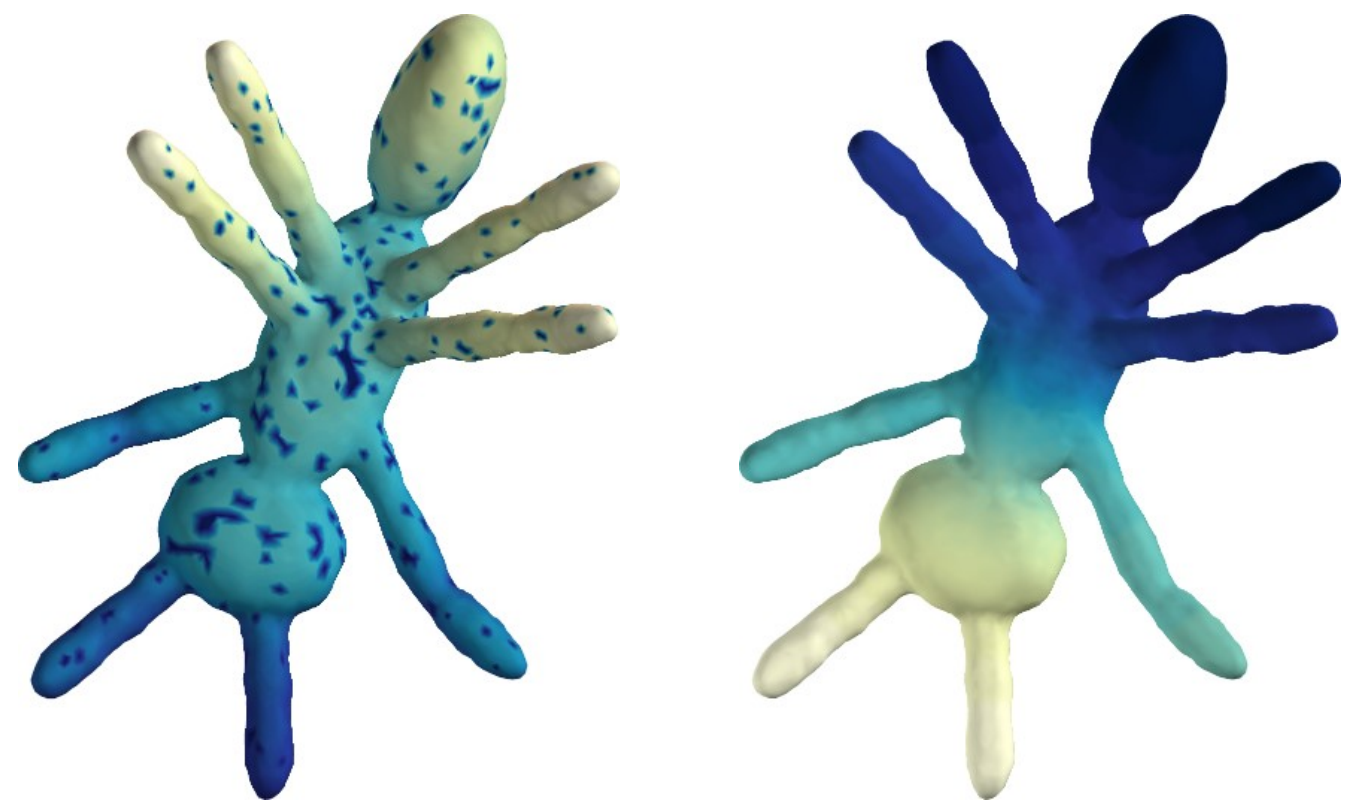

Fonte: Elaborada pelo autor.

\subsubsection{Ordenação dos vértices}

A ordenação dos vértices é uma parte importante do método desenvolvido, uma vez que utilizaremos de ferramentas de anál ise de séries temporai s para a comparação das características. Na Figura 19, é possível visualizar o efeito da ordenação dos vértices. A leitura dos vértices é feita de forma linear e a ordenação dos mesmos está sujeita à essa ordem, a princípio, al eatória. Para que todas as mal has possuam uma ordenação uniforme e comparável, optou-se por utilizar o vetor de Fiedler como função de ordenação.

O vetor de Fiedler é obtido através da anál ise espectral do operador discreto de LaplaceBel trami, sendo o autovetor associado ao primeiro autoval or não nulo. A vantagem dessa função de ordenação é a de ser invariante à isometrias do objeto, ou seja, deformações isométricas preservam o vetor de Fiedl er. Um ponto a ser levantado é sobre o sentido da ordenação, ou seja, apesar da ordenação ser a mesma, o sentido dos vértices pode estar invertido. Para contornar esse problema, são criadas duas séries com as duas ordenações possíveis.

Vale ressal tar que outros algoritmos de ordenação podem ser utilizados desde que mantenham a característica entre objetos da mesma classe.

\subsubsection{Ext ração das características}

As características escolhidas foram a curvatura gaussiana e a variação de superfície, como explicado anteriormente no Capítulo 3. Ambas as características são de cál culo rápido e, por serem intrínsecas, são boas candi datas à recuperação de objetos utilizando o método proposto. 
Figura 20 - Ilustração das características utilizadas: variação de superfície (à esquerda), com cores azuis representando regiões de baixa curvatura; e curvatura gaussiana (à direita), com cores azuis representando curvaturas côncavas, e vermel has, curvaturas convexas
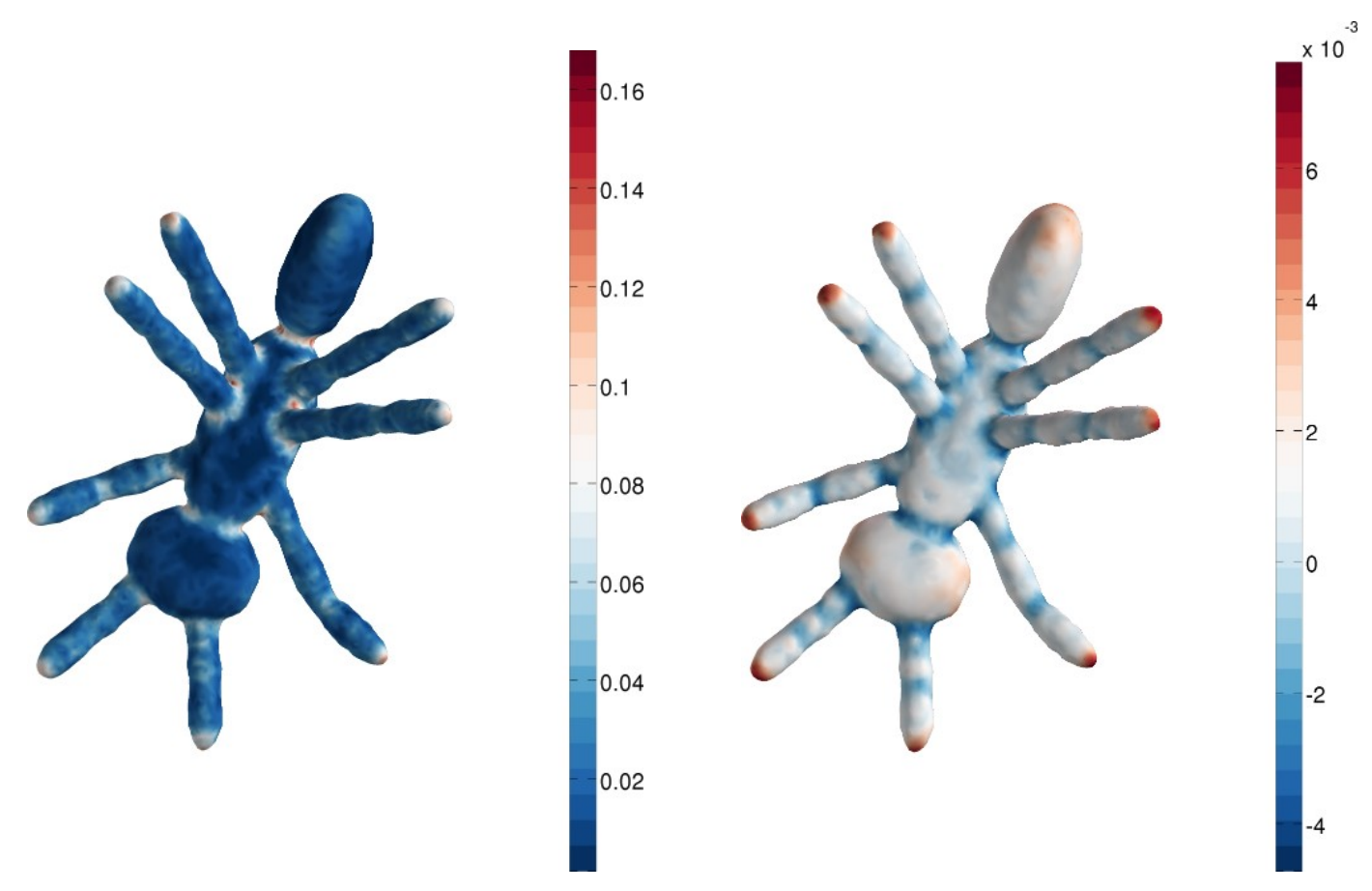

Fonte: Elaborada pelo autor.

Na Figura 20 é possível visual izar a diferença entre as duas características.

Para a curvatura gaussiana, a implementação utilizada foi a implementada por Gabriel Peyre, disponível no pacote computacional Graph Toolbox ${ }^{2}$ para M ATLAB. Nessa implementação, a área $B(v)$ (como descrito na subseção 3.1.1) corresponde à área dos triângulos incidentes no vértice em que se está cal culando a curvatura.

A variação de superfície é originalmente of erecida para cál culo da curvatura média sobre nuvem de pontos. No nosso caso, a implementação foi feita adaptando-se o conceito para uma mal ha triangular. Em nuvem de pontos, a informação de vizinhança é extraída a partir das distâncias entre os pontos, o que não é necessário no caso de uma mal ha que já contem essa informação. Então, utilizamos a 3-estrela de cada ponto.

Com as características extraídas, apl icamos a ordenação de tai s característi cas utilizando o vetor de Fiedl er. Um exemplo da ordenação obti da pode ser visualizado na Figura 21.

\subsubsection{Comparação com a base}

A pós sua extração é montado um vetor para a fase de comparação. Nesse estági o são utilizadas as técnicas de correlação cruzada e DTW. Como o DTW se trata de uma técnica de programação dinâmica, seu tempo de processamento é um pouco mai or que a correlação

2 <http://www.mathworks.com/matlabcentral/fil eexchange/5355-tool box-graph>, último acesso em 25/04/2016 
Figura 21 - Sinal obtido ao se combinar o vetor de Fiedler com as características extraídas. Nesse caso, a característica é a curvatura gaussiana.
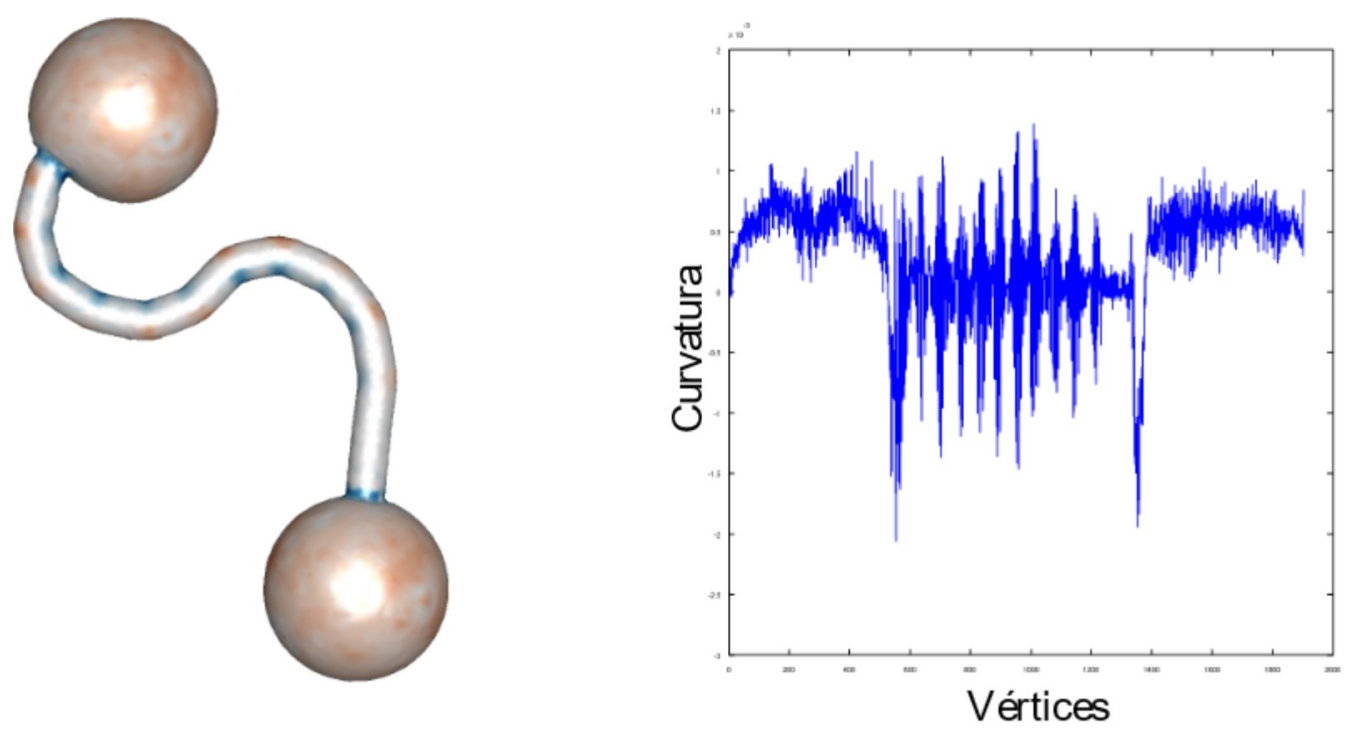

Fonte: Elaborada pelo autor.

cruzada. Nessa úl tima, a transl ação das séries é de $25 \%$ o tamanho do sinal , diminuindo o custo de processamento.

A implementação do DTW utilizada foi a apresentada por Dan Ellis ${ }^{3}$. As modificações efetuadas foram feitas para que as séries pudessem ser tratadas nos dois sentidos, uma vez que a ordenação de Fiedler pode resul tar em sentidos contrários.

Para a correlação cruzada, a implementação utilizada é a presente no próprio M ATLAB 4 . Novamente, para esse descritor foi necessário aval iar as séries duas vezes, sendo uma delas com a série invertida. $O$ val or obti do com esse método é mai or conforme as séries são mais si milares, então é necessário adaptar esse val or para que se torne um valor de distância, (Equação 3.14).

\subsection{Resultados}

Uma visão geral dos resultados pode ser visto nas Figuras 22, 23 e 24. Para obtenção de tais resul tados os objetos foram comparados com a base compl eta e os model os mais semel hantes foram ranqueados através da métrica escol hida - nesse caso foi a correl ação cruzada- e estão dispostos em ordem de maior similaridade da esquerda para a di reita. Nas figuras também estão apresentados os resul tados para tamanhos de janela escol hidos para o scattering wavelets, de cima para baixo.

Observe que diferentemente do modelo do caval o, que possui uma série de características capaz de separar bem a própria classe das demais, os model os da formiga e do homem apresentam

3 Disponível em <http://www.ee.columbia.edu/ dpwe/resources/matlab/dtw/>, último acesso: 25/04/2016.

4 função $x \operatorname{corr}($.$) .$ 
Tabela 1 - Tabela com resul tados quantitativos utilizando variação de superfície como característica na base SHREC 2011. O método de comparação é a correlação cruzada.

\begin{tabular}{c|c|c|c|c|c}
\hline Tamanho da janela & Vizinho mais próximo & Camada 1 & Camada 2 & Medida e & DCG \\
\hline 256 & 0.8900 & 0.6004 & 0.6854 & 0.4976 & 0.8332 \\
512 & 0.9367 & 0.6036 & 0.6846 & 0.4956 & 0.8437 \\
1024 & 0.9433 & 0.6511 & 0.7163 & 0.5253 & 0.8627 \\
2048 & 0.9517 & 0.6467 & 0.7170 & 0.5247 & 0.8633 \\
\hline
\end{tabular}

Fonte: Elaborada pelo autor.

Tabela 2 - Tabela com resul tados quantitativos utilizando curvatura como característica na base SHREC 2011. O método de comparação é a correlação cruzada.

\begin{tabular}{c|c|c|c|c|c}
\hline Tamanho da janela & Vizinho mais próximo & Camada 1 & Camada 2 & Medida e & DCG \\
\hline 256 & 0.8167 & 0.4523 & 0.5191 & 0.3767 & 0.7411 \\
512 & 0.8883 & 0.5121 & 0.5808 & 0.4201 & 0.7844 \\
1024 & 0.9167 & 0.5802 & 0.6499 & 0.4727 & 0.8258 \\
2048 & 0.9217 & 0.5605 & 0.6502 & 0.4722 & 0.8221 \\
\hline
\end{tabular}

Fonte: Elaborada pelo autor.

outros obj etos em seus resul tados de busca. A nal isando os resul tados retornados pel a busca da formiga, entretanto é possível observar que o model o dos hal teres apresenta certa similaridade, se considerar que o corpo do inseto é formado por partes esféricas e partes cilíndricas. No caso do modelo do homem, todos os modelos retornados são humanoi des, apesar de estarem categorizados como "homem" e "mul her" dentro da base escolhida.

Nas Tabelas 1, 2, 3 e 4 podemos verificar os valores numéricos para uma consulta real izada entre os modelos da base. Para obter esses resultados, utilizamos cada modelo da base como um modelo de busca e então os resultados foram computados de acordo com o ranqueamento dos modelos. Pelos val ores numéricos é possível se ver que a correlação cruzada apresenta mai or precisão na recuperação dos objetos. I sso pode ser explicado pelo fato dessa métrica real izar uma comparação das séries com um deslocamento temporal, permitindo um mel hor possível alinhamento. Outra possível explicação está nos tipos de filtros utilizados para o scattering wavel ets. Por serem adaptados di retamente de processamento de áudios, tais filtros foram escol hi dos para essa apl icação específica. Entretanto o uso de outro banco de filtros para processamento geométrico poderia ser mais eficaz.

Em 2015 surgiu uma nova versão da competição para recuperação de objetos não rígi dos. Nessa versão, submetemos nosso método para avaliação. Uma visão geral do gráfico de preci são-revocação pode ser visto na Figura 25. A pesar no nosso método estar apresentado em décima colocação, por utilizar apenas uma característica simples para recuperação dos objetos, acreditamos que são bons resultados. Na Tabela 5, apresentamos os resul tados quanti tativos apresentados no artigo final da competição (LIAN et al., 2015). Para as submissões, utilizamos janelas do scattering wavelets de tamanhos 256, 512 e 1024 com a característica variação de superfície. 
Figura 22 - Exemplo de consulta real izada para o modelo de um cavalo. O el emento mais à esquerda é o modelo de consulta. Cada linha representa uma tamanho de janel a utilizado.

(a) Variação de superfície.
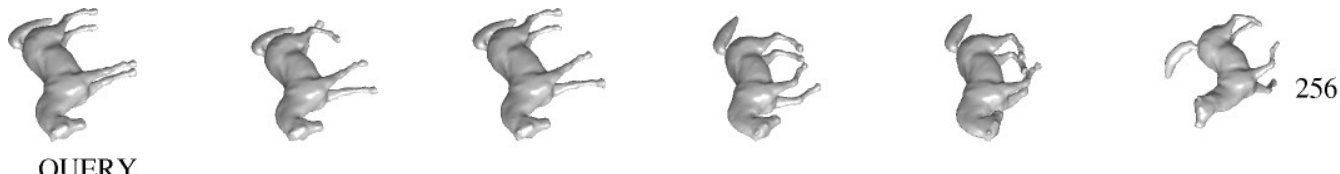

QUERY
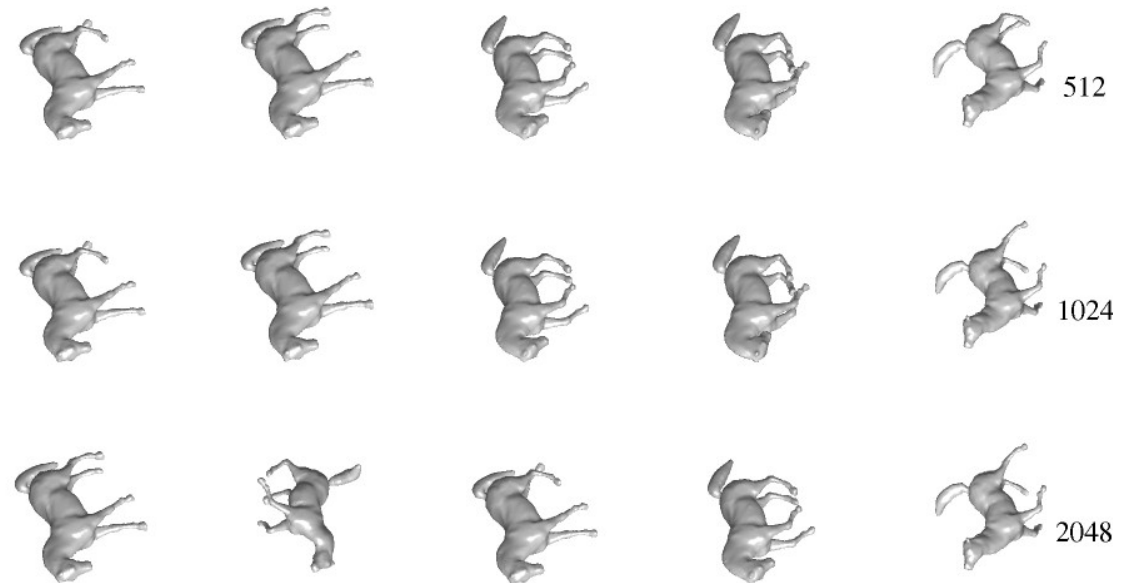

Fonte: Elaborada pelo autor.

(b) Curvatura gaussiana.
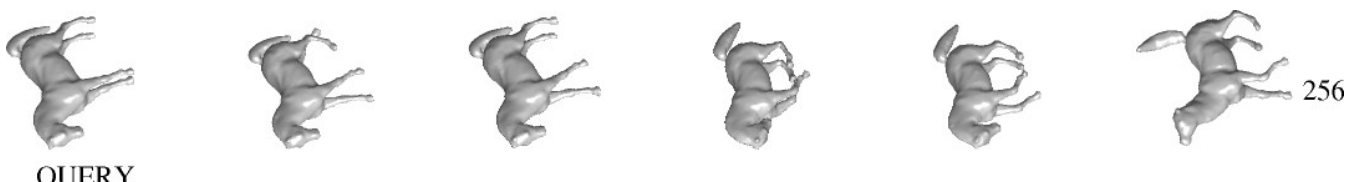

QUERY
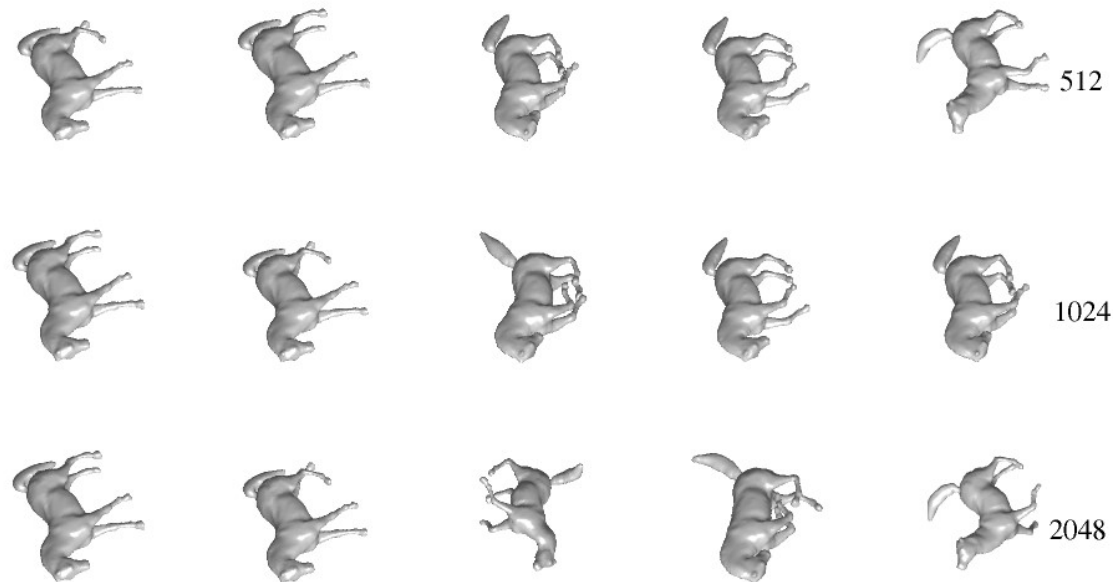

Fonte: Elaborada pelo autor. 
Figura 23 - Exemplo de consulta real izada para o modelo de um formiga. O elemento mais à esquerdaé o modelo de consulta. Cada linha representa uma tamanho de janel a utilizado.

(a) Variação de superfície.
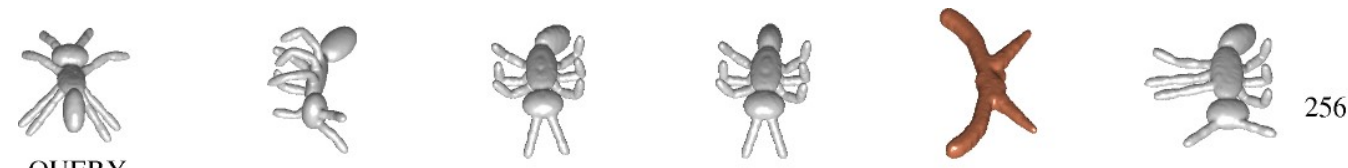

QUERY
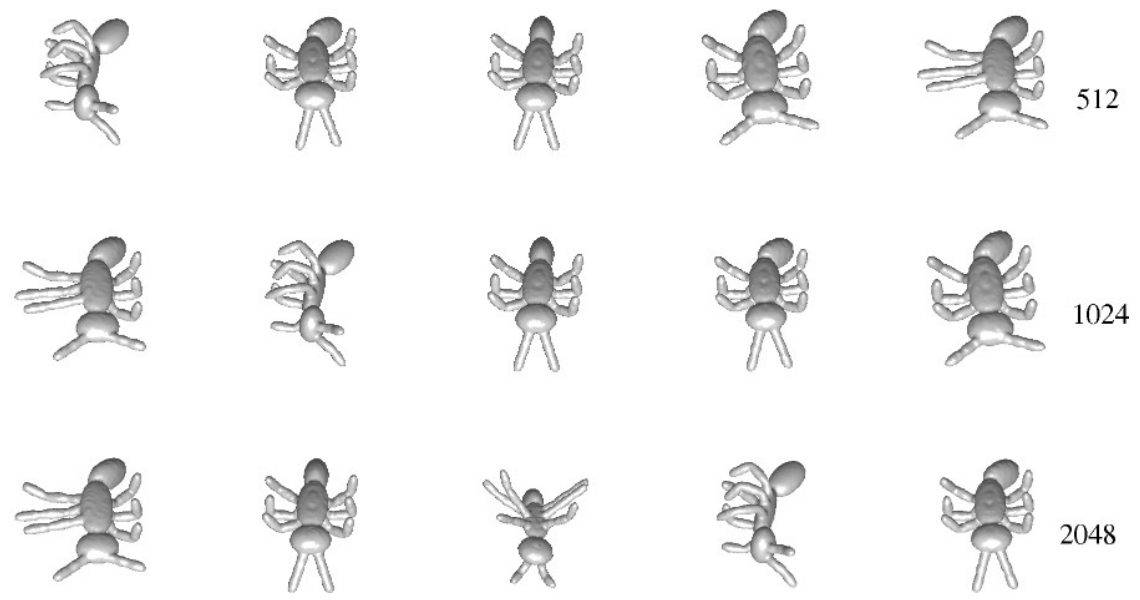

2048

Fonte: Elaborada pelo autor.

(b) Curvatura gaussiana.
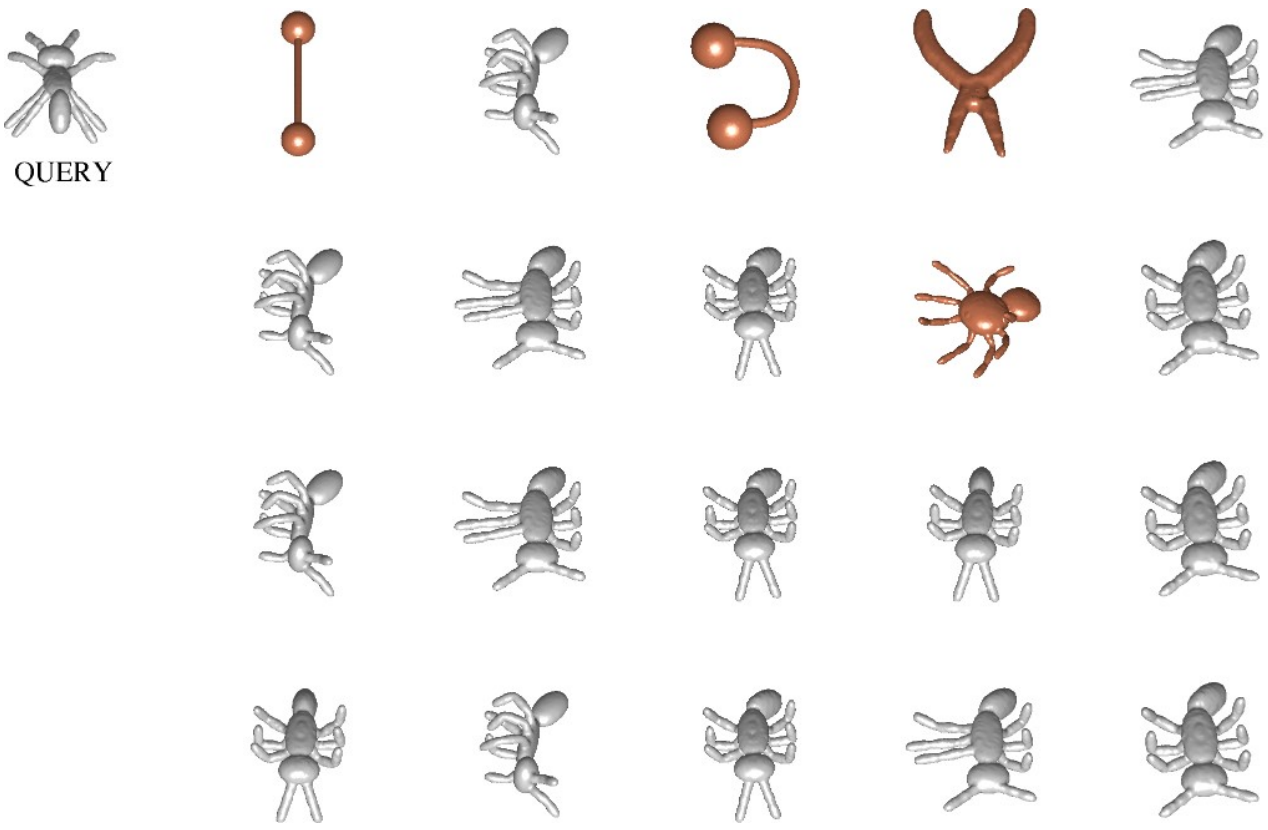

Fonte: Elaborada pelo autor. 
Figura 24 - Exemplo de consul ta real izada para o modelo de um humano. O el emento mais à esquerda é o modelo de consulta. Cada linha representa uma tamanho de janela utilizado.

(a) Variação de superfície.
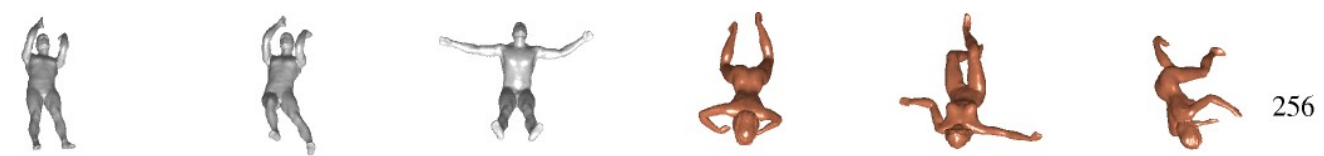

QUERY
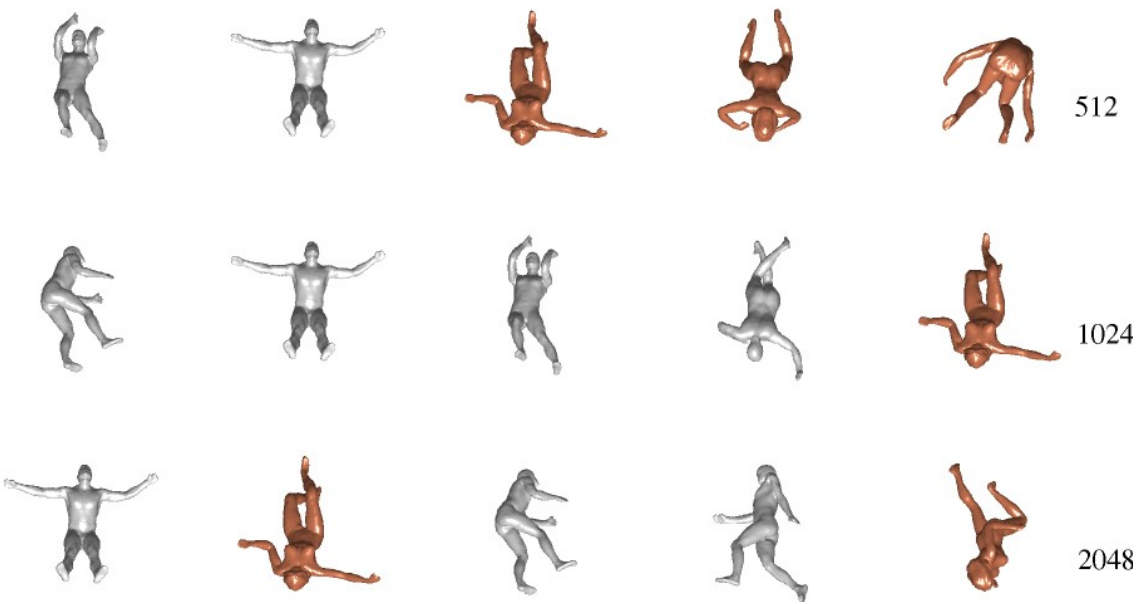

Fonte: Elaborada pelo autor.

(b) Curvatura gaussiana.
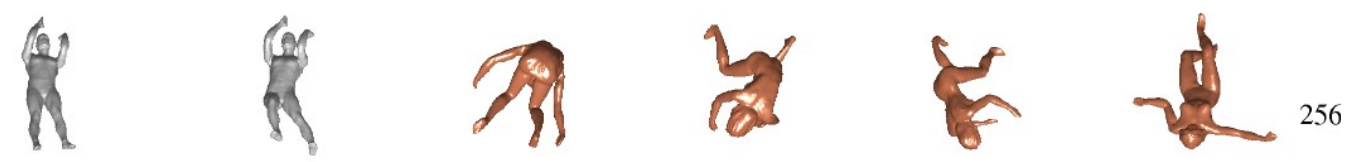

QUERY
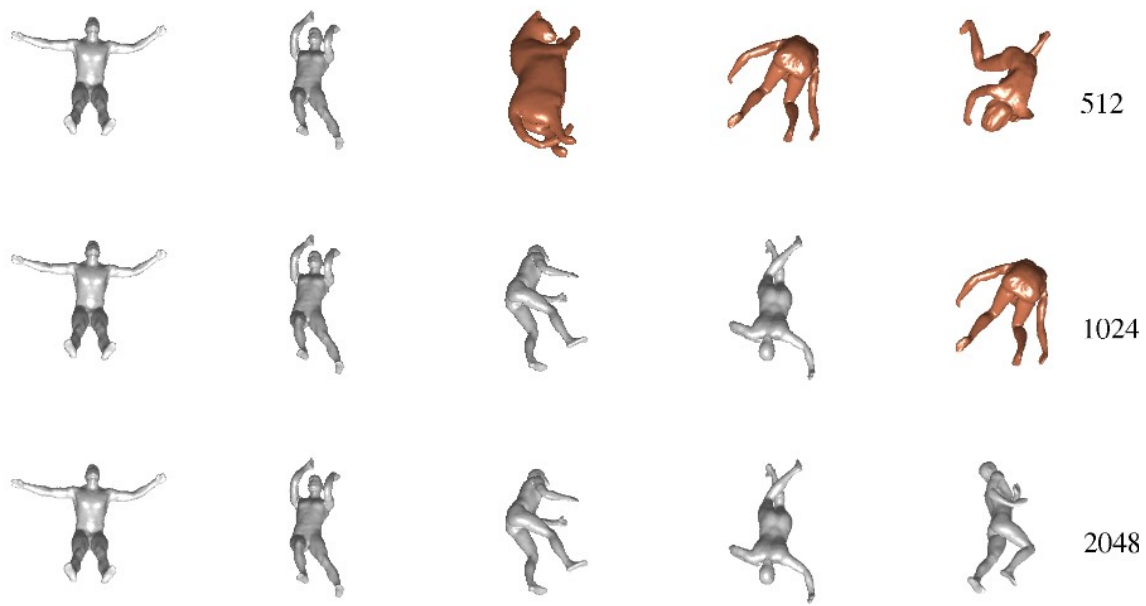

Fonte: Elaborada pelo autor. 
Tabela 3 - Tabela com resul tados quantitativos utilizando variação de superfície como característica na base SHREC 2011. O método de comparação é o DTW.

\begin{tabular}{c|c|c|c|c|c}
\hline Tamanho da janela & Vizinho mais próximo & Camada 1 & Camada 2 & Medida e & DCG \\
\hline 512 & 0.7950 & 0.6040 & 0.7537 & 0.5370 & 0.8357 \\
1024 & 0.8533 & 0.6195 & 0.7625 & 0.5456 & 0.8464 \\
2048 & 0.8467 & 0.5741 & 0.7146 & 0.5103 & 0.8245 \\
\hline
\end{tabular}

Fonte: Elaborada pelo autor.

Tabela 4 - Tabela com resul tados quantitativos utilizando curvatura como característica na base SHREC 2011. O método de comparação é o DTW.

\begin{tabular}{c|c|c|c|c|c}
\hline Tamanho da janela & Vizinho mais próximo & Camada 1 & Camada 2 & Medida e & DCG \\
\hline 256 & 0.2650 & 0.2797 & 0.4464 & 0.3003 & 0.5718 \\
512 & 0.7700 & 0.5339 & 0.6837 & 0.4827 & 0.7934 \\
1024 & 0.8700 & 0.5929 & 0.7307 & 0.5239 & 0.8410 \\
2048 & 0.8700 & 0.5728 & 0.7023 & 0.5020 & 0.8310 \\
\hline
\end{tabular}

Fonte: Elaborada pelo autor.

Figura 25 - Gráfico obtido na competição SHREC 2015. O melhor resultado obtido com o nosso método foi utilizando a janela de 1024.

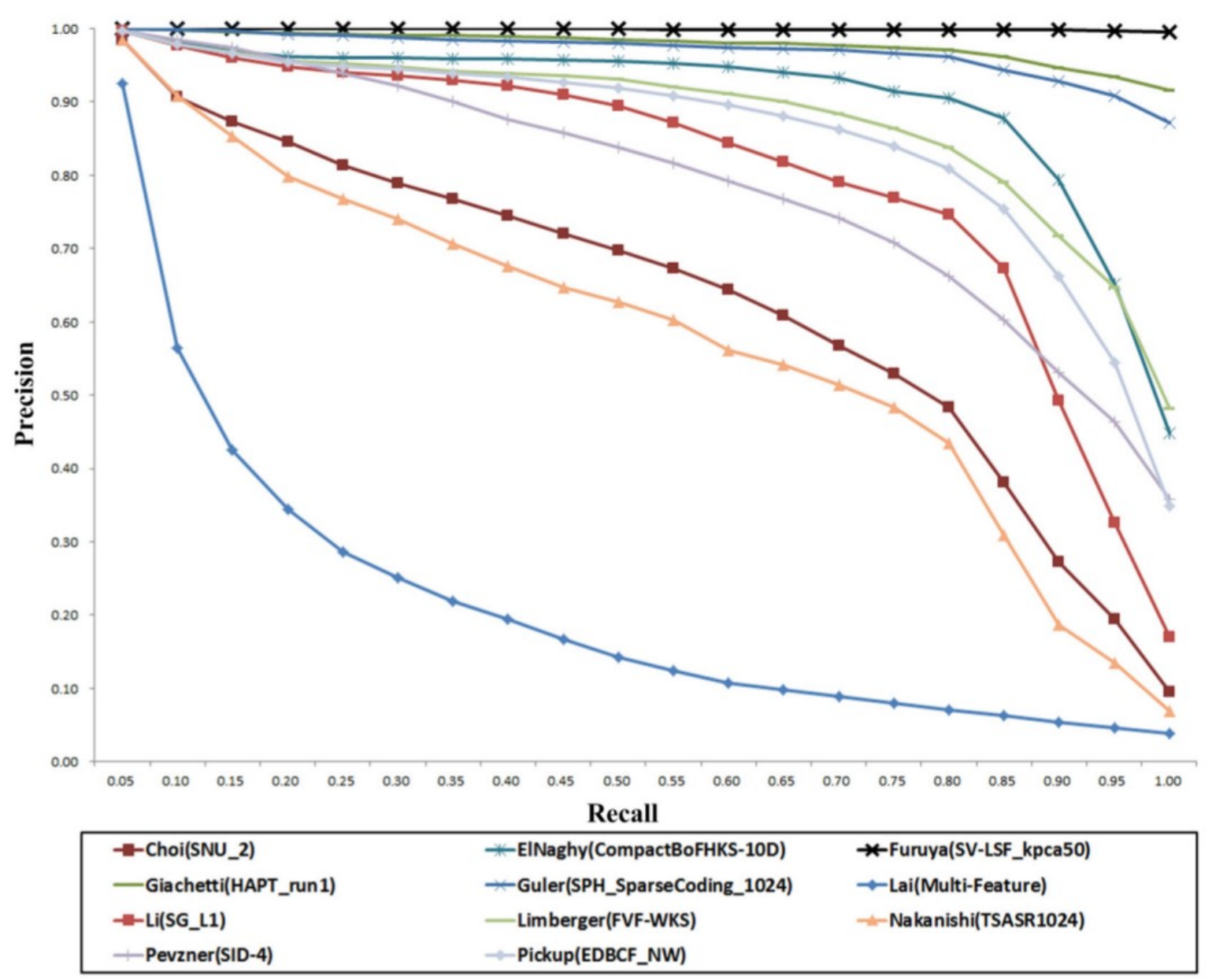

Fonte: Elaborada pelo autor. 
Tabela 5 - Resultado obtido na competição SHREC 2015 para diferentes tamanhos de janela e utilizando variação de superfície como característica.

\begin{tabular}{c|c|c|c|c|c}
\hline Tamanho da janela & Vizinho mais próximo & Camada 1 & Camada 2 & Medida e & DCG \\
\hline 265 & 0.8133 & 0.4638 & 0.5445 & 0.4203 & 0.7498 \\
512 & 0.8608 & 0.7458 & 0.5498 & 0.4292 & 0.7673 \\
1024 & 0.8958 & 05316 & 0.5960 & 0.4722 & 0.7975 \\
\hline
\end{tabular}

Fonte: Adaptada de Lian et al. (2015).

\subsection{Discussão}

Nossa abordagem para recuperação de objetos inova no senti do de apresentar uma nova ferramenta de comparação entre os objetos. Ao se ordenar as características dos vértices através do vetor de Fiedler, é possível simular uma série temporal, criando assi m, uma dependência na ordem das características. E, com isso, é possível utilizar ferramentas de processamento de sinais para se anali sar as séries, com apenas uma característica, e então real izar as comparações entre elas.

Podemos notar, pelos resultados apresentados, que o método é capaz de recuperar bem os objetos da mesma classe. O principal problema está nos detal hes que cada classe apresenta. A pesar de visivel mente serem semel hantes, al gumas sutilezas nas mal has fazem com que elas pertençam a outra classe, como foi visto na Figura 24, em que a consulta foi feita com um exemplar da classe homem, porém, vários objetos retornados pertenciam à classe mul her. O que, entretanto, não diminui a qualidade do método, uma vez que ambas as cl asses fazem parte da semântica ser humano.

Além disso, vale ressaltar que a principal característica do método - ordenação dos vértices - pode ser al terada, uma vez que se escol ha outra ordenação invariante à isometria. Por se tratar de um método que depende da ordenação das característi cas de cada mal ha, é necessário apresentá-los de maneira a simular uma série temporal. E, anal ogamente, a característica utilizada também precisa ser bem di scrimi nativa entre mal has de classes di ferentes, para que o método seja capaz de real izar uma recuperação boa. 

CAPÍTULO

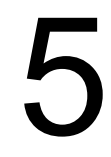

.

\section{MÉTODO PARA RECUPERAÇÃO PARCIAL \\ DE OBJETOS}

Dif erentemente da recuperação de objetos, a recuperação parcial de objetos visa encontrar apenas partes que são semelhantes em dois modelos diferentes. Apesar dos objetivos serem diferentes, muitos métodos de recuperação de objetos são modificados para que se adequem à recuperação parcial de objetos.

Nesse capítul o apresentamos como isso pode ser feito através de técnicas que utilizam processamento de sinais temporais.

\subsection{Método}

O método empregado nesse capítulo se assemelha ao apresentado na seção 4.1, que pode ser visto pela Figura 26. Para que o método seja capaz de encontrar partes semelhantes através da análise de sinais diferentes, se fez necessário dividir o objeto em pequenas partes com al gum significado. Além disso, al teramos a métrica utilizada para medir a similaridade entre as partes do objeto, introduzindo o CRP para comparação entre dois objetos tridimensionais representados como séries temporais. A característica utilizada para descrever as mal has foi - Heat Kernel Signature, por apresentar bons resultados reportados na literatura. A seguir apresentamos detal hadamente os passos do al goritmo construído.

\subsubsection{Segment ação dos objetos}

A segmentação dos objetos é um passo essencial para o método desenvolvido para a recuperação parcial de objetos. A opção de segmentar a mal ha foi influenciada pelo descritor escolhido: CRP, que será explicado com detal hes mais adiante. Ao segmentarmos os objetos, consequentemente estamos i sol ando regiões de interesse. Na montagem da série completa, os 
Figura 26 - Pipeline empregado para a recuperação parcial de objetos.
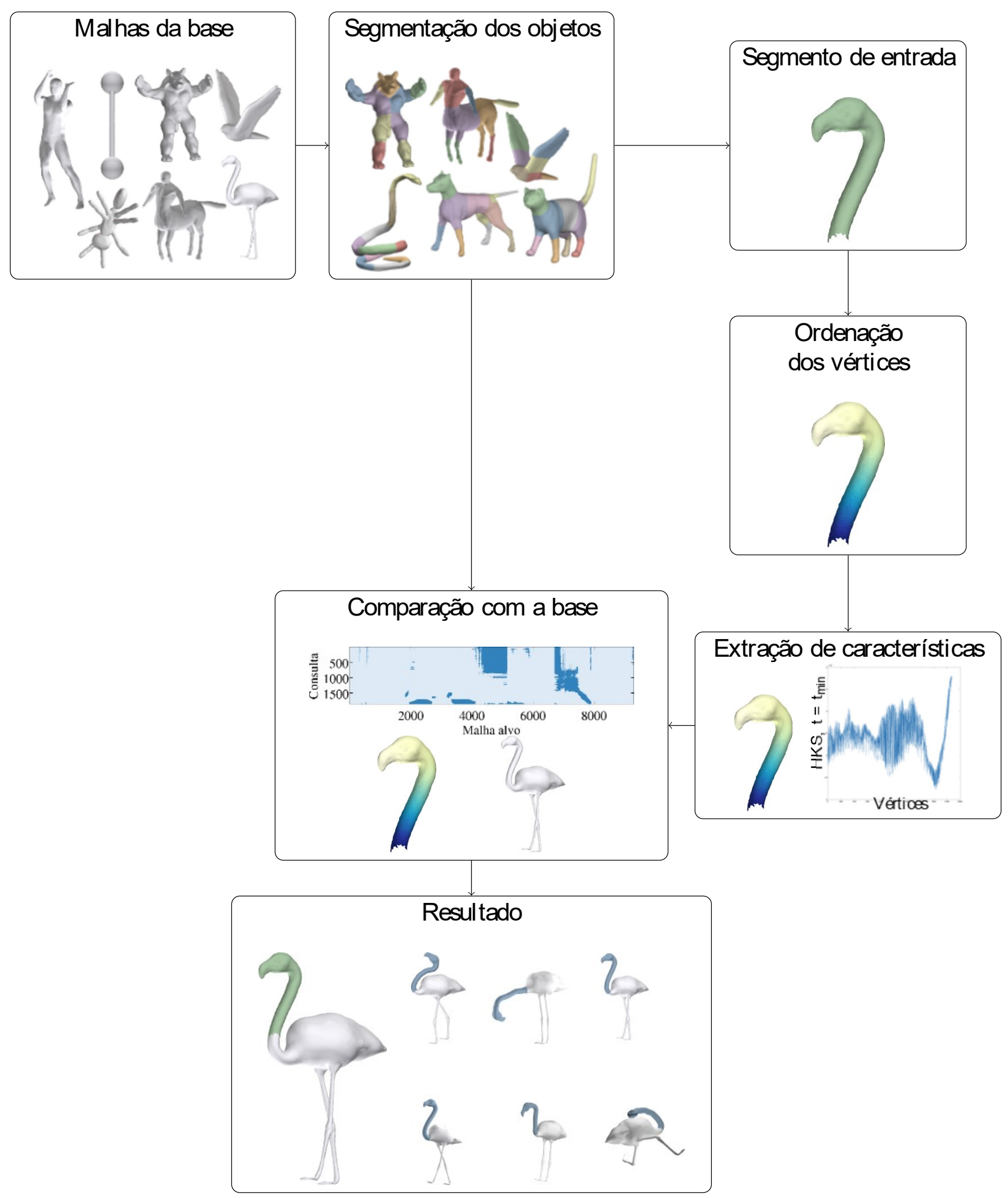

Fonte: Elaborada pelo autor.

vértices são primeiramente organizados por região e depois pela ordem dentro da região.

Para o método de recuperação parcial, utilizamos o al goritmo consensus, desenvol vido 
Figura 27 - Subdivisões de um objeto tridimensional. Comparação entre o resultado gerado pelo al goritmo de Rodola, Bulò e Cremers (2014) (à esquerda) e a modi ficação implementada para se adequar ao problema (à direita).
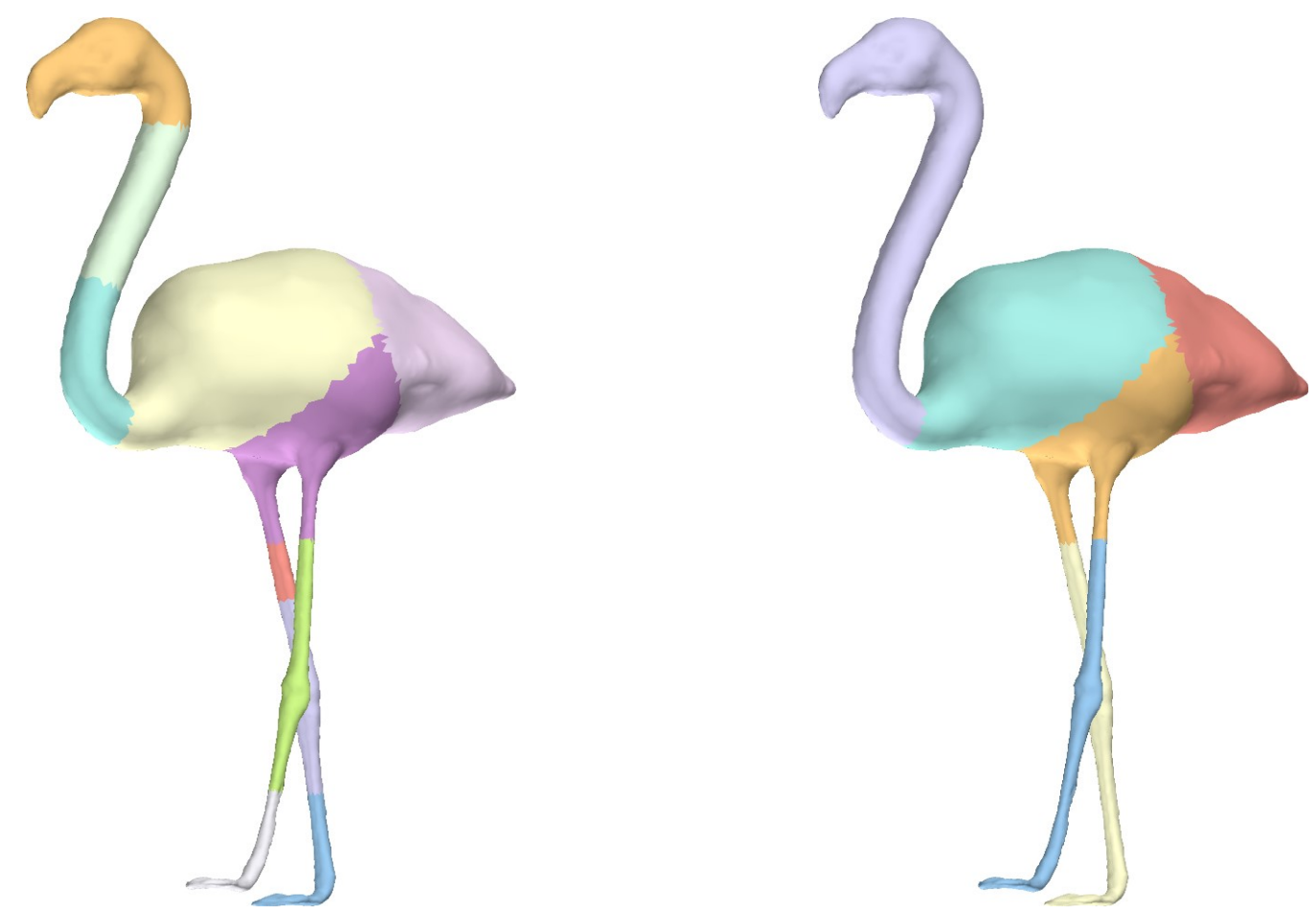

Fonte: Elaborada pelo autor.

por Rodola, Bulò e Cremers (2014) para realizar as segmentações'. Esse al goritmo busca por regiões estáveis a deformações, el egendo regiões candidatas, ou seja, através de possíveis segmentações, regiões que são mais propensas a estarem corretas são escol hi das para fazerem parte da segmentação final . A partir da segmentação obtida pel o al goritmo consensus, real izamos al gumas modificações na segmentação final, após observar a maneira como as mal has eram segmentadas. A segmentação final divide as extremidades de al gumas mal has em várias partes, o que não é interessante para o CRP, pois a ordenação dos vértices pode ficar comprometida. Por serem parte de um mesmo segmento, é interessante construir-se a série de vértices dentro desse mesmo segmento.

Esse problema é identificado principal mente em mal has que possuem regiões que não apresentam ramificações, como é o caso do pescoço e das pernas do flamingo (vide Figura 27). Constatado isso, modificamos o al goritmo para que regiões de extremidade permaneçam em um único segmento.

A modi ficação acrescentada ao al goritmo é a de verificação dos segmentos. Para cada segmento é real izado uma contagem de segmentos vizinhos. Caso o segmento só possua apenas um vizinho, ele é um segmento de extremi dade. Então real iza-se uma nova verificação: se ao juntarmos os dois segmentos, o resultado obtido também possuir apenas um vizinho, então

1 Código disponível em <http://vision.in.tum.de/members/rodola/code>, último acesso em 01/02/2016 
teremos que são, de fato, extremi dade que foram separados pelo al goritmo consensus e eles são combinados.

\subsubsection{Extração das características}

As características escol hidas para o nosso problema foi o HKS, apresentado na subseção 3.1.4. Por ser uma característica multidimensional, possui mais informações. Além disso, é muito utilizada na literatura para caracterização de objetos tridimensionais. Nas fases iniciais de desenvolvimento, a utilização de curvatura não apresentava resul tados sati sfatórios, deixando a desejar em al guns aspectos. Como o HKS consegue representar a evolução da característica no tempo (difusão do cal or), optou-se por ele. Em nossas implementações, os núcleos de cal or foram cal culados em interval os logaritmicamente espaçados com tempo inicial $t_{\min }=0: 03$ e tempo final $t_{\max }=1: 5$. Sun, Ovsjanikov e Guibas (2009) sugeriram a utilização de $t_{\min }=4 \ln (10)={ }_{1} \mathrm{e}$ $t_{\max }=\ln (10)=1300$, entretanto, por estarmos realizando uma comparação entre várias mal has diferentes, esses val ores variavam de objeto para objeto. Para evitar que essa variação af etasse a comparação das características, optamos por escol her um valor fixo.

Analogamente ao método para recuperação de objetos, cada parte possui seu próprio sinal ordenado pelo vetor de Fiedler que é extraído da mal ha completa. É possível observar que cada segmento diferente de uma mesma mal ha possui diferentes frequências, como mostra a Figura 28, em que mostramos as frequências para o tempo ini cial da difusão do cal or. Utilizando essa intuição é possível, a partir de um segmento de entrada, encontrar outras malhas que possuem regiões com frequências semelhantes.

No caso em que o segmento de entrada é desconhecido, ou seja, não faz parte do banco de dados, os cál culos do HKS são feitos utilizando-se a condição de fronteira de Dirichlet: $\mathrm{u}(\mathrm{x} ; \mathrm{t})=0$ para todo $\mathrm{x} \in \partial \mathrm{M}$. A ordenação dos vértices nesse caso também é feito pelo vetor de Fiedler obtido do segmento avulso.

\subsubsection{Comparação com a base}

O método utilizado para encontrar os segmentos semel hantes entre as mal has é o Gráfico de Recorrência Cruzada (do inglês, Cross Recurrence Plot) (apresentado na subseção 3.3.3). Pela Figura 29 é possível verificar que a matriz de recorrência é capaz de encontrar regiões, em uma mesma mal ha, que são semel hantes. A região destacada em verde, na mal ha, é a região que se deseja buscar (query), enquanto que a região destacada em azul é a região mai s semel hante encontrada. Utilizando dessa lógica, é também possível encontrar regiões que são semel hantes em mal has que são diferentes.

Entretanto o CRP é apenas um resul tado qualitativo da semel hança entre duas regiões semel hantes. Para que uma métrica $\mathrm{m}(\cdot)$ possa ser extraída, utilizamos o al goritmo $\mathrm{S}_{\max }$, que mede a maior região de recorrência na matriz CRP. Com esse val or numérico é possível estimar 
Figura 28 - Ilustração exemplificando as diferenças de frequências em diferentes regiões de um mesmo objeto. As janel as das frequência estão igual mente escal adas para fins de comparação. No eixo das abscissas estão os vértices ordenados de cada região; e nas ordenadas estão os val ores do HKS no tempo $t=t_{\min }$

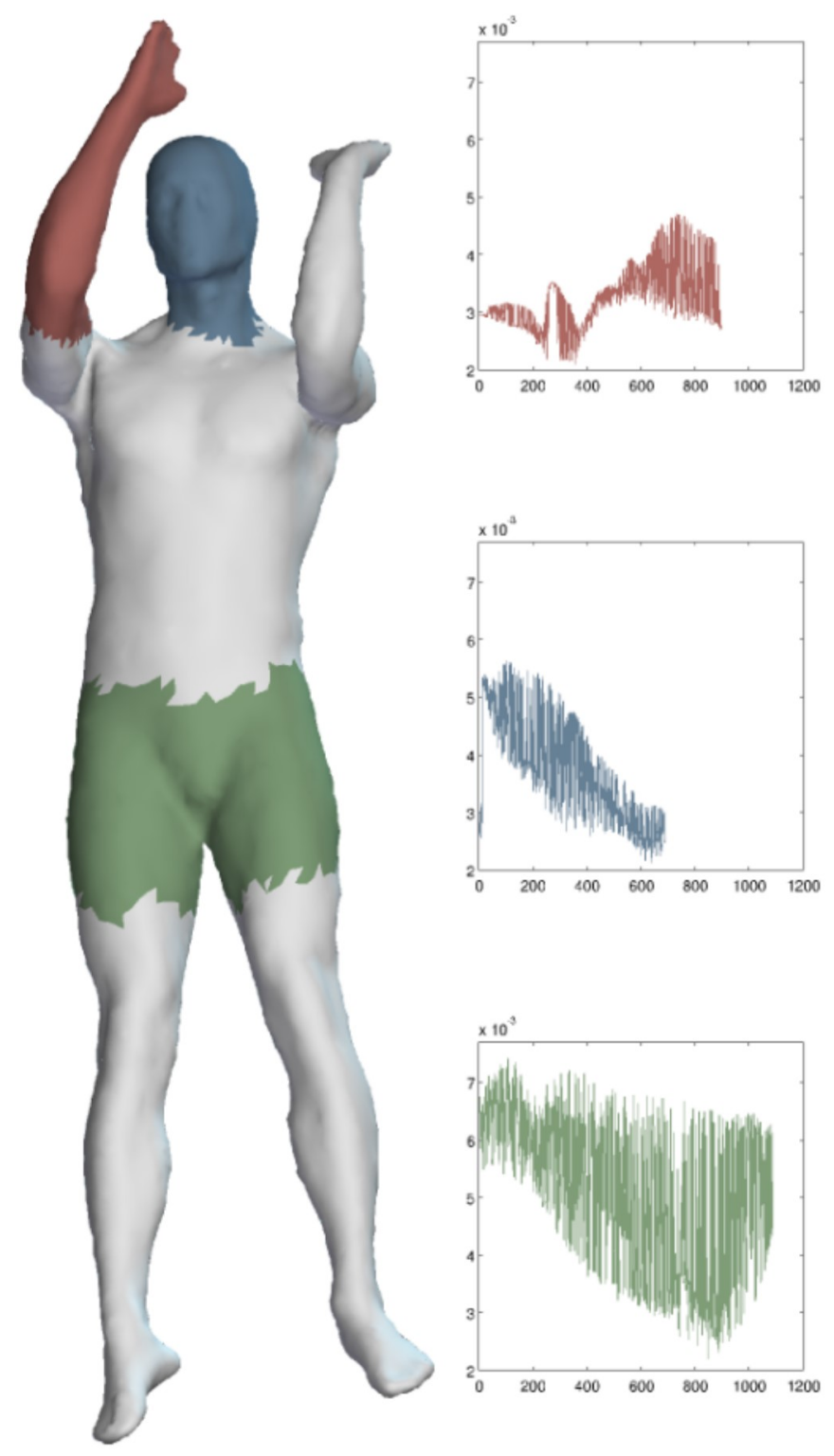

Fonte: Elaborada pelo autor.

as regiões que mais se parecem com o segmento inicial dado:

$$
\mathrm{m}\left(\mathrm{M}_{1} ; \mathrm{M}_{2}\right)=\frac{1}{\mathrm{~S}_{\max }} ;
$$

em que $M_{\text {i }}$ representam as malhas tridimensionais. Observe que não se trata de uma medida de distância, uma vez que para segmentos idênticos não possuem medida $S_{\max }$ infinita. Apesar di sso, é possível se ter uma ideia de semel hança das malhas, já que as mal has mais próximas possuem maior $S_{\text {max }}$. 
Figura 29 - Dado um dos braços do centauro como entrada (em verde), a matriz do CRP resultante mostra os candidatos semel hantes. As mel hores partes estão destacadas em azul escuro e correspondem à região azul destacada no centauro da direita.

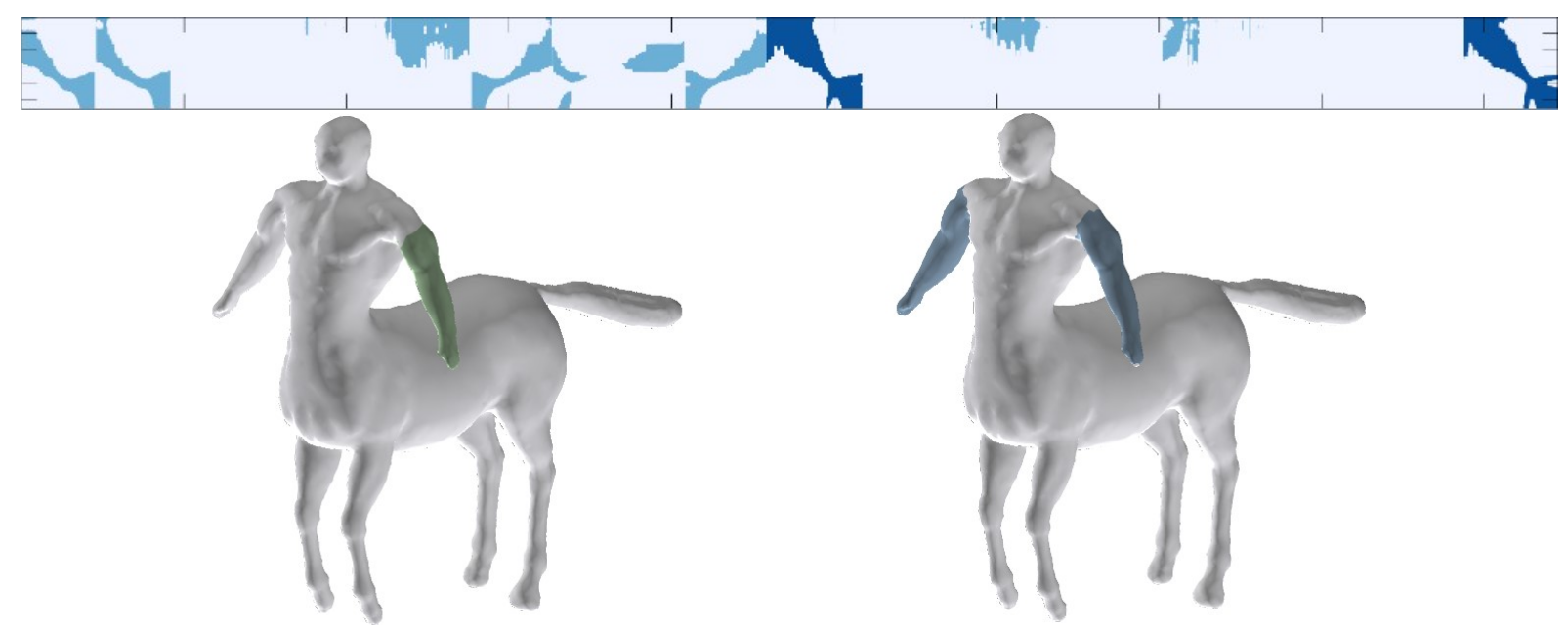

Fonte: Elaborada pelo autor.

Uma observação importante a ser feita está no pré-processamento das imagens CRP. A matriz obtida pel o al goritmo élimiarizada em threshol $d=0$ 0:0045, quefoi obtido através de testes com al gumas mal has. Além disso, por se tratarem de regiões em uma imagem, foi necessário realizar um processamento dessas regiões para que vértices desconexos correspondessem a regiões desconexas. Caso as áreas da imagem não pertencessem a vértices conexos da mal has original, as regiões são separadas desconectando as áreas da imagem.

Por se tratar de uma métrica simples, que não leva em consideração o contexto dos objetos, nem a semântica de cada um, nem sempre o mel hor val or do $S_{\max }$ corresponde a uma região de interesse. Observe um exemplo na Figura 30. Apesar de possuírem uma região em comum - tórax -, as regiões destacadas na matriz CRP não correspondem à essa intersecção em comum. Isso ocorre porque o al goritmo considera que a região do centauro que possui maior $S_{\max }$ é a região de uma das patas.

\subsection{Resultados}

Nessa seção apresentaremos os resultados obtidos para a recuperação parcial de objetos a partir de fragmentos dados como entrada. Vale a pena observar que tais fragmentos podem ser extraídos a partir de uma mal ha de interesse, afim de encontrar outros obj etos que contenham uma parte similar; ou encontrar, na mesma mal ha de entrada, partes si milares. Podemos observar um exemplo do segundo caso na Figura 31, em que o fragmento de busca utilizado é uma das patas da formiga, destacado em verde. $O$ al goritmo desenvolvido busca por fragmentos semel hantes na mesma mal ha e os resultados encontrados estão destacados em azul.

Para se encontrar a partir de um segmento de uma mal ha outras regiões de interesse em 
Figura 30 - Dado um dos braços do humano como entrada (em verde), a matriz do CRP resultante mostra os candidatos semel hantes. A região mais semel hante encontrada pelo $S_{\max }$ está destacada em azul e corresponde à região em azul do centauro.

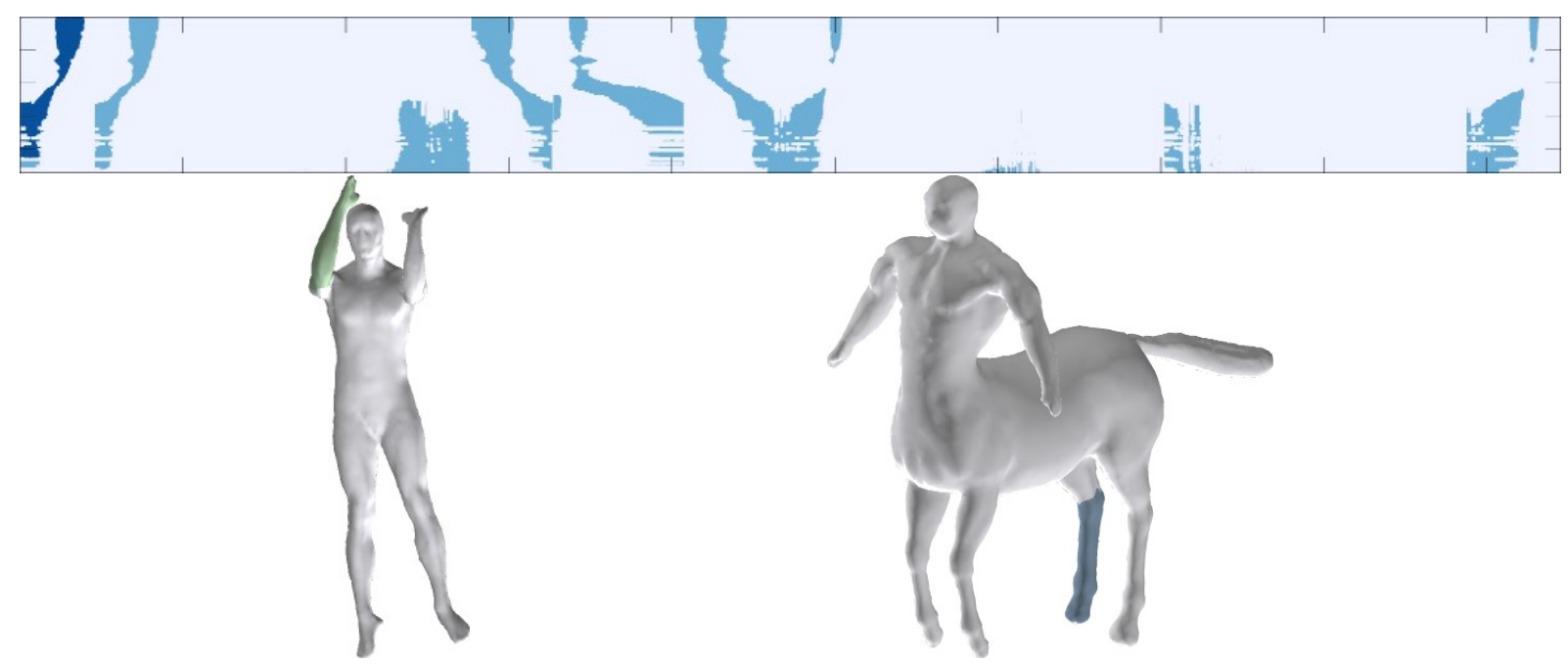

Fonte: Elaborada pelo autor.

Figura 31 - Utilizando uma das pernas da formiga como entrada (em verde), é possível encontrar as demais pernas e as antenas (em azul).
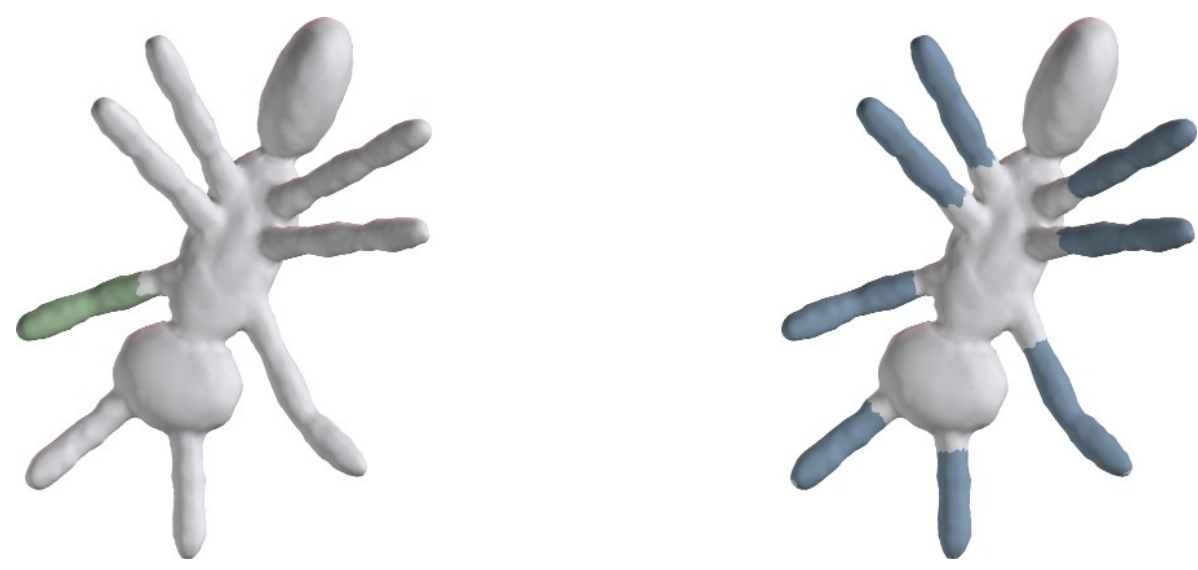

Fonte: Elaborada pelo autor.

um banco de objetos, utilizamos o SHREC 2011. Apesar de não ser um banco de dados dedicado à recuperação parcial de objetos, é possível realizar a sel eção de segmentos em uma das mal has e então realizar a busca. Nas Figuras 32, 33 e 34, é possível observar al guns exemplos que foram executados. Para uma mal ha escol hi da e segmentada manual mente, o método processa o segmento e então faz comparações com todos os objetos do banco a fim de encontrar as regiões que são mais semel hantes à região desejada.

Para os resultados de recupeação parcial não foram realizados medi das quantitativas, pois não há um meio preciso de dizer que o método de recuperação parcial é mais eficiente do que outro ao se aval iar partes de objetos. Entretanto, uma possível medida de aval iação seriam testes com usuários, nos quais a similaridade visual seria usada. Nesse tipo de aval iação não se 
Figura 32 - Resultado gerado pra uma busca completa no banco de dados utilizando uma das pernas do Armadillo como entrada (em verde). Resultados destacados em azul. Foram exigidos duas partes mais semel hantes em cada modelo, para essa consulta.
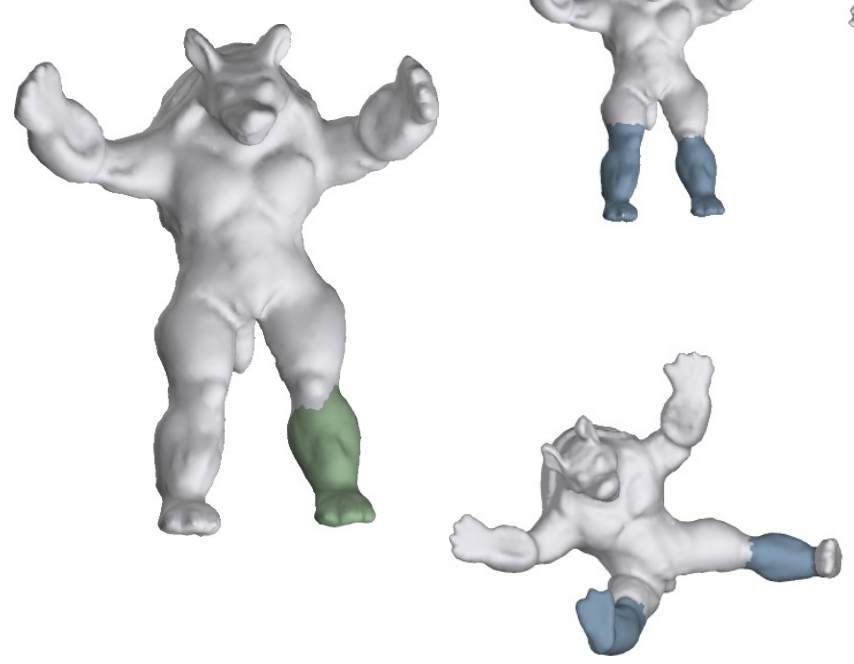
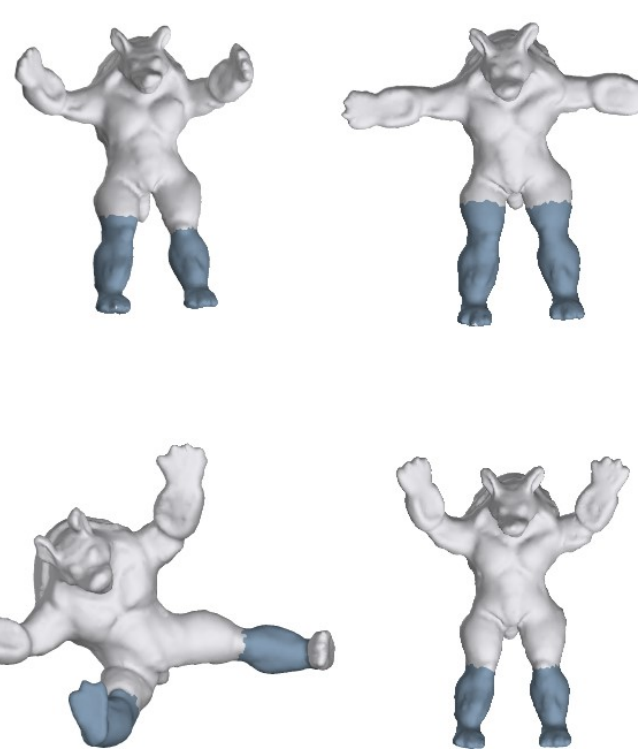
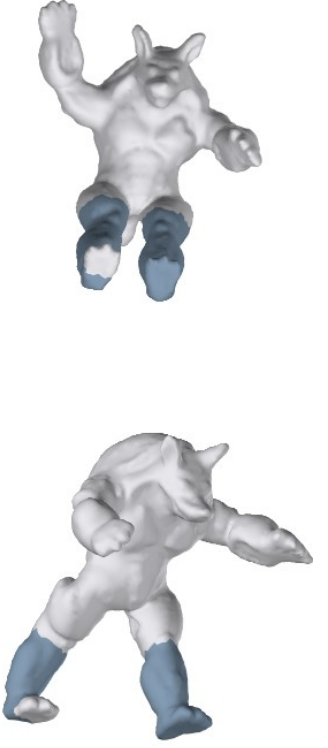

Fonte: Elaborada pelo autor.

Figura 33 - Resultado gerado pra uma busca completa no banco de dados utilizando um do braços do modelo masculino como entrada (em verde). Resultados destacados em azul.
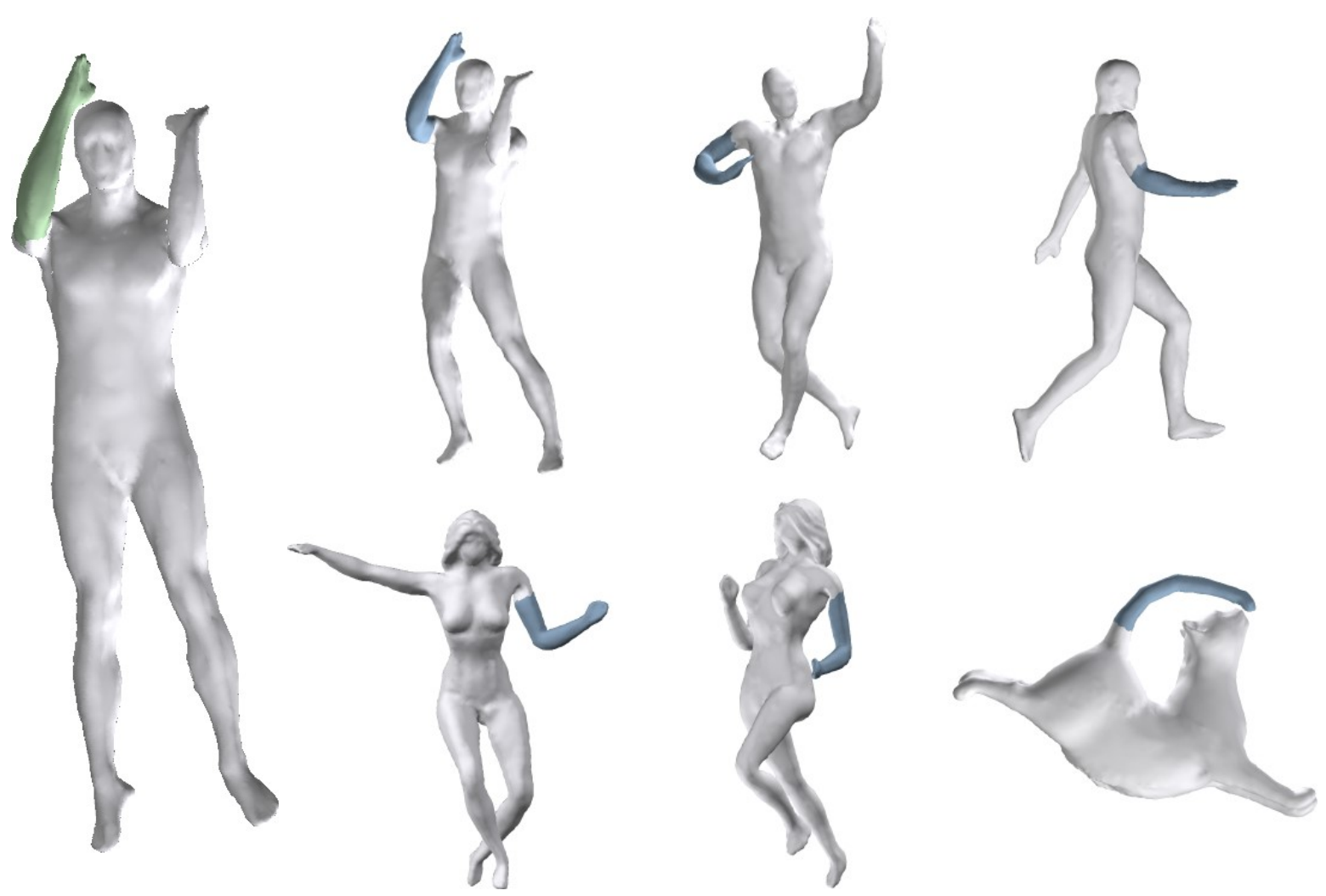

Fonte: Elaborada pelo autor. 
5.3. Discussão

79

Figura 34 - Resultado gerado pra uma busca completa no banco de dados utilizando um do braços do modelo masculino como entrada (em verde). Resul tados destacados em azul.
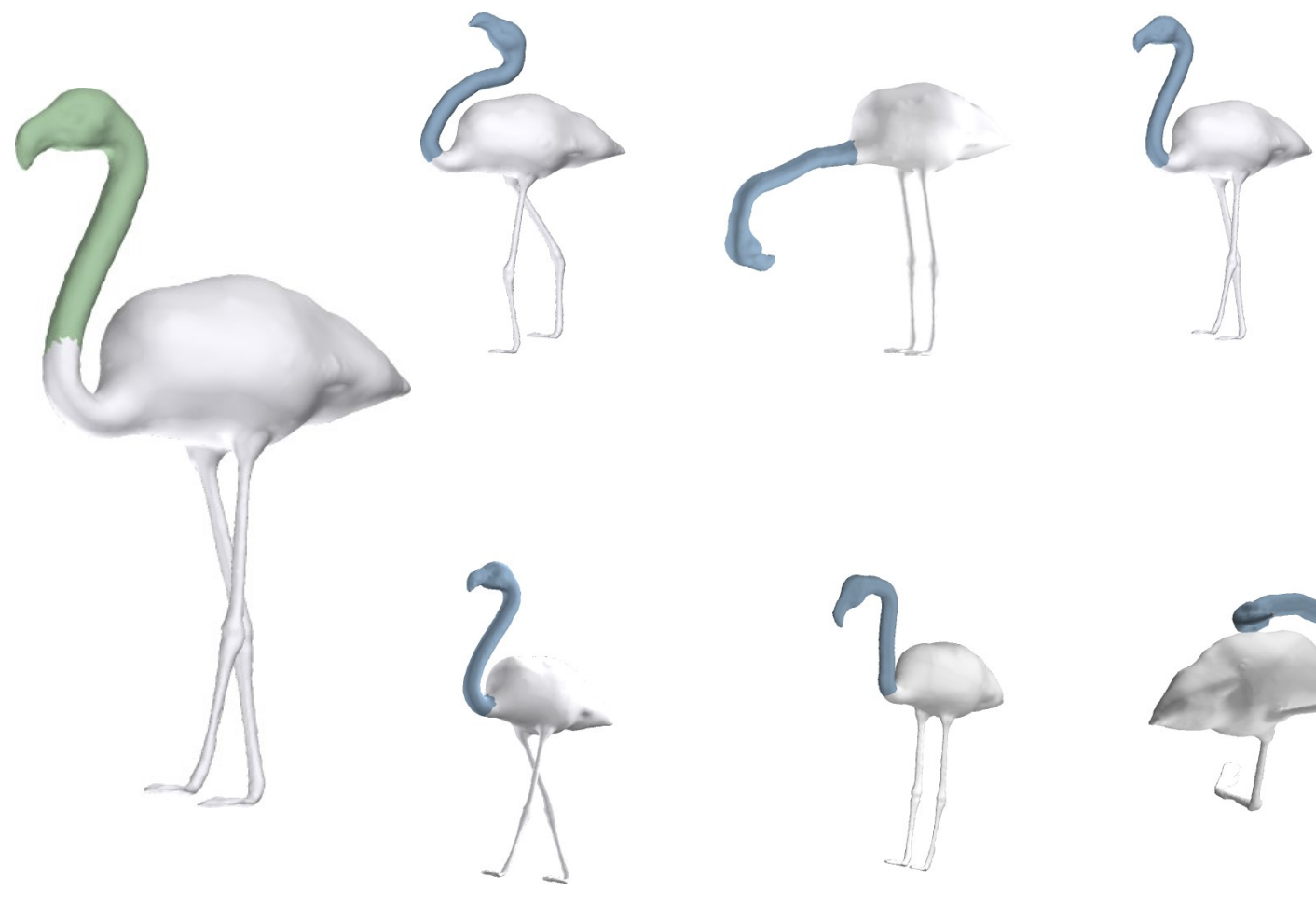

Fonte: Elaborada pelo autor.

levaria em conta a classe dos objetos, mas sim a semântica da parte e o do obj eto recuperado, como o que acontece na Figura 33. Nesse exemplo, existem outras classes que não apenas a principal (figura feminina e rabo do gato), mas o segmento semel hante obtido é visual mente satisfatório.

5.3 Discussão

A proposta apresentada nesse capítulo é a utilização do CRP como ferramenta para comparação entre segmentos de mal has, visando encontrar regiões semel hantes no próprio objeto, como também em outros objetos-alvo. Essa abordagem se fez possível por estarmos descrevendo uma malha tridimensional como um sinal temporal para cada segmento. Em segmentos semelhantes é possível encontrar a recorrências do sinal, e com isso, identificar as regiões semel hantes que são de interesse.

Pel os resul tados apresentados, o método se mostrou bastante eficiente em encontrar regiões da mesma mal ha e regiões de outras mal has que são idênti cas à região dada como entrada. Como o método utiliza uma janela de comparação, é possível notar que nas regiões mais críticas, ou seja, nas pontas das características, o método apresenta al gumas fal has para a identifi cação. Entretanto isso não af eta bruscamente os resul tados, como apresentado na seção anterior. 
Como apresentamos no início do capítulo, é necessário que as mal has passem por um pré-processamento que éo de segmentação. Esse processo é necessário para que as regiões sejam anal isadas e sua comparação seja feita de forma adequada. Isso é uma das limitações do método apresentado, uma vez que, no caso das segmentações não serem as mesmas, o comportamento dos result tados pode não ser o esperado. Além disso, a característica utilizada para a descrever a mal ha como um sinal temporal também precisa ser discriminativa, como o utilizado no método apresentado (Heat Kernel Signature). 


\section{CONSIDERAÇÕES FINAIS}

Como foi apresentado nessa dissertação de mestrado, uma nova ferramenta já muito utilizada nas áreas estatísticas para análise e comparação de séries temporais foi introduzida no âmbito do processamento geométrico. Ao se utilizar o vetor de Fiedler para ordenação dos vértices do obj eto tridimensional , é possível simular uma série temporal e então se obter uma comparação dos objetos. Com os resultados apresentados, apesar de não superarem os resultados encontrados na literatura, pode-se observar que a si mplicidade da característica utilizada torna o método desenvolvido atrativo. Além disso, por se utilizar de ferramentas já desenvolvidas e presentes em pacotes matemáticos, sua implementação também é bastante facilitada.

Algumas das principais dificul dades encontradas no al goritmo desenvolvido está na distinção de classes semel hantes. Como apresentado nos resultados de recuperação de objetos, Capítul o 4, a distinção entre classes de humanos não se mostrou bem sucedida. Entretanto, vale ressal tar que a semel hança das classes é visivel e só há a distinção semântica de gênero. Além disso, na recuperação parcial de obj etos, é possível observar que a segmentação da mal ha também é um fator restritivo para o método. Uma vez que, para segmentos semel hantes, a similaridade é visível mesmo que a classe não seja.

\subsection{Trabalhos futuros}

Por se tratar de uma técnica nova, o método apresentado ainda precisa passar por al guns estudos mais aprofundados para que, possivelmente, haja uma mel hora no desempenho para recuperação de objetos total e parcial . O objetivo desse trabal ho de mestrado foi de estudar a viabilidade do método para recuperação de objetos e, tendo apresentado bons resultados, é válido o estudo de tópicos específicos que circundam nossa técnica baseada em séries temporais com foco na recuperação de objetos e na recuperação parcial de objetos. 


\subsubsection{Recuperação total}

Para a recuperação de objetos, podemos destacar al guns pontos a serem investigados no futuro:

- Suavização do sinal. Como os sinais apresentados apresentam característica muito ruidosa, os descritores temporais podem estar apresentando resultados não ótimos. Com uma suavização das séries é possível que haja uma mel hora na recuperação de objetos semelhantes.

- Relação da ordenação dos vértices. Nessa dissertação de mestrado utilizamos a ordenação dada pel o vetor de Fiedler, por ser uma ordenação isométrica, ou seja, é equivalente para objetos que pertencem à mesma cl asse e não possuem al teração na topologia.

- Combinação de características. Para a comparação de objetos tridimensionais, utilizamos apenas uma característica para montagem da série temporal. Entretanto, ao utilizar um conjunto de características que se complementam e possi bilitem uma melhor descrição do objeto, é possível que se obtenha mel hores resultados

- Banco de filtros utilizados. Para que os coeficientes de wavel ets fossem extraídos, foram utilizados bancos de filtros baseados em wavelets e que são comuns para a análise de áudio e derivados. Como foi visto no Capítulo 4, os resultados apresentados foram bons. Entretanto a possível utilização de filtros capazes de extrair coeficientes ótimos para o contexto de processamento geométrico pode apresentar mel hora nos resultados.

\subsubsection{Recuperação parcial}

Em se tratando de recuperação parcial de objetos, os mesmos tópicos apresentados para a recuperação de objetos podem ser reestudados aqui. Além disso, ai nda existem outros tópicos que necessitam de investigação mais profunda:

Analisar o efeito de recuperação utilizando mais partes ao mesmo tempo. Nos testes realizados que foram apresentados, os segmentos de consulta são sempre de uma mesma região da mal ha segmentada, ou em sua maioria, apenas de uma região. Para se buscar por mais regiões ao mesmo tempo, é necessário se tomar cuidado com a ordenação das regiões e como isso pode af etar a ferramenta de comparação CRP.

- Comparação com di ferentes segmentações em um mesmo objeto. Ao apresentarmos as regiões segmentadas, limitamo-nos apenas a um al goritmo de segmentação utilizado para dividir os objetos em regiões de interesse. Entretanto, por se tratar de um método de comparação de segmentos, é intuitivo pensar que mesmo que a segmentação não seja a mesma- o que ocorre em objetos isométricos - é possível que haja bons resul tados caso as próprias segmentações sejam semelhantes. 
- Paral elização do código.

\subsection{Publicações}

O desenvolvimento desse método estudado durante o mestrado resul tou em uma colaboração para o Workshop of 3D Object Retrieval, um evento especial izado em recuperação de objetos e que hospeda o concurso SHREC. No ano de 2015, uma das propostas submetidas ao concurso era a recuperação de objetos dentro de uma base de dados. Nesse concurso, 11 grupos se inscreveram para processar 1200 mal has presentes no banco de dados of erecido. Nosso método participou dessa versão do concurso com o algoritmo apresentado no Capítulo 4, mostrando resul tados satisfatórios, mesmo sendo uma técnica ainda em desenvolvimento. $O$ artigo publicado encontra-se na biblioteca da Eurographics (LIAN et al., 2015).

Ao final da Dissertação de Mestrado, outra publicação foi realizada no Conference on Graphics, Patterns and Images, realizado em 2016, na cidade de São José dos Campos, e entitulada Partial Similarity of 3D Shapes Using Cross Recurrence Plot (NAKANISHI et al., 2016) . Essa publicação é referente ao método desenvol vido para recuperação parcial de objetos. 

ABDELRAHMAN, M.; EL-MELEGY, M.; FARAG, A. Heat kernels for non-rigid shape retrieval: Sparse representation and efficient classification. In: IEEE. Computer and Robot Vision (CRV), 2012 Ninth Confer ence on. [S.I.], 2012. p. 153-160. Citado na página 41.

AGATHOS, A.; PRATIKAKIS, I.; PAPADAKIS, P.; PERANTONIS, S.; AZARIADIS, P.; SAPIDIS, N. S. 3d articulated object retrieval using a graph-based representation. The Visual Computer, Springer, v. 26, n. 10, p. 1301-1319, 2010. Citado na página 37.

ALLIEZ, P.; COHEN-STEINER, D.; DEVILLERS, O.; LÉVY, B.; DESBRUN, M. Ani sotropic polygonal remeshing. In: ACM. ACM Transactions on Graphics (TOG). [S.I.], 2003. v. 22, n. 3, p. 485-493. Citado 2 vezes nas páginas 42 e 43.

ANDÉN, J.; MALLAT, S. Multiscal e scattering for audio classification. In: ISMIR. [S.I.: s.n.], 2011. p. 657-662. Citado na página 48.

Scattering representation of modulated sounds. In: Proc. of the 15th Int. Conference on Digital Audio Effects (DAFx-12). [S.I.: s.n.], 2012. Citado na página 48.

BERGER, M.; NONATO, L. G.; PASCUCCI, V.; SILVA, C. T. Fiedler trees for multiscale surface analysis. Computers \& Graphics, Elsevier, v. 34, n. 3, p. 272-281, 2010. Citado na página 37.

BRONSTEIN, A. M.; BRONSTEIN, M. M.; KIMMEL, R. Efficient computation of isometryinvariant distances between surfaces. SI AM Journal on Scientific Computing, SIAM, v. 28, n. 5, p. 1812-1836, 2006. Citado na página 35.

CHATFIELD, C. The analysis of time series: an introduction. [S.I.]: CRC press, 2003. Citado na página 51.

CHEN, D.-Y.; TIAN, X.-P.; SHEN, Y.-T.; OUHYOUNG, M. On visual similarity based 3d model retrieval. In: WILEY ONLINE LIBRARY. Computer graphics for um. [S.I.], 2003. v. 22, n. 3, p. 223-232. Citado na página 37.

CHEN, X.; RAMADGE, P. J. Music genre classification using mul tiscal e scattering and sparse representations. In: IEEE. Information Sciences and Systems (CISS), 2013 47th Annual Confer ence on. [S.I.], 2013. p. 1-6. Citado na página 48.

CHUNG, F. R. Spectral graph theory. [S.I.]: American Mathematical Soc., 1997. Citado na página 44.

DESBRUN, M.; MEYER, M.; SCHRÖDER, P.; BARR, A. H. Implicit fairing of irregular meshes using diffusion and curvature flow. In: ACM PRESS/ADDISON-WESLEY PUBLISHING CO. Proceedings of the 26th annual conference on Computer graphics and inter active techniques. [S.I.], 1999. p. 317-324. Citado na página 45. 
ELAD, A.; KIMMEL, R. On bending invariant signatures for surfaces. Pattern Analysis and Machine Intelligence, IEEE Transactions on, IEEE, v. 25, n. 10, p. 1285-1295, 2003. Citado na página 35.

FANG, R.; GODIL, A.; LI, X.; WAGAN, A. A new shape benchmark for 3d object retrieval. In: Advances in Visual Computing. [S.I.]: Springer, 2008. p. 381-392. Citado na página 38.

HAAR, F. B. T.; VELTKAMP, R. C. Automatic multiview quadruple alignment of unordered range scans. In: IEEE. Shape M odeling and Applications, 2007. SMI' 07. IEEE International Confer ence on. [S.I.], 2007. p. 137-146. Citado na página 36.

HARPER, L. H. Optimal assignments of numbers to vertices. Journal of the Society for Industrial and Applied Mathematics, SIAM, v. 12, n. 1, p. 131-135, 1964. Citado na página 45.

HILAGA, M.; SHINAGAWA, Y.; KOHMURA, T.; KUNII, T. L. Topology matching for fully automatic similarity estimation of $3 \mathrm{~d}$ shapes. In: ACM. Proceedings of the 28 th annual conference on Computer graphics and inter active techniques. [S.I.], 2001. p. 203-212. Citado na página 34.

JAIN, V.; ZHANG, H. A spectral approach to shape-based retrieval of articulated 3d models. Computer-Aided Design, El sevier, v. 39, n. 5, p. 398-407, 2007. Citado na página 34.

KANTZ, H.; SCHREIBER, T. Nonlinear time series analysis. [S.I.]: Cambridge university press, 2004. Citado na página 55.

KEOGH, E.; RATANAMAHATANA, C. A. Exact indexing of dynamic time warping. Knowledge and Information Systems, Springer-Verlag, v. 7, n. 3, p. 358-386, 2005. ISSN 02191377. Disponível em: <http://dx.doi.org/10.1007/s10115-004-0154-9>. Citado 2 vezes nas páginas 51 e 52.

LAVOUÉ, G. Bag of words and local spectral descriptor for $3 \mathrm{~d}$ partial shape retrieval. The Eurographics Association, 2011. Citado na página 36.

LEIFMAN, G.; KATZ, S.; TAL, A.; MEIR, R. Signatures of 3D Models for Retrieval. 2003. Citado na página 58.

LIAN, Z.; GODIL, A.; BUSTOS, B.; DAOUDI, M.; HERMANS, J.; KAWAMURA, S.; KURITA, Y.; LAVOUÉ, G.; NGUYEN, H. V.; OHBUCHI, R. et al. Shrec' 11 track: Shape retrieval on non-rigid 3d watertight meshes. 3DOR, v. 11, p. 79-88, 2011. Citado 2 vezes nas páginas 38 e39.

A comparison of methods for non-rigid 3d shape retrieval. Pattern Recognition, El sevier, v. 46, n. 1, p. 449-461, 2013. Citado 3 vezes nas páginas 26, 33 e 35.

LIAN, Z.; GODIL, A.; FABRY, T.; FURUYA, T.; HERMANS, J.; OHBUCHI, R.; SHU, C.; SMEETS, D.; SUETENS, P.; VANDERMEULEN, D. et al. Shrec' 10 track: non-rigid 3d shape retrieval. 2010. Citado na página 38.

LIAN, Z.; GODIL, A.; SUN, X.; ZHANG, H. Non-rigid 3d shape retrieval using multidimensional scaling and bag-of-features. In: IEEE. I mage Processing (ICIP), 2010 17th IEEE International Conference on. [S.I.], 2010. p. 3181-3184. Citado na página 35. 
LIAN, Z.; ZHANG, J.; CHOI, S.; ELNAGHY, H.; EL-SANA, J.; FURUYA, T.; GIACHETTI, A.; GULER, R. A.; LAI, L.; LI, C.; LI, H.; LIMBERGER, F. A.; MARTIN, R.; NAKANISHI, R. U.; NETO, A. P.; NONATO, L. G.; OHBUCHI, R.; PEVZNER, K.; PICKUP, D.; ROSIN, P.; SHARF, A.; SUN, L.; SUN, X.; TARI, S.; UNAL, G.; WILSON, R. C. Non-rigid 3D Shape Retrieval . In: PRATIKAKIS, I.; SPAGNUOLO, M.; THEOHARIS, T.; GOOL, L. V.; VELTKAMP, R. (Ed.). Eurographics Workshop on 3D Obj ect Retrieval. [S.I.]: The Eurographics Association, 2015. Citado 6 vezes nas páginas 31, 38, 56, 64, 69 e 83.

LIU, Z.; MITANI, J.; FUKUI, Y.; NISHIHARA, S. Multiresolution wavelet analysis of shape orientation for $3 d$ shape retrieval. In: ACM. Proceedings of the 1st ACM international conference on Multimedia information retrieval. [S.I.], 2008. p. 403-410. Citado na página 37.

LIU, Z.-B.; BU, S.-H.; ZHOU, K.; GAO, S.-M.; HAN, J.-W.; WU, J. A survey on partial retrieval of $3 d$ shapes. Journal of Computer Science and Technology, Springer, v. 28, n. 5, p. 836-851, 2013. Citado 3 vezes nas páginas 28,29 e 36.

MAHMOUDI, M.; SAPIRO, G. Three-dimensional point cloud recognition via distributions of geometric distances. Graphical Models, Elsevier, v. 71, n. 1, p. 22-31, 2009. Citado na página 35.

MARWAN, N.; KURTHS, J. Cross recurrence plots and their applications. Mathematical Physics Resear ch at the Cutting Edge, CV Benton Editor, p. 101-139, 2004. Citado 2 vezes nas páginas 53 e 54 .

MEMOLI, F. On the use of gromov-hausdorff distances for shape comparison. In: THE EUROGRAPHICS ASSOCIATION. Eurogr aphics symposium on point-based graphics. [S.I.], 2007. p. 81-90. Citado na página 35.

MÉMOLI, F.; SAPIRO, G. A theoretical and computational framework for isometry invariant recognition of point cloud data. Foundations of Computational Mathematics, Springer, v. 5, n. 3, p. 313-347, 2005. Citado na página 35.

NAKANISHI, R. U.; ONO, J. P.; PAGLIOSA, P.; NONATO, L. G.; PAIVA, A. Partial similarity of $3 d$ shapes using cross recurrence pl ot. In: Confer ence on Graphics, Patterns and I mages (SI BGRAPI ). [S.I.: s.n.], 2016. v. 29. Citado 2 vezes nas páginas 31 e 83.

OHBUCHI, R.; OSADA, K.; FURUYA, T.; BANNO, T. Salient local visual features for shapebased 3d model retrieval. In: IEEE. Shape Modeling and Applications, 2008. SMI 2008. IEEE International Conference on. [S.I.], 2008. p. 93-102. Citado na página 34.

OVSAANIKOV, M.; BRONSTEIN, A. M.; BRONSTEIN, M. M.; GUIBAS, L. J. Shape google: a computer vision approach to invariant shape retrieval. Proc. NORDIA, v. 1, n. 2, 2009. Citado na página 36.

OVSIANIKOV, M.; MÉRIGOT, Q.; MÉMOLI, F.; GUIBAS, L. One point isometric matching with the heat kernel. In: WILEY ONLINE LIBRARY. Computer Gr aphics For um. [S.I.], 2010. v. 29 , n. 5, p. 1555-1564. Citado na página 33.

PAULY, M.; GROSS, M.; KOBBELT, L. P. Efficient simplification of point-sampled surfaces. In: IEEE COMPUTER SOCIETY. Proceedings of the confer ence on Visualization' 02. [S.I.], 2002. p. 163-170. Citado na página 43. 
PAULY, M.; KEISER, R.; GROSS, M. Multi-scale feature extraction on point-sampled surfaces. In: WILEY ONLINE LIBRARY. Computer graphics for um. [S.I.], 2003. v. 22, n. 3, p. 281289. Citado 2 vezes nas páginas 43 e 44.

PINKALL, U.; POLTHIER, K. Computing discrete minimal surfaces and their conjugates. Experimental mathematics, Taylor \& Francis, v. 2, n. 1, p. 15-36, 1993. Citado na página 45.

REEB, G. Sur les points singuliers d' une forme de pfaff completement intégrable ou d' une fonction numérique. CR Acad. Sci. Par is, v. 222, p. 847-849, 1946. Citado na página 34.

REUTER, M.; WOLTER, F.-E.; PEINECKE, N. Laplace-spectra as fingerprints for shape matching. In: ACM. Proceedings of the 2005 ACM symposium on Solid and physical modeling. [S.I.], 2005. p. 101-106. Citado na página 34.

RIJSBERGEN, C. K. van. I nfor mation Retrieval. 1975. Citado na página 58.

RODOLA, E.; BULÒ, S. R.; CREMERS, D. Robust region detection via consensus segmentation of deformable shapes. In: WILEY ONLINE LIBRARY. Computer Graphics For um. [S.I.], 2014. v. 33, n. 5, p. 97-106. Citado 3 vezes nas páginas 16, 37 e 73.

RUSTAMOV, R. M. Laplace-beltrami eigenfunctions for deformation invariant shape representation. In: EUROGRAPHICS ASSOCIATION. Proceedings of the fifth Eurographics symposium on Geometry processing. [S.I.], 2007. p. 225-233. Citado na página 36.

SHAO, T.; XU, W.; YIN, K.; WANG, J.; ZHOU, K.; GUO, B. Discriminative sketch-based 3d model retrieval via robust shape matching. In: WILEY ONLINE LIBRARY. Computer Graphics For um. [S.I.], 2011. v. 30, n. 7. Citado na página 37.

SHILANE, P.; MIN, P.; KAZHDAN, M.; FUNKHOUSER, T. The princeton shape benchmark. In: IEEE. Shape Modeling Applications, 2004. Proceedings. [S.I.], 2004. p. 167-178. Citado 3 vezes nas páginas 38, 55 e 57 .

SORKINE, O. Laplacian mesh processing. Tese (Doutorado) - Tel Aviv University, 2006. Citado na página 45.

SUN, J.; OVSANIKOV, M.; GUIBAS, L. A concise and provably informative multi-scale signature based on heat diffusion. In: WILEY ONLINE LIBRARY. Computer graphics for um. [S.I.], 2009. v. 28, n. 5, p. 1383-1392. Citado 3 vezes nas páginas 34, 47 e 74.

SUNDAR, H.; SILVER, D.; GAGVANI, N.; DICKINSON, S. Skel eton based shape matching and retrieval. In: IEEE. Shape Modeling I nternational, 2003. [S.I.], 2003. p. 130-139. Citado na página 34.

ZOU, G.; HUA, J.; DONG, M.; QIN, H. Surface matching with salient keypoints in geodesic scal e space. Computer Animation and Virtual Worlds, Wiley Online Library, v. 19, n. 3-4, p. 399-410, 2008. Citado na página 36. 